\title{
MERCADOS INFORMAIS COMO FONTE ALTERNATIUA \\ DE LIQUIDEZ PARA OS AGRICULTORES
}

\author{
ALIUINIO DE ALMEIDA \\ Eng… Agro.
}

Orientador: Prof. Or. Paulo Fernando Cidade de Araújo

Dissertação apresentada à Escola Superior de Agricultura "Luiz de Queiroz", da Universidade de São Paulo, para obtencão do titulo de Mestre

en Agronomia. Grea de Concentracão: Econonia Agrária.

$$
\begin{aligned}
& \text { PIRACICABA } \\
& \text { Estado de São Paulo - Brasil } \\
& \text { Novembro - } 1994
\end{aligned}
$$


Ficha catalográfica preparada pela Seça de Livros da Divisăo de Biblioteca e Documentaçăo - FCLQ/USF

Almeida, Alivinio de
A447m Mercados informais como fonte alternativa de liqui dez para os agricultores. Firacicaba, 1994. $204 \mathrm{P}$.

Diss. (Mestre) - ESALQ

Bibliografia.

1. Crédito agricola 2. Financiamento agricola 3. Mercado financeiro I. Escola Superior de Agricultura Luiz de Queiroz, Firacicaba 
MERCADOS INFORMAIS COMO FONTE ALTERNATIVA

DE LIQUIDEZ PARA OS AGRICULTORES

ALIVINIO DE ALMEIDA

Aprovada em: 13/01/1995

Comissao Julgadora:

Prof. Dr. Paulo Fernando Cidade de Araújo

ESALQ/USP

Prof. Dr. Evaristo Marzabal Neves

ESALQ/USP

Prof. Dr. Léo da Rocha Ferreira

UERJ

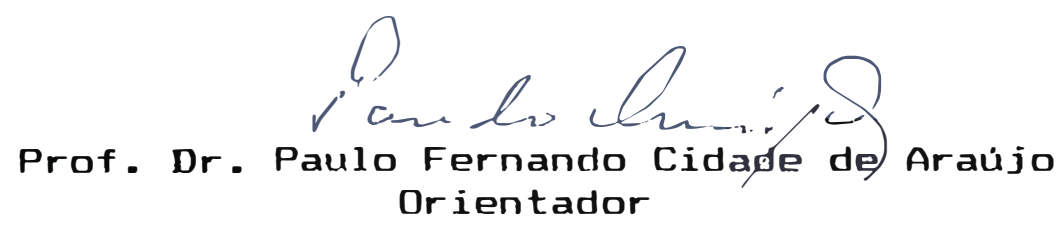




\begin{abstract}
A Djanira, Celeste e Elzina
A memória de Roque A. Almeida
\end{abstract}

Ofereco.

à minha mulher, Dilza

Ded ico. 


\section{A GR A DEC I M ENT O 5}

Thicialmentes gostar ia de faser um agradecimento especial ao professor paldo Fernando cidade de Arájo. Agradegow the nä́o apenas pela or ientacto neste trabalho mas, aceima disso, por ter wme permitido compartithar de sua

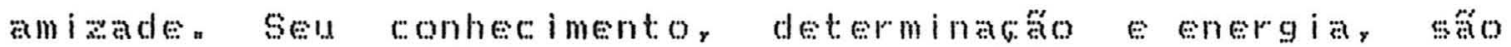
exemplos dignificantes para os que tem o privilegio de desfrutar des sua companhian

A outros tres professores desejo expressar minha grat i töon Dr. Evar isto Marzabal Neves, Dr, Ricardo Shirota

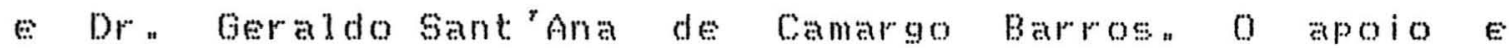
estimulo constantes, recebidos destes os tempos de graduactó, for am fundamenta is para alcancar este momenton

Agradeco, também, ao Professor. Dr. léo da Rocha Ferreira pelas análises e sugestóses oferecidas ao trabalhon

A quatro grandes amigos, sempre presentes durante a elaborazo deste trabalho, registro meus sinceros agradecimentos "Săo eles Caio rakagaki Yamaguishi, Márcia Maria 5. Previtalle, Pedro Wenriquez "da Conceicáo Júnia Cristina P $P$ " da Conceison 


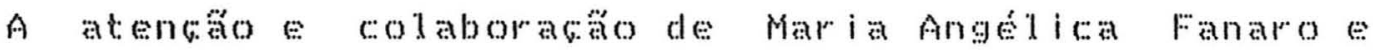
L.wciane Cristina cipriano merecemy tambemy o meu destaque e agradeci imenton

A algumas pessoas com as quais tenho convivio mais recente expresso minha grat icton pelo estimulo constantey agradeco aos colegas do Tnstituto de Economia Agricolar especialmente, aos do centro de financiamento e de Tnvest imentos Públicos na Agr iculturan

Destaco, tamberm, o apoio de quatro instituicoses na elaboracáo deste trabalho sä́ elas o centro de pesquisa em Economia Agricola da Fundaga de Estudos Agrarios l.uiz de Queiroz C... CEPEAFEALQ, O DEPartamento de Economia e Sociologia Rural da Escola superior de Agricultura lubia de Queiroz -... DESR/ESALQ, O Conselho Nacional de Desenvolvimento cientifico e Tecnológico - CNPa e o Thstituto de Economia Agrícola da secretaria de Agricultura E Abasteciment: - T.: TA/SAA

Finalmente, gostaria de agradecer d minha esposa Thadila Medeiros da silva Almeida pelo carinho, cuidado e paciencia a mim dedicados, principalmente nos momentos mais dificels is 


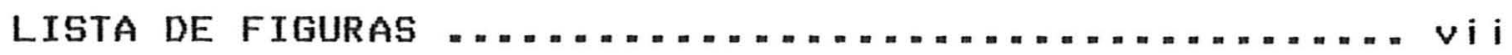

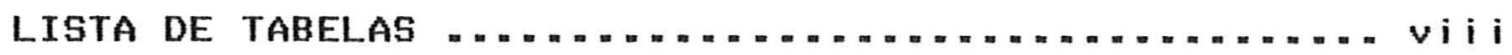

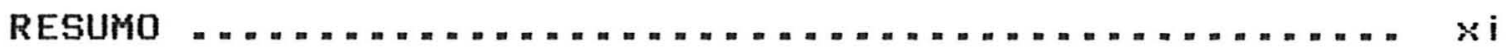

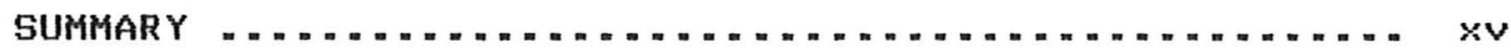

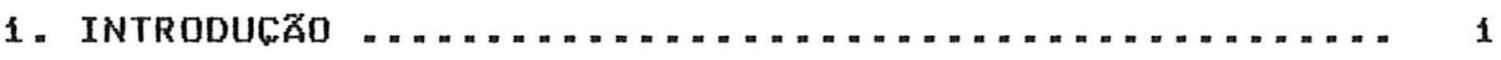

1.1. O Estudo dos Mercados Informais:

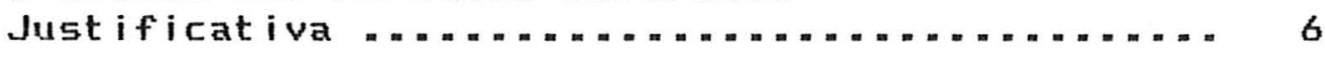

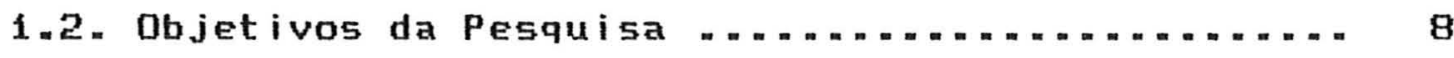

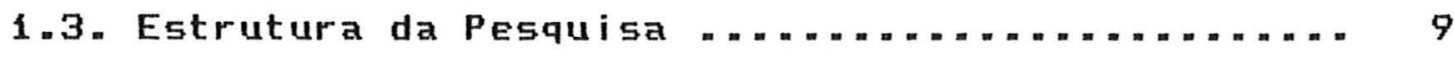

2. FINANCIAMENTO RURAL NOS MERCADOS INFORMAIS:

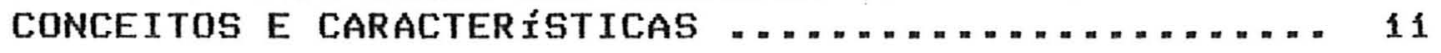

2.1. MFRIs em Países de Diferentes

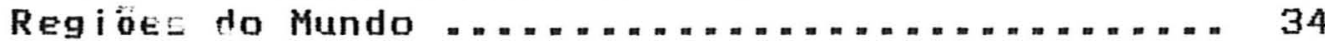

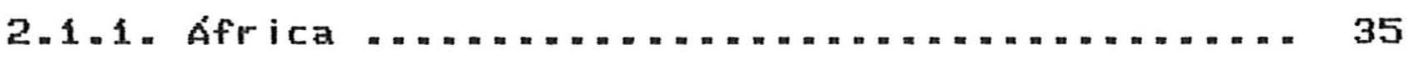

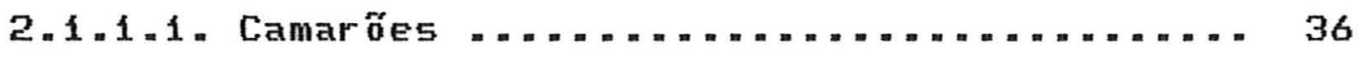

2.1.1.2. Etiópia $\ldots=\ldots \ldots \ldots \ldots \ldots \ldots \ldots \ldots \ldots \ldots \ldots \ldots \ldots \ldots$ 37 


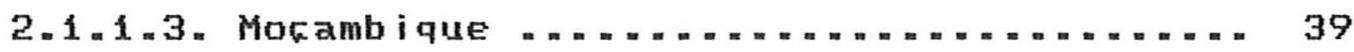

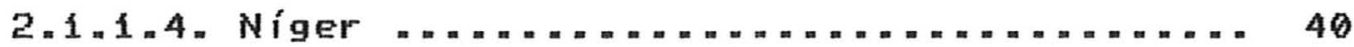

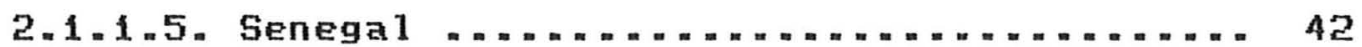

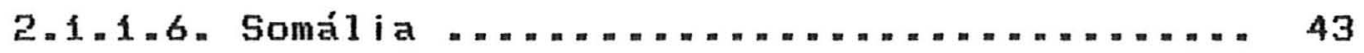

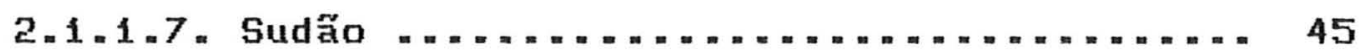

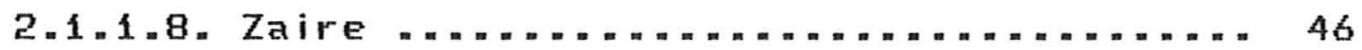

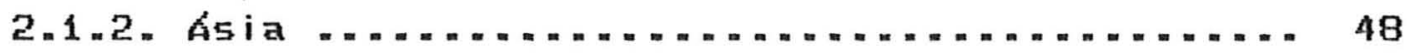

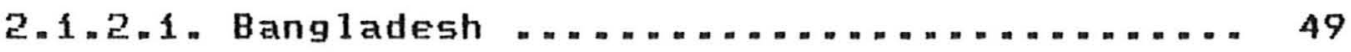

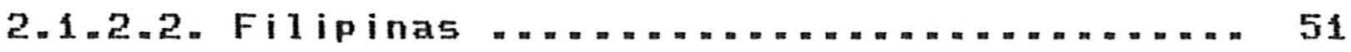

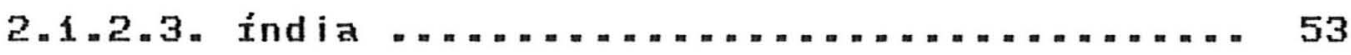

2.1.2.4. Indonésia $\ldots \ldots \ldots \ldots \ldots \ldots \ldots \ldots \ldots \ldots \ldots \ldots \ldots \ldots$ 5. 5

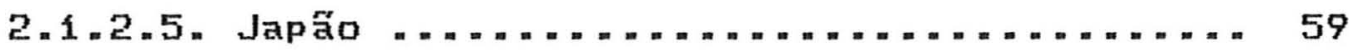

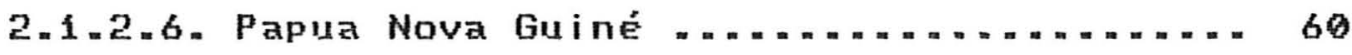

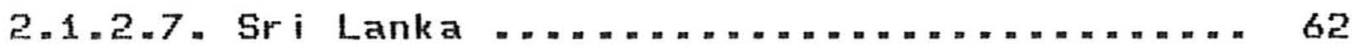

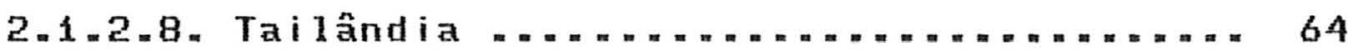

2.1.3. América do Norte e América Latina . . . . " . " . " 66

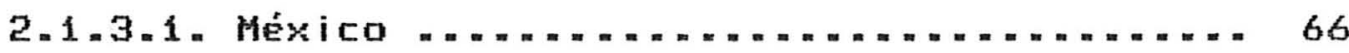

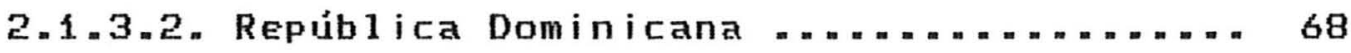

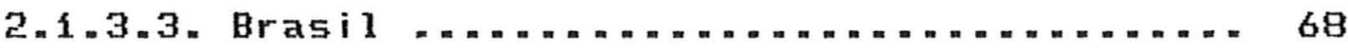

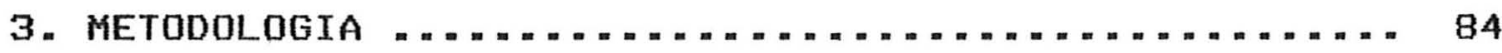

3.1. Aval iąấo do Crédito Rural Formal ............ 84

3.2. Procura por Liquidez nos MFRIs $\ldots \ldots \ldots \ldots \ldots \ldots \ldots . \ldots=85$

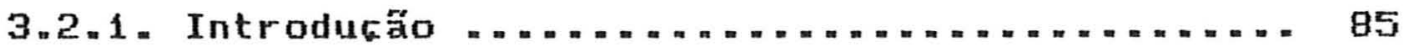




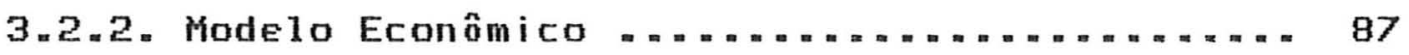

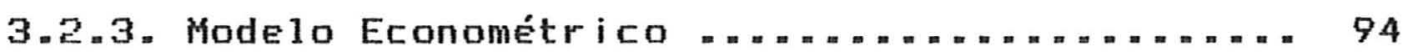

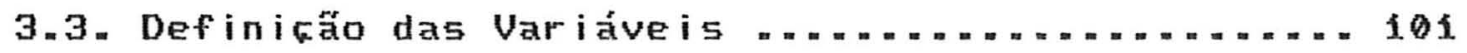

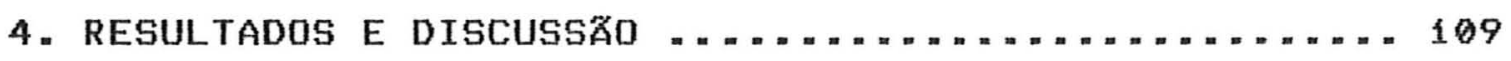

4.1. Crédito Rural Formal no Brasil:

A Crise dos Anos $80 \ldots \ldots \ldots \ldots \ldots \ldots \ldots \ldots \ldots \ldots \ldots \ldots \ldots+\ldots 10$

4.2. Desempenho Econômico dos Agricultores ......... 133

4.2.1. Indicadores de Desempenho Económico ...... 139

4.2.2. Características dos Empréstimos .......... 147

4.3. Análise da Demanda por Liquidez em

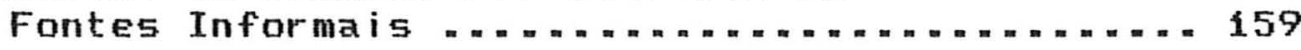

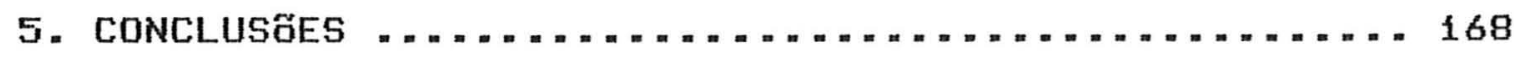

6. REFERÊNCIAS BIBLIOGRAFICAS $\ldots \ldots \ldots \ldots \ldots \ldots \ldots \ldots \ldots \ldots$ 18

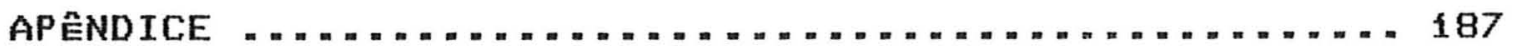




\section{LISTA DE FIGURAS}

Figura 2.1. Agentes de Crédito Informa1, Segundo o Tipo de Emprést imo

Figura 4.1. Composigão dos Principais Haveres Financeiros, Brasil, 1972-1993

Figura 4.2. Participacấo dos Depósitos no Total de Haveres Financeiros, Brasil, 1972-1993

Figura 4.3. Indice de Financiamentos Concedidos Via SNCR, Brasil, 1970-1993 


\section{LISTA DE TABELAS}

Tabe1a 2.1. Principais Diferengas entre Crédito

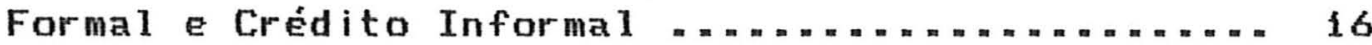

Tabela 2.2. Sinopse das Formas de Emprést imo nos Mercados Informais de Crédito, em Regióes Selecionadas, Brasi1, Ano Agrícola 1989/90 ..... = 74

Tabela 4.1. Taxa Anual de Inflaçóa na Economia, Medida pela Variaçáo do índice Geral de Precos (IGP-DI) da Fundaçón Getúlio Vargas, Brasil, 1970-1993 "... 112

Tabela 4.2. Participacáo Relativa dos Principais Haveres Financeiros em Poder do Público no Total de Haveres Financeiros da Economia, Brasil, 1972-1993

Tabela 4.3. Taxa Nominal e Real de Juros do Crédito Rural, Brasi1, 1970-1993

Tabela 4.4. Crédito Concedido pelo Sistema Nacional de Crédito Rural, Segundo a Fonte de Origem dos Recurso5, Brasil, 1987-1993

Tabela 4.5. Financiamentos Concedidos a Produtores

E Cooperativas, Através do Sistema Nacional de Crédito Rural, Segundo a Finalidade, Brasi1, 1970-1993

Tabela 4.6.- Número de Produtores Analisados, Segundo o Tipo de Agricultor, o Município, a Situaçáo de Mútuo de Crédito Rural e a Fonte de Recursos, Brasil, Ano Agrícola 1989/90, Safra de Veráo ." =" 136 
Tabela 4.7.- Indicadores Econômicos Médios da Atividade Agrícola $E$ Fatores Associados ao Desempenho Económico dos Produtores da Amostra, Segundo a Situaçáo de Mútuo e o Tipo de Crédito Rural Recebido, Brasil, Ano Agrícola 1989/90,

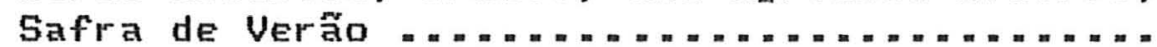
140

Tabe1a 4.8.- Indicadores Econômicos Médios da Atividade Agrícola $E$ Fatores Associados ao Desempenho Econômico dos Agricultores de Pequeno Porte e Baixa Renda (Grupo 1), Segundo a Situaçáo de Mútuo e o Tipo de Crédito Rural Recebido, Brasil, Ano Agrícola 1989/90, Safra de Verão

Tabela 4.9.- Indicadores Econômicos Médios da At ividade Agrícola e Fatores Associados ao Desempenho Econômico dos Agricultores Comerciais (Grupo 2), Segundo a Situacão de Mútuo e o Tipo de Crédito Rural Recebido, Brasil, Ano Agrícola 1989/90, Safra de Verão

Tabela 4.10.- Indicadores Econômicos Médios da At ividade Agrícola $E$ Fatores Associados ao Desempenho Econômico dos Agricultores Comerciais em Larga Escala (Grupo 3) Segundo a Situacáo de Mútuo e o Tipo de Crédito Rural Recebido, Brasil, Ano Agrícola 1989/90, Safra de Verão ... ". . . ... 145

Tabela 4.11.- Empréstimos Formais e Informais, Segundo Grupos de Produtores e Finalidade dos Empréstimos, Brasi1, Ano Agrícola 1989/90, Safra de Veráo ... = 149

Tabela 4.12.- Empréstimos Formais e Informais, Segundo Grupos de Produtores e Origem dos Recursos, Brasil, Ano Agrícola 1989/90, Safra de Veráa .... 150 
Tabela 4.13n- Empréstimos Informais, Segundo Grupos de Produtores e Unidade de Valor, Brasil, Ano Agrícola 1989/90, Safra de Veräo ... ". " . . . . . . 152

Tabe1a 4.14.- Características dos Empréstimos Formais e Informais Tomados pelos Produtores da Amostra. Brasi1, Ano Agrícola 1989/90, Safra de Verão .... . 154

Tabela 4.15.- Características dos Empréstimos Formais E Informais, Segundo Grupos de Produtores, Brasil, Ano Agrícola 1989/90, Safra de Verão .......... 156

Tabela 4.16. Participacâo Percentual Média do Crédito Informal no Crédito Total Recebido, Valor Bruto da Producão Agrícola e Despesas Dperacionais Típicas da Producão, Segundo Grupos de Produtores, Brasi1, Ano Agrícola 1989/90, Safra de Verão ... . . 158

Tabela 4.17. - Est imativa dos Parâmetros das Relaçóes entre o Valor dos Empréstimos Tomados nos Mercados Informais $e$ Fatores Condicionantes da Demanda por Liquidez na Amostra de Produtores, Brasil, Ano

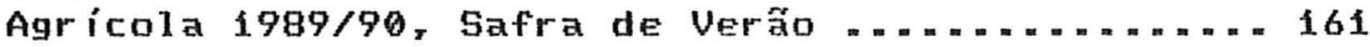

Tabela 4.18.- Est imativa dos Parâmetros das Relacóes entre o Valor dos Empréstimos Tomados nos Mercados Informais e Fatores Condicionantes da Demanda por Liquidez nos Grupos de Produtores, Brasil. Ano Agrícola 1989/90, Safra de Verấo ................ 165 


\section{MERCADOS INFORMAIS COMO FONTE ALTERNATIUA \\ DE LIQUIDEZ PARA OS AGRICULTORES}

Autor: ALIUINIO DE ALMEIDA

Orientador : PROF. DR. PAULO FERNANDO CIDADE DE ARAúJO

\section{RESUMO}

0 presente estudo tem por objetivo principal quadificar e, na medida do posalved, quantificar a participacto e a importancia dos mercados informas no financiamento da agricultura brasideiran para alcangar tal objetivo procederse, inicialmentey a conceituactio de coredito rural informal e a caracteriagato dos seus principais agentes esas formas operacionas sombase na literatura disponived säo redatadas também, experiencias de financiamento Informal em alguns países, dentres os quas o Brasil considerando a estreita redacto entre os mercados formal e informats, discutecse oprocesso de exastán do Sistema Nacional de Crédito Rural -.. SNCR, no periodo $1970 \cdots$ $1.993 n$

$$
\text { A segury com base em informateses sobre 2.79 }
$$
produtores ruras de desempenho económico desses produtores e as coaracter ísticas 
dos emprestimos tomados em fontes formas e informas no ano agritola 1989/90. Finalmentey gao identificados alguns fatores economicos relevantes para expl icar a demanda por

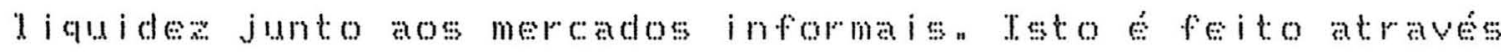
do ajutamento de modelo econometrico (tobit) "As andises stá feitas para a amostra como um todo e para grupos de produtores constitufdos com base nos sistemas de producko agricola que estes desenvolvem pequeno porte e baixa renday comercial e capital wintensivoy e comercial em larga

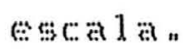

Oe resultados encontrados na pesquisa revedam que a intermediacto finaneseira informal tem papel bem definido no desenvolvimento das atividades de individuose firmas, servindo de elo de ligata ontre o capital propro e os recursos obtidos nos mercados formats

No Brasil, os mercados informats desempenham papel relevante junto aos produtores agr icolas sua participacto no financiamento rural tem erescido nos lít imos anosy por dificuldades do proprio gistema formal de crediton A instabilidade econômica que atingiu o país após os anos 80 desgatou o SNCR quase por completon Em fog3, o volume de creditos concedidos, em termos reats, atraves desse sistemats foi inferior ao concedido em 1970. 
Quanto aos produtores analisados, as evidencias empiricas mostram que a maioria nä́ toma crétito rurad,

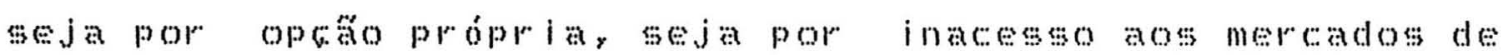
crediton Tsso é observado particularmente em relacto aros produtores de ba ixa renda

Outra constatacáto que os produtores que praticam agricultura comercial em larga escala buscam intensamente caredito rural, independentemente da or gem dos recursos Esses agr icultores enfrentam sérios problemas de liquidez e, por lsso, tem maior propensáo ao endividamenton

Nos empréstimos informaisy o juro real tem mar amplitude de variacto que nos formats en termos medios a taxa real de juros nos emprestimos informas equivale a 3 vezes a praticada nas operacoses formas n Em termos de importanceian, observanse que o financiamento informal da atividade agricola representa cerca de $30 \%$ dos creditos recebidos pelo produtores da amostran

Para a amostra em seu todo, o modelo econométrico desenvolvido nesta pesquisa mostrou que a area explorada as despesas operacionats tipicas da producáa sáso importantes fatores explicativos da demanda por liquidez nos mercados informas " por outro lado, o modelo dos produtores de batina renda revelou que o preso dos recursos 
e a categoria do produtor săo variveis de grande importância " o modelo relativo ao grupo de produtores em larga escala evidencia que a taxa real de juros do crédito informal, a area explorada peloprodutor e as despesas operacionats tipicas da producta agricola tem o efeito esperado sobre a demanda por liquidez nos mercados informa is . 


\title{
INFORMAL MARKETS AS AN ALTERNATIUE SOURCE OF LIQUTDITY TO THE FARMERS
}

\author{
Author: ALIUINIO DE ALMEIDA
}

\section{Adviser: PROF. DR. PAULO FERNANDO CIDADE DE ARAÚJO}

\section{SUMMARY}

The general purpose of this research is to analyas the role and importance of the informal financial markets in the Brazil ian agricultures

Th order to obtain a better understanding of rural financial markets, a conceptual framework of formal and informal markets is presented, together with some empirical evidences of informal arrangements in different countries and regions of the world, including Brazil,

The specific objectives of the study were pursued in three parts. First, an attempt was made to discuss the critical and exhausting process that, since 1980, has been Imposed by economice factors to the national system of rural (.) redit in Brazil (SNCR).

second, an attempt was made to provide empirical 
evidence on the differences whith may exist between borrowers and non worrowers n The borrowers were examined according to the financial markets thes had accessed (formal, informal, and both)" loan characteristics concerning the principal value, interest rates, torm of the loans, borrower" ${ }^{3}$ transation costs and loan purposes were also considered in this analysisn

Third, the redationghips between amount of additional ligudity (credit) demanded in the informal markets and major determining factors were estimated through a tobit c.:ensored moded 1 ,

The basite source of information was a sample of ezg farmers from 10 different agr icultural regions o rhis sample was designed to include farms representative of the major types of farming in the $1999 / 90$ agricultural year"

The major findings of this study are summar aced in the following

Tmportant differences were found between farmers who dase coredit (formal and/or informal) and farmers who do not: use credit. The farmers cassified as borrowers always presented average performaneses higher than the non borrowers In total sample the non worrowers were the 
dargest group.

rhe large scade farmers were the most act ive borrowers in both rural financial markets (formal and informal)" Their outstanding debt position sugest a very strong need for additional liquidity " The commerciad farmers group, as expected, had little access to the informal marketsy probably due to their facility to obtain formal loans or to their self finance capacityn small farmers group, on the other hand, had ditte acesess to the formal market, but: might be identified as very active borrowers in the informal market: 5

In the informal markets, the real interest rate levels and variation were considerably higher than the ones in the formal market. Also, the value of informal loans represented $30 \%$ of the total loan value in the sample studied.

The econometric model for total sample suggests that the amount of 1 iquidity/credit: demanded in the informat markets was directly redated to operational expenditures (labor and other inputs) and inversedy redated to land in operation. All the est imates of the coefficients had the expected signs for ald the specified variables, aceording to the a perori constraints of the economite moded "However, 
xvi i i

the est imates for interest rate of informat credity anount: of formal credit, and level of education of the farm operator were not statisticaldy significant " th other words, these factors did add ang significant contribution to explain variations in the quantity of ligudity demanded.

The econometric moded adusted for the smald farmers group showed that interest rate of informal loans financial cost of formal credit, and land in operation were important explanatory factors: al of them with the expect:ed signs

Finally, the conometric moded for the large scale farmers group suggests that the amount of ligudity demanded is influenced by interest rate of informal loans, and in operation and operational expenditures "The conomic relations were also as proposed in the economic $\operatorname{moclel} 1$ 


\section{INTRODUCROO}

Discutir a importâneia dos mercados informas no financiamento da agricultura pressupose que a at ividade de intermediacá financeira é relevante para o desenvolvimento de uma agr icudtura comercial e integrada aos demais atores da coconomian

ADAMS Et ali (1987) argumentam, nessesentido, que a atividade financeira, atraves do credito dos servicos de depósitos oferecidos a individuos e firmas favorece a agricultura por facilitar principadmente: manejo do risco empresariady geraca e transforencia de poder de compra de recursos financeirosg intercambio de liquidez entre os participantes dos mercadosy realizacaso de investimentos e aquisicáo de bens de consumo duraveis: e, num quadro ma ior de referencia, a propria distribuicaso de renda pessoal no setor 
GONZÁLESWEDA (1984) Observa que os servigos prestados pelo sistema financeiro contribuem para integrar mercados er dessa maneira, aceleram a integracáco rural wurbanan

\begin{abstract}
POMAREDA \& CEBREROS (1993) Enfatian que a alta quad idade dos mecanismos financeiros possibilita a modernizacto do setor rural, dentro de um modelo de desenvolvimento sustentado, de um processo de abertura comercial e de liberacta economiconfinanceiran
\end{abstract}

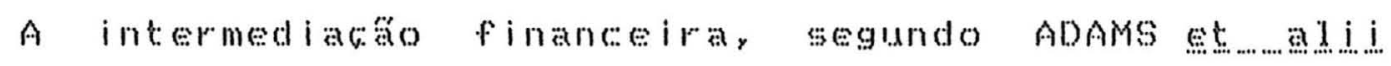
(1987) é um processo difuso, sutil, com um grande numero de atores e que resulta de pequenas acoses isoladas n Tnclusivey dessas atividades apenas parte de registraca em a istemas contabeisy emprestimos feitos por familiares e amigos, associacoses informats de poupanca e cordito e agentes privados ocorem, tipicamentes sem qualquer forma de registron

No Brasil, a intermediacáco financeira na agricultura possui também essas caracteristicasn os produtores tem à

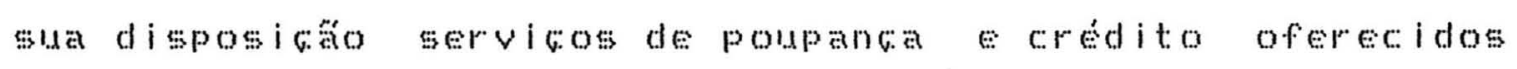
por agentes formats e informais.

Os intermediários formais, basicamente bancos e cooperativas de productao no caso de repaseses de 
emprest imos bancarios) operam dentro de padrós rigios segundo as normas do sistema Nacional de Crédito Rural -. SNCR .

Os mercados financeiros rurats informas -... MFRts, objeto principal desta pesquisar tem como asentes de credito comerciantes de insumos, produtos e servitos, agroindustrias, cooperativas, associanos de produtores a moneylenders.s, dentre outros nemprestimos realizados por esses intermediarios esta for do do controle governamental, sendo negociados livemente entre as partes er mutas vezes, baseados unicamente em acordos verbais.

No entanto, apesar das expressivas diferengas estruturais, os mercados formal e informal possuem estreita

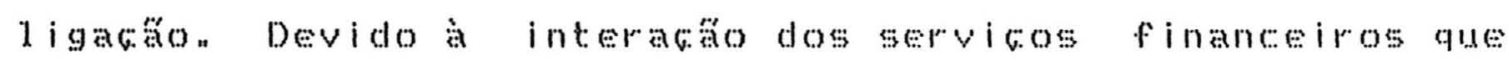
oferecem, esses mercados sás ora complementares, ora substitutos, Tnclusive, SETBE1.. \& MARX (1987) recomendamy no intuito de melhorar as ligacoses entre ambos, o uso de

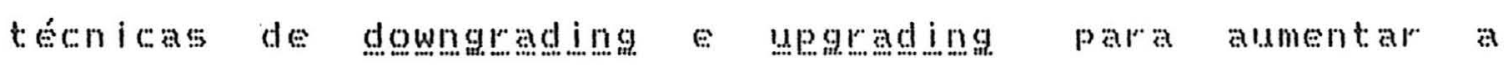
eficiencia dos agentes formatse ampliar o desenvolvimento dos informats

Nesse contexto, para compreender o papel dos MFRTs no

1 No Brasil, a atividade praticada por esses agentes ser i a algo semelhante a agiotagem. 
financiamento da agricultura brasileira é necessario discutir, também, aspectos referentes ao mercaco formal de cored to rural n

A criacáno do sistema Nacional de Crédito Rural a. SNCR, em meados da decada de 6 , teve como principais objetivos ampliar o volume de recursos crediticios destinados

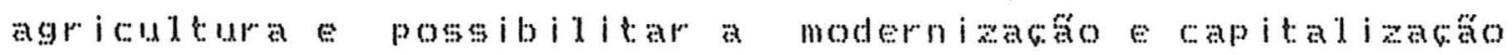
das un idades des productán

A opcáo por operacional i ar o funcionamento do sistema através da participacaro compulsória da rede bancára permitiu às autoridades monetarias controlar os recursos encaminhacos ao setor agropecuarion o coredito passous entán, a ser usado como mecanismo de planejamento, orientando o desenvolvimento de regiós efou culturas especificas Ao facilitar a aquisicaro de fertilizantes e máquinas agricolas, o SNCR estimulou também o desenvolvimento da industria de insumos agricolas recem implantada no pais

Nos anos 70 o SNCR atingiu o apogeu, fornecendo volume: cosescente de recursosy ano apos anor da tawas de juros expressivamentesubs id a a a as

Os anos 80, porém, evidenciaram as consequencias da 
crise internacional do petroleo, do endividamento externo e da recessaro protongadan No Brasil, assistiuse ao esgotamento do modelo de substituicaro de importacoes, à

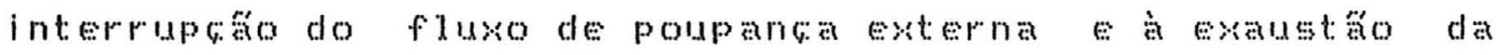
capacidade de poupancato sotor publicon o crescimento descontrolado da inflacio foi a carateristica marcante desse períodon Nö́ mais haviam condiäes de manter o processo de crescimento económico das décadas anterioress

A alta inflacko por sua very implicold anmento generalizado do custo de oportunidade dos recursos

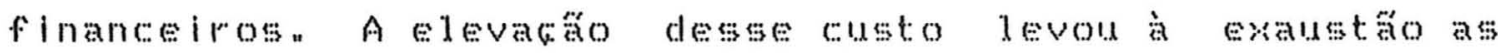
principais fontes de recursos do sNCR, tais como depósitos a vista e recursos governamentaisn bim decorrencian, registraramse decrescimo na quantidade ofertada, elevacáo dos encargos financeiros e maior rigidez no racionamento dos recursos dest inados ao financiamento rural "

Frente a esse cenarloy os produtores rurais reduriram sua demanda por emprestimos formats e passaram a acar os recursos própros de maneira mais eficienten Adicionalmente, quando hecessario, buscaram fontes alternativas para financiar suas at ividadesn o fato de a productán agricola brasileira mostrar corescimento anualy em termos absolutosy sugere a utilizago de volume consideravel de recursos. Mais que issog te um indicativo de 
que boa parte desses recursos provém de fontes financeiras a 1 t: ernat: ivas

Esssa busca por alternativas estimulou o corescimento dos mercados informats de coreditor seja complementando, geja substituindo o credito rural formal " Demonstrando grande flexibilidade operacional e rapidez na concessán de recursos, a intermediacaro informal ampliou seu espaco entre producores de todos os niveis tecnolosicos, tipos de agricultura esescalas de producton

\subsection{O Estudo dos Mercados Informais: Uma Justificativa}

O SNCR tem enfrentado serias dificulates para financiar os produtores de forma adequadan A escassez de recursos e o racionamento do crédito têm sido acentuadosn

Por outro daco, a despeito das restricoses no financiamento formal, a producaro agricola brasileira tem mostraclo, em termos absolutos, crescimento anual " Esse aumento, principalmente devido a ganhos de produtividade e

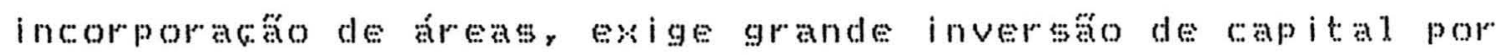
partie dos produtoresn 
procuram ot:imian o uso dos recursos propros e utidiar fontes informals de credito comoforma de aumentar sua liquidez: Nesse aspector a contribuicio dos mercados Informats tem sido expressivan rodavia, pouco se sabe acerca da estiptura de funcionamento e do potencial desses mercaclos como alternativa financeiran

Assim sendo, esforcos sta justificados no sentido de melhor conhecer ofinanciamento informal na agricultura brasileiran fé necessario identificar os intermediar ios as as formas operaciona is, bem como anad isar as caracter isticas dos emprestimos readizados Ademais, é preciso determinar custos, benefícios efatomes econômicos es nowoconomicos relacionados a busca de 1 iquidez junto aos mercados informa is

Dada a interacio com o mercado formal de coreditor é de vital importancia que formuladores de politicar empresarios e estudiosos levem em conta as coracter isticas dos mercados

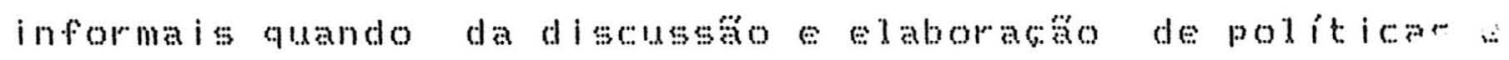
estrategias em busca de um novo padro de financiamento para o setor ruraln

${ }^{2}$ Nesta pesquisa, liquidea é entendida como o comando imediato sobre recursos finane iros. 


\subsection{Objetivos da Pesquisa}

Esta pesquisa tem como proposta principal qualificar en na medida do possived, quantificar a participacaro a importâne ia dos mercedos informas no financiamento da agricultura brasideiran

Nesse contexto, pretendewse conceituar o coredito informat, identificar seus principals agentes e formas operacionats a, quando pose ivel, estabelecer comparacos com o corectito formal.

Objet ivasese, ainda, colher na literatura evidencias sobre o funcionamento dos mercados informata de crécito rural em diversos países do mundo es particularmentey no Bratil

Na medida em que o uso do financiamento informal está relacionado ao desempenho do mercado forma de cereditor pretende-we apontar os prineipais problemas que afetaram o SNCR Em periodo recente.

Em etapa posterior, ut ilizandowse informacoses levantadas junto a ely9 produtores wurats, tomadores ou năo de credito na safra de verá do ano agricola $1989 / 90$. almejam-ses os seguintes objetivos especificosn 
a) descrever o perfit dos produtores da amostra com base em ind icadores de desempenho económitio:

b) caracterian os emprestimos realizados segundo a or igem dos recursos, a finalidade, o valor principal o orazo da operaction

c) Est imar a tawa real de juros, os custos de transactón para o tomador e o custo financeiro efetivo dos emprestimos:

d) avaliar as implicacóse do uso dos mercados informas pelos produtores de maneira isolada ou conjunta ao uso de c.rédito formal: er

e) identificar os principais condicionantes da procura por liquider nos mercados financeiros ruras informas apl icando um modelo econometrico de acordo com a proposicáa de: $\operatorname{TOB} \operatorname{Tn}(1.958)$

\subsection{Estrutura da Pesquisa}

No Capitulo e, apresentam-se a conceituacto de coredito rural informal, a caracterianaca dos principais agentes e as formas operacionais dos MFRTs, combase ma 1 iteratura 
disponivel. sato redatadas, também, experiencias de financiamento informal em alguns paises, incluindowse Brasil.

No Capitulo 3, säo discutidos os procedimentos metodologicos que norteiam a análise dos dados b bem como apresentadas as relacóseconômitas esperadas e discutidas as hipoteses a serem testadas no modelo econometricon

No Capitulo 4, os resultados obtidos saro expostos es anad isados em tress pates a primeira discute o processo de exalusto das fontes de recursos do SNCR no periodo fo7o1.993. A segunda reune informages sobre os produtores da amostra e os emprestimos por eles realiandosn A terceira parte exibe os resultados da analise econométrica dos fatores condicionantes da demanda por l iquidez nos mercados informa is

Finalmentey no capítulo by estao condensadas as principais conclusós da pesquisa e algumas sugestóses sobre ofinanciamento da agricultura brasideiran 


\section{FINANCIAMENTO RURAL NOS MERCADOS INFORMAIS: CONCEITOS E CARACTER ÍSTICAS}

A excessiva e ineficiente intervencta do Estado nas at ividades econômicas tem constituido forte estimulo ât expansáto da chamada "economia informal" "

Aspectos como o grande nimero de pessoas envolvidas, o expressivo volume de capital movimentado, a diversidade e flexibilidade dos negócios na economia informal tem atraido a atencero de estudiosos, formuladores de políticas e empresarios

Entre as diversas operacónes informats, a intermediaca financeira parece desempenhar papel especiat, dando sustentacáo a desenvolvimento de atividades efirmas L.TEDHOLM (1989) argumenta que a ma i or ia das firmas y urbanas ou rurass, inicia as operacoses utiliando recursos

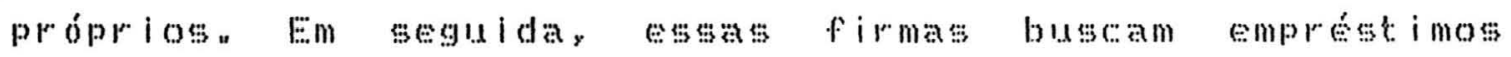


informa is para cont inuar suas at ividades e, em estagio mais avangado, procuram coredito formal ${ }^{3}$

Nessa sequencia, o crédito informal aparece como edo de ligacáo entre os recursos proprios o coredito formaln

Na agricultura, o aporte de recursos oriundos dos mercados financeiros informa s parece náo ser despreáved, principalmente no financiamento das atividades de alguns tipos de produtores.

Nesse contextor tornase plassived conceituar e

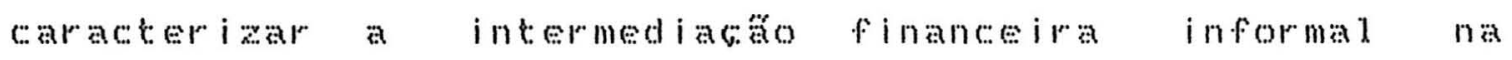
agricultura, bem como destacar algumas diferencas em

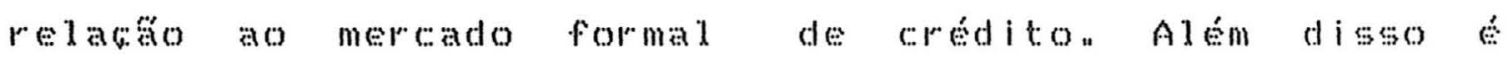
recomendatued investigar o seu funcionamento no caso brasideiron

SEgundo ADAMS (1989) toda transacto financeira que näo

${ }^{3}$ para initiar as atividades, uma firma necessita de cap ital fixo obtido, geralmente, em poupancas pessoais ou junto a fontes familiares thiciactas as operacoses a necessidade de capital de trabatho (giro) predomina é financiada pelo fluxo de ca ixa da própra firman a medida em que a firma amadurecer passa a contar com fontes financeiras informais tais como fornecedores de insumos, moneylenderse e outros cfontes primárias de crédito de

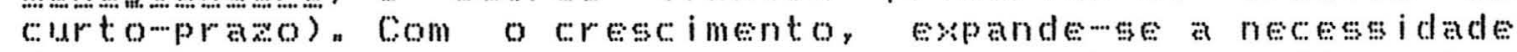
de capital fixo ede giron Neste pontor a firmatem condicoses de acessar os mercados formals de creditor inclusive por ter aciumbato garantias que podem ser oferecidas na tomada de emprestimos (1.. TEDHOLM, 1989)" 
ebteja sob a supervisato, regulamentago e monitoramento de um banco central ou das autoridactes monetarias pode ser considerada informaln

Adaptando esse conceito para a questar da intermediacáto financeira na agr icultura brasi leirar pode-se definir como financiamento informal "

todo empréstimo em dinheiro, insumo ou servico, realizado por um agente (indivíduo ou firma) a um produtor rural, estando, tal operacão, fora do controle direto das Autoridades Monetárias.

Essa definicáco aproximase daqueda estabelecida por CAsTro (1970) como sendo eredito näowintitucionat "o emprestimo concedido por comerciantes, industriais e particulares a produtores rurais, quer en torangaos mercantis, quer atraves da efetiva prestacă de capital, mediante pagamento de juros" " o autor observa a inda que

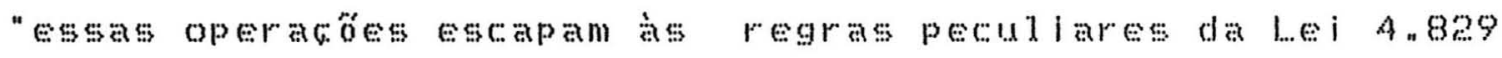
(que instituiu o SNCR) e das que the sáto complementaresy regulandowse pelos preceitos da legislaciónomom código Civil, código comercial etc... ")"

Na literatura, os termos ngometitucionasen ngow

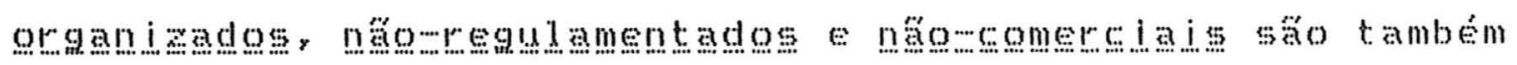


wti i iados para caracterian os mercados informais (ADAms, (.989)

Dentre as formas operacobes de intermediaca financeira informad conhecidas as mais commes son

a) emprestimos em dinheiro obtidos junto a particularese firmas;

b) escambos (trocactroca) do tipo insumo/produto ou

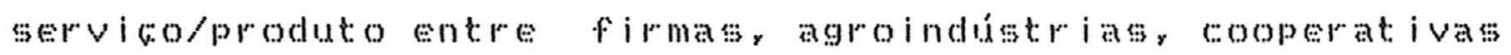
produt ores:

c: compras/vendas antecipadas de producta futuraz e, d) poupanga e emprestimo realizados por consóreios ou associacótes de proclutores rurais.

Notanserse pois, que nos mercados informats as transacoos nás sáo feitas unicamente em dinheiron devido à wua natureace coracteristica, o credito informal tornacse a base de diversas operacoses, interligando comercio, tenencia da terra e mercados produtivos (SANDERATNE, 1989). Entretanto, apesar do corescente numero de estudos sobre credito informal, pouco se conhece a respeito da interata entre mercados informats, poupanca rural, mercados de terra, de trabalho ede produtos (ONCHAM, 1989)"

En comparata a mo mercato formal de coreditor as principais diferencas na estrutura e funcionamento dos 
MFRIs podem ser vistas na rabeda én. Nestar săo apresentadas as pricipais caracter ist icas de cada mercadon

0 mercado formal envolve, geralmente, emprestimos de: maior valor e prazos mais longos "Normalmente, sáno exigidas garantias e reciprocidaces financeiras dos colientes, que precisam manter estreito redacionamento com as instituicós para ter acesso aos servicos de poupana e corediton excesiva burocracia o atraso a a demora na l iberactádo dos recursos sấ, também, mu to comuns no mercado formal n conjunto de fatores limita o acesso ao crectito a um numero redua ido de beneficiáriosn

A burocraciar associada a i baxo nivel educacional, principalmente nas dreas rupais de paises em desenvolvimento, agrava a dificuldade de obtencero de crédito formal.

VON PTSCHKE (1983) actescenta que as agencias forma

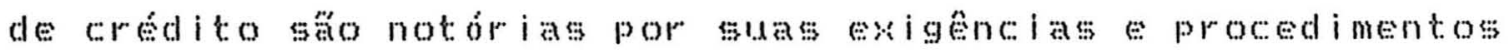
algo inflexiveisn Tais instituifós náo têm conseguido exito em oferecer servicos para a populacto rural pobre que util ian o crécito informal os pequenos mutuár ios que obtêm emprestimos de instituiouses formas demoram a receber os recursos, a passo que os ofertantes informats concedemono com rapider. 
Tabela 2.1.- Principais Caracteristicas dos Mercados Formais e Informais de Crédito.

\begin{tabular}{|c|c|c|}
\hline Iten: & $\begin{array}{l}\text { Hercado } \\
\text { Fortal }\end{array}$ & $\begin{array}{l}\text { Hercado } \\
\text { Infornal }\end{array}$ \\
\hline Valor Transacionado & grande & pequeno \\
\hline Prazo do Eapréstiano & médio a longo & curto \\
\hline Custo Financeiro & baixo & alto \\
\hline Custo de Transarão & alto & baixo \\
\hline frea de Atuação & grande & pequena \\
\hline Garantia Exigida & alta & baixa \\
\hline Reciprocidade & financeira & pessoal \\
\hline Burocracia & grande & pequena \\
\hline $\begin{array}{l}\text { Demora na Liberacão } \\
\text { dos Recur s05 }\end{array}$ & grande & pequena \\
\hline $\begin{array}{l}\text { Imprevistos } \\
\text { Sdoencas, consuno } \\
\text { faniliar, } \\
\text { adversidades } \\
\text { climáticas, } \\
\text { invest inent os de } \\
\text { alto risco) }\end{array}$ & กลี0 & sir \\
\hline Agentes & $\begin{array}{c}\text { bancos E } \\
\text { cooperat ivas }\end{array}$ & $\begin{array}{l}\text { noneglenders, vendedores de insunos, } \\
\text { casas de penhor, parentes, } \\
\text { grupos de poupanca, ROSCAs, } \\
\text { corretores de enprést inos, } \\
\text { instituicốes financeiras n-regulamentadas } \\
\text { agroindústrias }\end{array}$ \\
\hline
\end{tabular}

Fonte: Dados da Pesquisa. 
outra caraceristica do mercado formad de coredito é que seus agentes costumam exigir dos tomadores de emprestimo a aplicacaro dos recursos em at:ividades produtivas, esquecendo a natureas fungived da liquidez: marginal do credito que eles mesmos conoedem (CHRTsten, 1.989)"

VON PTSCHKE (1983) ressat a a inda que a precariedade dos servicos prestados por essas instituicoses devens a tress fatores princ: ipais:

a) alto custo para negociar com pequenos mutuarios e poupadores geograficamente dispersos:

b) or ientacáo urbana dessas instituicoses er

c) diferencas (ulturats existentes entre ofertantes de emprést: imos e mutuários n

Argumenta LADMAN (1984) que, incluidas as despesas de transacto para o tomador, os custos totais dos emprestimos forma is tornamme muito elevados, o que leva os pequenos produtores dos países em desenvolvimento a recorrer às fontes informais de crédito.

Eim decorencia das restricós enfrentadas pelo setor financeiro formal, säo gerados dois tipos de demanda por servicos financeiros informas u uma direta e 
outra indireta (NAYAR, 1989). A demanda direta emana dos individuos cujo acesso ao setor formal é $1 \mathrm{imitado} p e d a$ inabilidade no ajustamento as regudamentagos do coredito ou pela falta de garantias suficientes para oferecer em troca de: um empréstimon

A demanda indireta, por sua vezy vem de clientes que estao insatisfeitos com os servicos prestados pedo setor formaln Essa insatisfacto pode estar redacionada ao racionamento dos recursos, ao atraso na liberacoso do

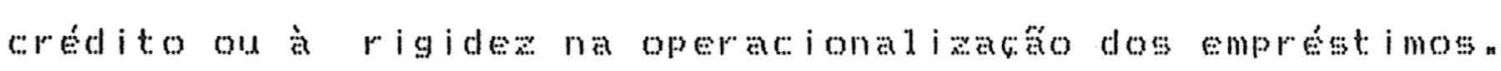

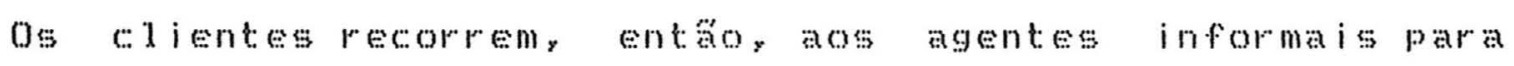
complementar seus recursos e/ou obtén los ma is faci i menten

ciente disso, o autor conclui que a demanda direta deverse à forga inerente das instituicoses do setor informal, enquanto que a demanda indireta deve-wes a contracáo (resultante das politicas governamentass) a à instabilidade cem funcro dos atrasos a mudancas nos procedimentos) do mercado formal.

OrERo (1989) destacay entre as caracteristicas operaciona is do próprio mercado financeiro formal, aquelas que est imulam a intermediaga informal na economian a) custos elevados na administracta de pequenos emprestimos: imos 
b) altos custos de transagáo para o tomador, decorrentes da expansáno da rede bancáriaz e,

c) racionamento de crédito devido a expectativa de riscos elevados na real iacacio de emprestimos para tomadores com ba i garant: ian

Nessa discussäo, ONCHAM (1989) actesesenta que sem uma l iberata efortiva das taxas de juros do cordito formal, de modo a refletir o custo de oportunidade dos recursos financeiros, o risco e os custos de transacio dos empréstimos, será dificil alcancar um sistema eficienten

0.5 mercados informas respondem, na maioria das veases, por emprestimos de pequeno montante e de curto prazo, tendo um carter mas local quanto aos agentes e pubico Envolvidos n fé frequente o emprestador näo exigir garantias reais nem cobrar juros sobre os recursos emprestados. Nesses mercados, as reciprocidades tem carater bastante pessoal entre as partesu o conhecimento e a confianca mitua entre emprestador e tomador constituem a base das operacoson.

Outro aspecto importante é que os agentes informats năo gastam tempo ou dinheiro tentando controtar a final idade de seus emprest imoss No caso de luso indevido dos recursos, os agentes bloquein a concessab de novos 
emprestimos ao coliente (ou grupo de cilentes) que desobedeceu o acordo original. Os emprestadores informats tem a seu favor o fato dey geralmenter conviverem no mesmo ambiente comercial ou social que os tomadores, o que thes

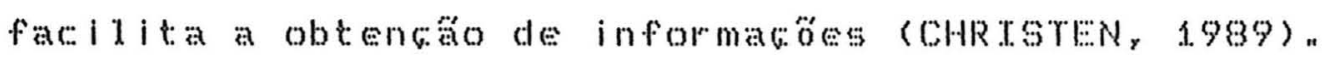

Entretanto, a falta de integracáo entre as unidades de servicos financeiros mult ipdos coupanga, depósitosem conta correntes empréstimos, etc. ") torna se um empecilho à plena atuaga dos agentes informats de credito. Quando esses servicos sáto integratos, informaceses adicionais sobre a capacidade gerenciad dos produtores -.. elemento que pode contribuir para diminuir o risco de inadimplencia, sáo geradas para os financiadores (LIEDHOL...M, 1989)"

CUEVAS (1989) observa que ligacóns mais consigtentes entre emprestimo e poupanca nos mercados informats serviriam para estimudar a confianca mitua e desenvolver a coredibididade entre os participantes dos mercados contudor duas imperfeicóses desses mercados dificultam o aprofundamento dessas 1 igatocos"

a) a incapacidade de real ian emprestimos de medio ou longo prazos, a inda que para tomadores confiádeis $e$,

b) a pouca seguranca oferecida pelos intermediários informas (individuos ou gruposs ass potenciais usurios vis 
Aclemais, a "marginalidade" dos agentes informa is de: coredito srestringindo as ligacosecomo setor financeiro formal) associada a pequena escala de recursos transacionadosy introduzem dificuldades na gerencia das cartaras de investimentor de ixando tais intermediarios vulneraveis ass futuacoses sasonas da disponibilidade dos recursos (CUEUAS, 1989),

Saber se os tomatores saro financeiramentesolventes, se tem fluxos de renda constantese confiaveisy se possuem outros débitos em andamento er ainda, se están readmente compromissados com o pagmento de suas dividas permite aos

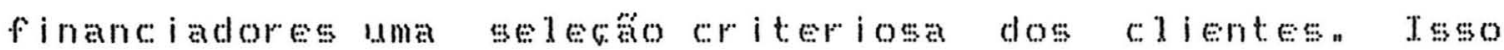
est imula o desenvolvimento e a sobreviveneia da carteira de empréstimos e mantém baxas as taxas de inadimplenciar evitando onerosas custas judiciais (CHRTSTEN, 1989).

Aspecto de extrema importancia a ser considerado sobre os mercados informats de coredito é a protica de altas taxas de jurosn

GERTDTs et ali (1991) ressaltam duas possiveis Expl icacoses (opostas entre si) para a cobranca desse elevado nivel de juros nos MFRTs A primeira é que os

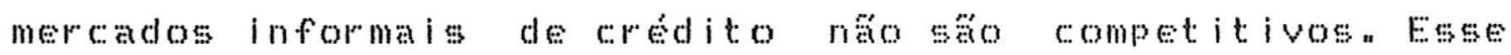
fato possibilitaria a alguns financiadores o controle 
monopolistico dos recursos, permitindowlhes extrair vantagens da relativa inelast icidade da demanda por crédito dos clientes e elevar substancialmenteseus lucrosn 0 ss autores observam que para o tomador, pressionado pelas restricoses de tempoy mitas veres importa mais a disponibilidade que o custo dos recursosn

Por outro lado, a segunda explicaca vai no sentido de que por serem competitivos, os mercados informas de credito apresentam taxas de juros que refletem os custos rea is dos recursos As taxas estariam, assim, representando o custo de oportunidade, o custo de transagato e o r isco de inadimplêne: ia, dentre outros componentes n

segundo os autoresy varios estudos a resperto das duas explicacoos chegaram a diferentes resultados no que concerne à ausencia ou presenga de ducro monopol istico nots MFRTs portom, o que mais se tem obererado é uma grande diversidade de arranjos, resultando num amplo espectoro de taxas de juros, refletindo os varios tipos de relacionamento entre financiador e tomador "

Ponto importante, a favor das fontes informas y e fato de que elas supremy prontamentey recursos para final idades näo atendidas pelo créclito formal, tais comon a) eventos näo esperados (geadas, doencas, frustracoses de 


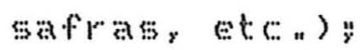

b) consumo no per ído prewcolheitan e,

c) investimentos de atto riscoy cujos recursos satory aradmente, conseguidos junto a parentes ou amigos (NEHMAN, 1.973) "

Esse tipo de observacáo tem levado, mutas veass, a sugestoes de que 1 igacoses entre os mercados financeiros formal e informa deveriam ser estabeleci ias, aproveitando o melhor de cada um e formandoy talves, um s istema miston

GERMTDS etali (1991) observam que o desafio de promover ligacoses entre os mercados reside no objet ivo de prover melhores e crescentes servicos financeiros a comunidaden Tsto, sem prejudicar as carateristicas favoraveis do setor informal de crediton flexibilidade, rapidea, transparencia nos procedimentos, relacionamento

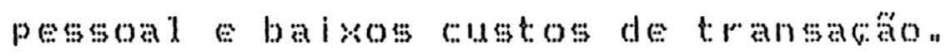

Algumas tentativas de aumentar a oferta de financiamentos nos mercados informats feitas por governos e/ou doadores internacionats fracasaramn Essas tentativasy visando aumentar o acesso ao coredito amortiável, năo levaram em conta os custos e riscos envolvidos nos emprestimos ao setor rurad " fétertor porémy que o aperfeicoamento da oferta de mervicos fimanceiros 
deve ser obtido atraves do aumento de financiamentos

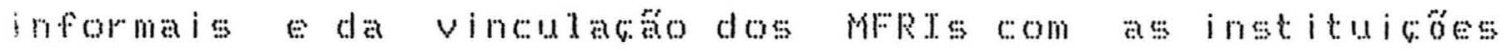
forma is (RI:LATORTO, 1989 )

ONCHAP (1989) defende a tese de que o papel dos mercados finaneseiros informas precisa ser medhor investigado, de modo a fornecer subsidios aos responsáveis

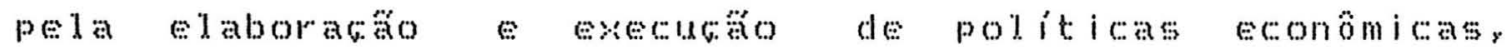
principalmente com vistas a aumentar a eficiência do próprio mercado financeiro formaln

Quanto aos agentes dos MFRTs, saberse que há diversos tipos atuando isolada ou combinadamentey dependendo da situacton ADAMS (1989) cita como principais" os monedenders; comerciantes de insumos efou produtos; penhoristasy parentes a amigos; grupos de poupanga

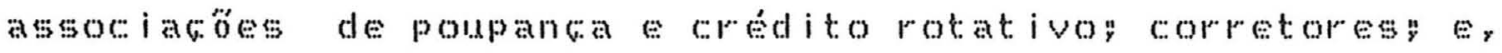

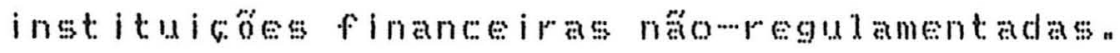

De maneira geral, eles podem ser corraterizados da seguinte forma:

\section{a) Mongey}

Individuos que emprestam recursos financeiros, geralmente no curto prazo, cobrando juros reais explicitos 


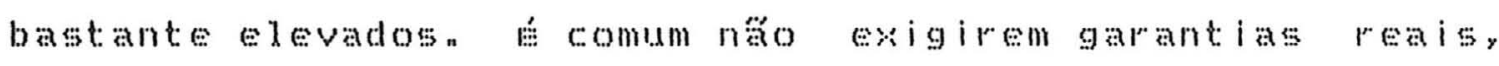
emprestando apenas para c: lientes conhecidos de longa datan No Brasil, essa atividade assemelhase da pratica da ag iot agem.

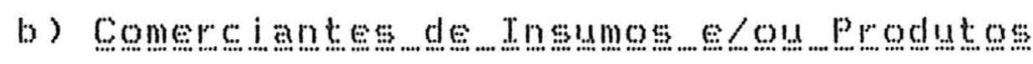

Basicamente, tem nos emprestimos apenas partes de suas at:ividaces. Entretanto, a manutenca da cilenteda e a garantia da venda de insumos ou do recebimento de mater ian... prima săo razós suficientes para readizar operacoses de emprestimos em dinheiro ou em espécie.

Pelo envolvimento com outras atividades alem do

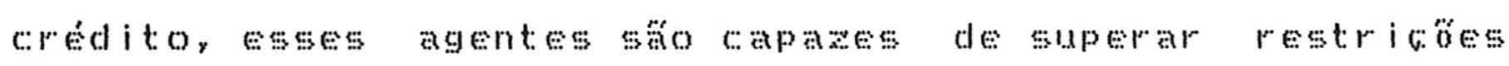
dos mercados finaneseros, tais como, assimetria de

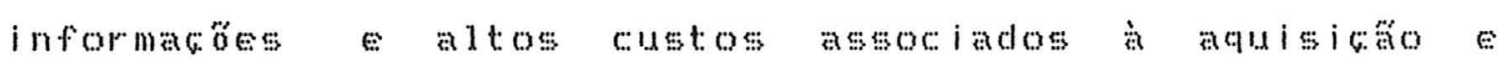

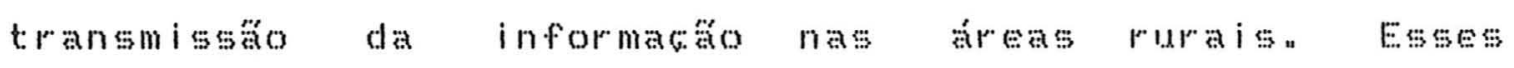
intermediarios conseguem transferir parte do risco da at ividade de emprest imo para outros mercados oberalmenter o r isco de inadimplência é compensado pela compra da producáo do financiado por um preco inferior ao preco do mercado (GERON, 1990$)$ " 


\section{(:) PEngorisg}

Concedem emprestimos com base em objetos deixados pelo tomador como garantia do futuro pagamenton No aso do pagamento náo ocorrer, ta is objetos saro vendidos/deiloados de forma a regperar o capital emprestadon

Bouman \& Houtman (1988) ${ }^{4}$ (: itados por ADAMs (x989), argumentam que a matoria dos penhoristas prefere que os tomadores resgatem seus emprestimos orecuperem os objetos que deixaram em garantian tssor obviamenter aumenta as chances de manterem uma certa col ientedan

BOUMAN \& BASTTAANSEN (1989), por sua VEz, ObERVam que as taxas de juros cobracas pelos penhoristas săo altas devido aos custos de gurata e de seguranga dos objetos deixados como garantia dos emprestimosn

Cons iderando a existence ia de penhor istas publicose privados, notane que uma das diferencas entre ambos está na forma de tratamento dada aos objetos correspondentes às dividas näo resgatadas pelos tomadores de corediton o

4 BOUMAN, FoJ AA \& HOUTMAN, R, Pawnbroking as an instrument of rural banking in the third world" Economic Development and Cultural Change, Chicago, 37(1) " $69-39$, 0 ct: " 1.988. 
penhorista publico promove leilöes para vender os objetos e o penhorista privado simplesmente realiag a venda no

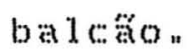

Tnteressante é fato de que sendo o resultado do le i läo super ior a soma do valor principal do empréstimo com os juros do periodo, o antigo dono do objeto pode rectamar o valor excedente junto ao penhorista. No caso da venda de badcag esse excedente fica para o penhorista como forma de $\operatorname{lus} 0$

\section{(1) Parentes esomigos}

Săo comuns emprestimos realizados por parentes e amigos năo envolverem a cobranga de juros, a exigência de garantias ou rigider nos prazos de pagamenton A caracteristica marcante desse tipo de financiamento é a expectativa de reciprocidade em emprestimos futurosn

\section{e) Gropos de popgenga}

Sáo encontrados na maioria dos paises es constituem importante fonte informal de crediton seu objetivo principal é captar poupancas e, posteriormente, aplicádas em atividades individuats ou de intereses comm ao grupon 


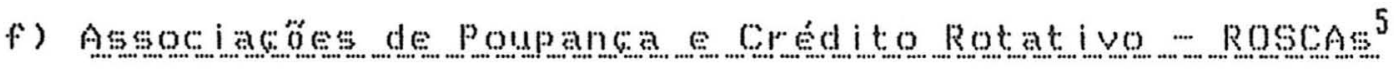

As associacoses de poupanga e coredito rotativo sáno organizacoses financeiras informas mas complexas que os

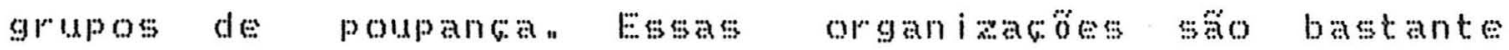
difundidas em países do terceiro mundo chegandor em alguns dedes, a ter mats participantes que o sistema formal de (.) ÉCItO (ADAMS \& CANAUEST, 1988) "

A at ividade basica consiste em reunir depositos es conceder empréstimos, lastreados nos depósitos, aos membros do grupo de maneira sequencial, ate que todos tenham recebidon o conhecimento a confianca mutua entre os participantes, bem como a responsabilidade social de resgate do emprestimo, atenuam/resolvem o problema da garantia e diminuem a taka de inadimplencian

De maneira geral, as Roscess funcionam da seguinte forman

a) os grupos sán automedecionados:

b) alguns grupos guardam registros escertos redativos aos depósitos, emprestimos e juros cobrados;

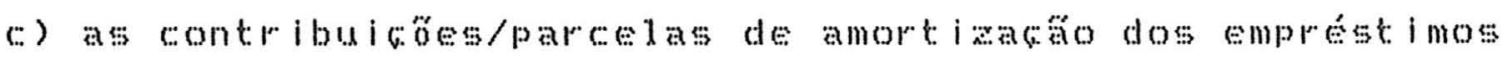
gäo recolhidas pelo tesoureiron

5 RosCAs sáo as iniciats de "Rotating savings and Crectit: Assoc: i at: i ons" " 
d) os membros interessados em empréstimos precisam dectarar esse interesse publ icamente a grupon

e) os participantes que chegam atrasados ou perturbam a reunita ou, ainda, náo pagam a contribuicăo, säo multados n 0: valores arrecadados com as multas podem ser ut i lizados para comprar comida, fornecer diversäo, complementar fundos de emergencia/ajuda mutua, ou, ocasionalmentey para d istribuicaro entre os participantes do grupoy er f) alem das sancós financeiras, existem as puniós sociats aplicadas aos inadimplentes" perda da reputaca na comunidade e impossibilidade de participar de outros grupos de poupanca/credito (CUEVAs, 1989 ).

No Brasil, os consorcios informats săo exemplos próximos desse tipo de associacion fin gerat, esses consórcios tem por objetivo facilitar a aquisicaro de bens de consumo duráveis por um grupo de pessoas "

NAYAR (1989) acrescenta que um dos meritos da Rosch ó o fato de que encoraja e facilita a realiancáde de poupanca por pesagas de baixa renda.

No que concerne ao tamanho do grupo, BOUMAN (1981) assinala que embora um grande grupo signifique mar quantia a ger arrecadada, também exibem maiores chances de fracasso e inadimplência. Além disso, grandes grupos 
clificultam a reuniáo dos membross principalmente em áreas rurais, onde as distâncias costumam ser expressivas

Adematsy a sazonalidade da renda agricola dificulta contribuicáno regular por parte dos agricultoress RosCAs em áreas rurais tendem a ser pequenas a a recolher pequenos Valores monetários (BOUMAN, 1.981)"

Em outro estudo, Bouman (1989) assinala que existe uma Var iactao do si stema de ROSCAs, a que o autor chama de

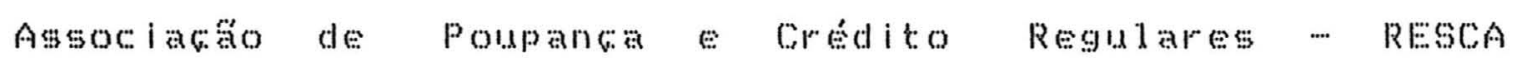
(iniciats de "Regular Savings and Credit Association"). A

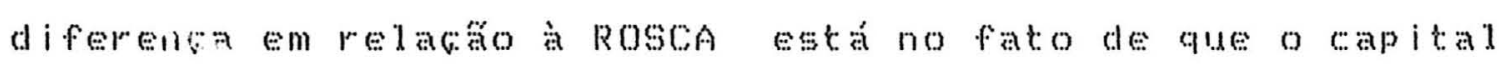
da RESCA aumenta a dongo de sua existencia, uma vez que emprestimos sato feitose liquidados dentro do perído de funcionamento. Ao final desse períodor o total arrecadado acrescido dos juros recebidos nos emprestimos é dividido entre os participantesn

\section{9) Corretores de Empéstimos}

A atuago desses agentes consiste basicamente na intermediacáo de emprestimos entre financiadores es tomadores med iante comissäo cobrada de uma ou de ambas as partes envolvidas 


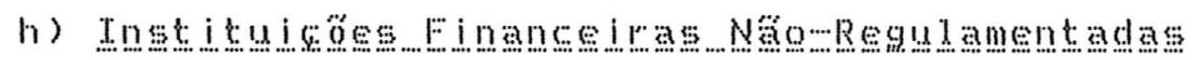

Esesas institulatos agem como bancosy tendoy inclusivey ânencias e funcionários em diversas regiós dos paises em que operam.

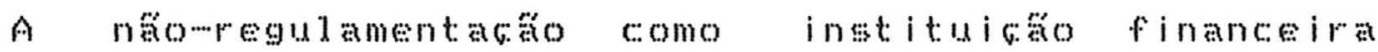

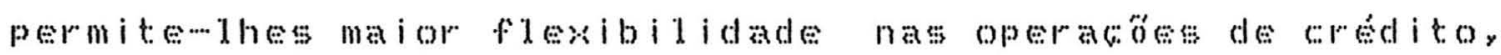
principalmente quando se trata da exigencia de garantias a

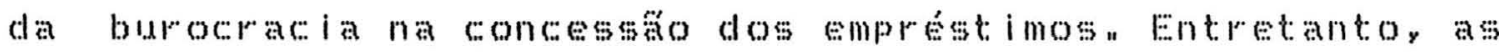
takas de juros praticadas por essas organizacón sáso

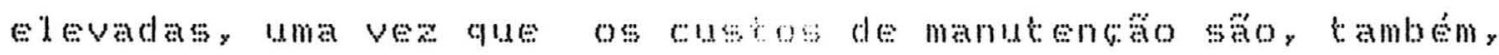
e. levactos.

De maneira gerad, segundo SANDERATNE (1989) E BOUMAN $(1989)$, os agentes informats de cordito podem, a indar ser

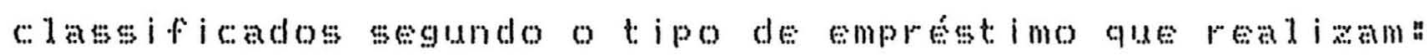
a) diretamente em dinheiro:

b) lastreados em produtos/servicosy er

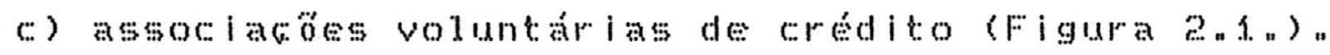

Ainda que qualquer produtor possa recorrer ao financiamento informal, e necessario ressaltar a significativa participacáo da mulher como usuaria dos mercados informa is de crediton 
Figura 2.1.- Agentes de Crédito Informal, Segundo o Tipo de Emprést imo Realizado.

\section{Intermediaçao Financeira Informal}

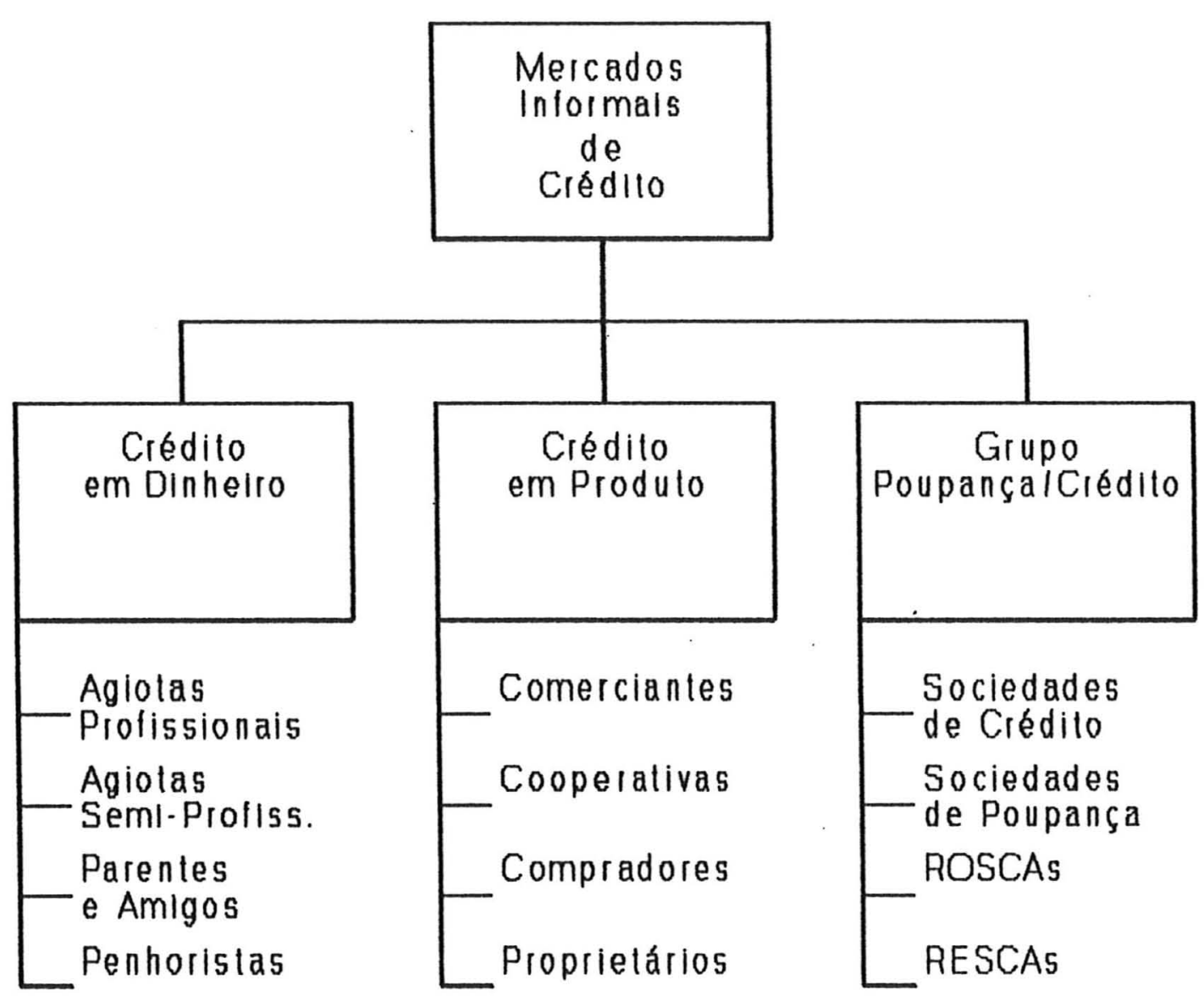

Fonle: SANDERATNE (1989) e BOUMAN (1989) 
OTERo (1989) argumenta que a busca por credito entre as mulheres deverse ao estímulo (ou obrigacios para assumir a gerencia das atividades urbanas ou rurais da famílian Essa necess idade tem entre outras razós"

a) migracăo do homem, principalmente em areas rurais da América Lat: ina estricar

b) altas taxas de divorcio e de abandono familiar por parte dos homens: ex

(i:) crescente custo devida eneceseidade de aumentar a renda famili ar

Além disso, muitas mulheres em dreas rurais de países em desenvolvimento condurem suas at ividades domésticas ey ao mesmo tempo, engajamme em outras atividades na propriedade e/ou fora delan Essa pratica visa a gerar renda, atenuar os riscos do empresendimento e tirar vantagem de mudancas sazona is e var iaco ós de mercadon

Apesar dessa responsabilidade crescente sobre a atividade produtivay a mulher enfrenta problemas na obtención de credito junto ao mercado formaln Alguns problemas sán inerentes a proprio setor financeiro formal e, outros, ao fato de serem mulheres pequenowaricultoras n Tsso compromete o acesso ao crédito formal e as apromima sensivelmente dos agentes informats (OTERO, 1989)" 
Dentre as dificuldades impostas pelosistema bancario

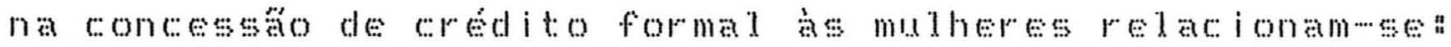

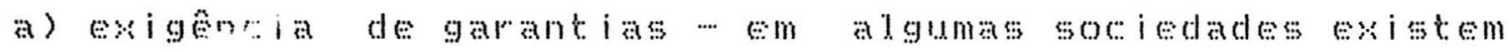
sérias restricoses a propredade de terras e de outros at: ivoss pela mulher:

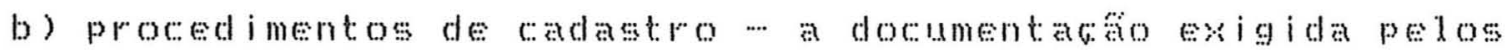
bancos para processar um emprestimo exige nivel de conhecimento exterior a real i a ade famil iar de aloumas mulheres: e:

(:) tamano do emprestimo a. a marora dos bancos prefere emprestar grandes quantias para diminuir o custo médio de intermedi actón

Uma vez apresentacas as principais caracteristicas dos MFRTs, torna rese recomendaved destacar, a seguir, algumas

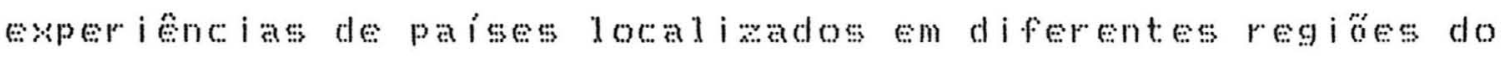
mundon

\subsection{MFRIs em Países de Diferentes Regióes do Mundo}

Há registros sobre o funcionamento dos MFRTs em diversos paises e diferentes tipos de economias Eses mercacos, entretanto, parecem ter mar importancia em parses de economia de ba ixa renda ou em desenvolvimenton Nestes, geralmente, o sistema formal de credito näo 
consegue atender as necessidades do setor agropecuarior seja pela falta de recursos ou pela excessiva rigidez do si is teman

\subsubsection{AFRICA}

No continente africano, em gerat, o aceses aos servicos financeiros formats é extremamente limitado esou obtido a custos de transacio mu ito elevadosn

Enquanto nos páses em desenvolvimento da América Latina ésia a relaca mimero de habitantes por agencia

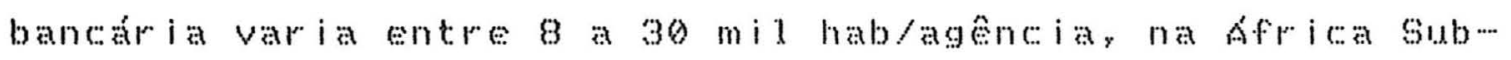
Sahariana essa relagáo é da ordem de $100 \mathrm{mil}$ a $420 \mathrm{mil}$ habitantes por agencia bancarian Tsso dificulta e encarece a tomada de crédito formal, principalmente nas áreas rurais onde há deficiência coronica de comunicacaro etransporte (CUEUAS, 1989)"

Além disso, restricoses de ordem macroeconomica e regulamentacose financeiras frequentemente prejudicam o atendimento as atividades rurais pelos poucos bancos existentesn Em consequencia, o financiamento informat torna-ise mats importante evidente. 


\subsubsection{Camaróes}

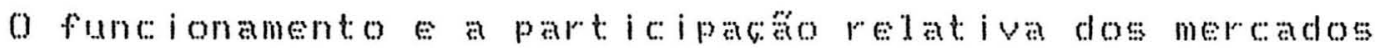
financeiros informas na agricultura de camarós foram EStudados pOr SCHR TEDER \& CUEUAS (1989)"

Eseses aut ores tomaram por base alguns grupos de ajuda

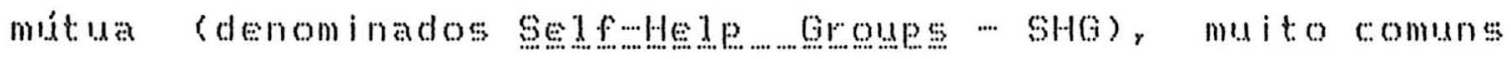
naquele país n Eles compresendem grupos de poupanca e crédito rotat ivo (ROSCAS) E nâno rotativo (Non ROSCAs) (:ujo objetivo o resolver problemas de liquider real e potencial dos participantes

Quando levantaram as informacoses da pesquisa, em 1988 , Schrieder \& Cuevas ver ificaram gue:

a) os SHg estudados tinham idade variando entre es 34 anos de existanciay

b) o numero de membros por grupo variava entre a 5350 individuos, contando com uma forte presenga feminina na sua c. ompos i crót

(:) a maioria $(70 \%)$ dos valores emprestados aos participantes dos grupos estava no intervalo de usq 3,00 a $45 \% 63,00 \%$

d) a taka media de juros cobrada sobre os emprestimos era de $33 \%$ an ano 
d) apenas 7\% dos grupos entrevistados timham financiamento en fontes formats de coredito:

e) os grupos financeiros informas haviam sido responsaveis por 27\% do total de emprestimos concedidos em camaróses naquele ano.

Esses resultados levaram os autores a concluir que os grupos informa de ajuda motua saco capazes de ajustar sua estrutura eprincipios operacionals a uma grande variedade cle circunstanciasn ra is grupos respondem, prontamente, a diferentes tipos de demandas por servicos financeirose, por isso, levam expressiva vantagem sobre o sistema formal

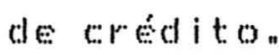

\subsubsection{Et iópia}

Dentre os intermediar ios financeiros informa is et iopes dois tipos merecem destague os Idirse os Ekybs cotermots ets $1 \mathrm{i}$, 1991$)$

0 Idirs sáo associacóses de ajuda mutua, comuns tanto em áreas urbanas como rurais, criadas com a finalidade de reunir poupangas e realizar emprestimos entre os participantes os emprestimos destinamos a finalidades emergenciais, náo atendidas pelas instituisoses formats tals comon gastos com casamentos, doencas, funera is, perdas 
por incêndio ou roubo, etcen

As operacos săo readiandas em bases estritamente pessonis, com severas sancoses de ordem social em caso de Inadimplêne i a do tomador"

0 emprestimos, bem como os pagamentos, podem ocorrer em dinheiro ou em espécie (produtos elou servicos). No caso dos Idirs rura is ganha importancia a troca de prestacáco de servicos entre os membros dos grupos"

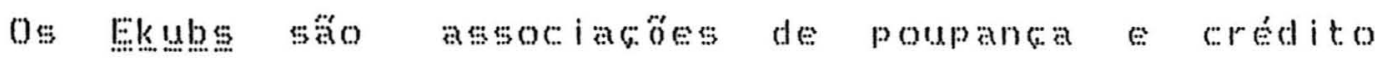
rotativo (ROSCAs) n Tais associacoses són mito comuns na Ei:t $\mathrm{i}$ óp i a

Esses grupos tem tamanhos diversos, variando entre o e 100 participantes. As regras tornamse ma contribuicoses de mator valor, à media em que o grupo (i.)

Nos Ekybs mais estruturados e complexos o vencedor da rodada tem que apresentar do is aval istas para poder receber opremio. A exigencia ce aval istas é uma forma de garantir que o premiado cont inuará participando da Rosce até o final de todas as rodadas 


\subsubsection{Mogamb ique}

Fistudo recentey conduzido por ARAúlo (1992), mostra que a conomia de Mogmbique foi sensivelmente afetada pelas turbulências pré e pós.windependencia "Dentre outras conseguenciasy a guerra civil provocou a ruptura da producto rural e o exodo da populaca para áreas urbanas em buscata de protectonon

o setor financeiro formal mogambicano é fortemente centraliandoy tendo como instituigro controladora o Banco de Mogamb i que (BM), exercendo, como um banco centrat, o controle das políticas de juros, cambio de corditon

No trato com o setor agricola, a instituicáco mas tradicionad é o Banco Popular de Desenvolvimento (BPD), um banco estatal, responsável por $3,5 \%$ do total de ativos financeiros do sistema bancarrion

No toceantes ao financiamento informal, Araujo observou sistemas tradicionats de troca de servicos entre os produtores, principalmente na época de colheitan

Outra modalidade informal comum entre os camponeses

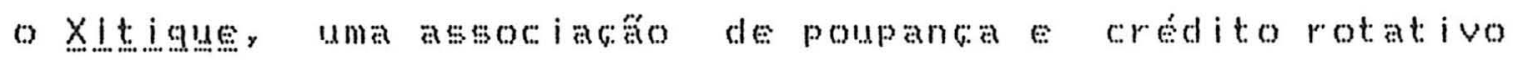
$(\operatorname{ROSCA})_{4}$ 
Além disso, o crédito com o objetivo de financiar consumo familiar ou at ividades de productor fornecido por comerciantes (Cantineiros) aparece como alternativa financeira em Mogambique. Em alguns casos, esses Cant ineiros atuam como guardadores de dinheiro, aceitando depósitos dos produtores.

Considerando as limitacoses naturats dos mercados informats no atendimento mais generaliando da populacăo rurad, Araujo sugere a estruturacto de um sistema semi-... formal de financiamento ruraln Dentre as funcoses desse sistema, o autor relaciona a capacidade de transferencia de recursos de unidades superavitarias para unidades deficitarias, objet ivando manter o equilibrio do sistema, o oferecimento de maior número de servicos de poupanga crédito e a exosicáo/distribuicáo dos riscos em operacónes de maior escalan

\subsubsection{Níger}

De maneira geral, descreve GRAHAM (1989), o escopo e a magnitude do financiamento informal rural no Niger săo substanciaisn A utilizacta de crédito obtido junto a comerciantes, guardadores de dinheiro e Tontines (ROSCAs) é comum nesse cenario, dominam empréstimos de curto prazo destinados a financiar o consumo familiar" 
Esse autor redata que ofinanciamento formal para a agricultura foi, durante algum tempor real iando atraves da Caina Nacional de Crédito Agricola (CNCA) "Nesse periodoy os emprest imos da CNCA eram realiandos em especies ou sejar em fertilizantes, sementes, animas de tratoro, eten A demanda pelos insumos era est imada por extensionistas oficiais junto a produtores selecionados

Entretanto, por problemas de administracaco, altas taxas de inadimplencia e pouco suporte financeiro, a CNCA prat icamente encerrou suas atividades, contribuindo para a ampl iacaso dos mercados informats no Niger.

Graham também constatou forte presenca do crédito informal na agricultura daguele pás rem seu estudor observou que 85\% dos produtores entrevistados tinham acesso ao coredito informal. Mais que isson o crédito informal, em 1.985, teve grau de importancia de 7,5 a 16,7 vezes ma or na formaga da renda agricola familiar gue o coredito formal para os produtoresn Assim sendo, a intermediaca informal leva significativa vantagem sobre a formal, principalmente por quatro aspectos:

a) realian pequenos emprestimos de curtoprazo:

b) tem grande flexibilidade operacional:

(:) concede coredito para consumo; e:

d) presta servicos de depósito/poupangan 


\subsubsection{Senega1}

Estudo conduatdo por Fl..AMANG (1989) revela que o setor informat, definido como a porato da atividade econômica fora do domínio do sistema legal formal e do governo, bastante expressivo no senegad . Acredita ase que, no mínimo, bo\% da populacio do senegal dependem desese set: or

As at ividades dessa exonomia informal sáo financiadas, principalmente, por individuos e agentes financeiros do proprio setor informal "Aspecto interessante dessesetor é agrande importancia relativa das mulheres como poupadoras elou invest idoras n

Segundo Fl..MMANG (1989) as poupangas nos mercados informas säo significativas e tipicamente mantidas em dinheiro, ao inves de serem depositadas em alguma instituicáo. 0s poupadores acumulam fundos ut i l izando as rontines ou, entäro, por meio de depósitos periódicos com individuos de confianga ("guardadores de dinheiro") da própria regiano onde residem.

Ocasionalmente, os recursos das rontines, dos comerciantes ou das poupanass colet ivas sáo depositados em bancos" No entanto, por serem de pequena montat tais 
recursos sáo pouco atraentes para as instituicoses finance iras

A maior parte das poupanas individuais ou coletivas no senegal é utilizada para final idades de consumo tais comon aquisicaro de bens dur áveisz manutenço da famíla na entressafray gastos com cer imonias religiosas: es cosos de doencin a

Quanto ao custo dos financiamentos informass foi constatado que os empréstimos familiares usualmente näo têm cobrancia de juros n por outro lado, o custo do cirédito obtido de fornecedores de mercadorias pode atingir ate $30 \%$ ao ano em termos reais. Já os emprestimos realizados por moneydenders podem ter juros reais variando entre gor o $1.00 \%$ a

\section{1-1.6. Somá1 ia}

Na Somalia, a agricultura responde por mais de $60 \%$ do Produto Nacional Bruto e emprega $80 \%$ da populaca economicamente ativa be uma agricultura voltada para a subsistenciat com pouco uso de insumos modernos (DELANCY, 1.989).

A dificuldade no acesso ao setor formal de cordito é 
um fator agravante para aqueles que desenvolvem at ividade agropecuaria, principalmente para os pequenos produtores, grande maria do setorn

Delancy observa que os emprestimos informats envolvendo dinheiro säo fornecidos por comerciantes, moneglenders, amigos ou membros da famíl ia do tomador

No caso dos moneylengersegrobolems de ordem redigiosa a If icultam as operacoses. Vale lembrar que a somalia é um pais de ma oria istâmica, onde a pratica da "agiotagem" é proibidan Ainda assim, mesmo em escala bastante reduatda esses agentes podem ser encontrados.

Fontes de crédito informal comuns sáo as shaloongo associacóses de poupanga e credito rotativo (ROSCAs)"

Os recursos obtidos nos mercatos informats soror geralmentey destinados a cobrir despesas de consumo fam i l iar elou de custeio da producion

Outra forma ut i ianda para desenvolver as at ividades rurais é at iliancáde grupos de trabalhos temporarios ou permanentes na execucouro de algumas tarefas os grupos temporarios sáo chamados de goob e constituídos por vizinhos dos produtores, trabathando em forma de mutiran 
0s grupos permanentes (Barbare) säo formatos por jovens e têm cunho social de auxilio aos produtores. o pagamento năo envolve dinheiroy geralmenter é feito em produtos a serem entregues ápoca da colheitan

\subsubsection{Sudão}

No sudăo, uma forma de intermediactáto financeira informal muito comum é o emprestimo em dinheiror readiando na fase de desenvolvimento da cultura com pagamento em

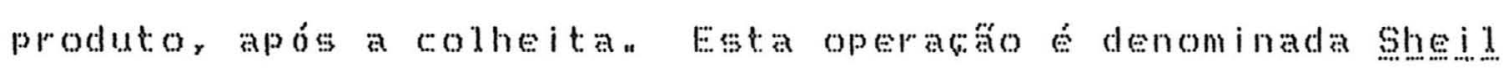
(KEUANE: , 1.993),

Dentre os agentes informate de credito operando em diferentes regioes do sudar kevane identificou comerciantes, fazendeiros, migrantes que retornaram ao país com melhor situacá financeiray parentes, etc.

Fato interessante é o registro de um grande numero de emprest imos, realizados pelos intermediarios informais, sem a cobranca de juros n Uma possível explicaca para isso seria a concessán de crédito em troca de apoio politicon

Porém, quando há juros no sheid, o valor cobrado näo é desprezived. El Medani (1983) (eitado por KEUANE (1993) est: imou uma taxa de juros variando entre $300 \%$ e $7000 \%$ ao 
ano, com media ponderada de $726 \%$ a a " Kevane sal ienta que a falta de informatoose ma is precisas esore os valores pagos pelos tomadores os precos de mercado dos produtos na epoca de pagamento dos emprestimos dificulta a

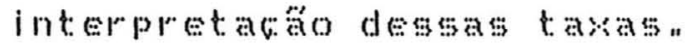

\subsubsection{Zaire}

Fl..APMANG (1989) obervou que os mercados informats de credito no zaire seguem o mesmo padra do senegaln

As poupancas nos mercacos informas sáso expessivase

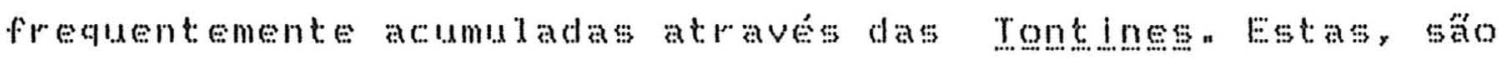
criadas para pessons, propositos e periodos de tempo especificos"

Por sua very depósitos de poupanca podem ser feitos com um comerciante ou parente de confiancan os empréstimos podem vir de um parente ou entä de um moneslenger. usuadmente por curto periodo de tempon o elo central parece ser o conhecimento pessoal e a confianca que os participantes tôm nos parceirosn

A maiorla dos empréstimos é dirigida para o consumo de bens durádés (ápas urbanas) e para suportar o per fodo de entressafra, principalmente a prewcolheita (áreas rurais), 
ocasionalmente, os pouparores fazem emprestimos de curto prazo para familiares ou amigos com propositos empresariats, geralmente para reposiofo de estoquesn Empréstimos de longowprazo com familiares ou amigos săo ut ilizados para iniciar uma empresa e tomam a forma de uma sociedade, até que o tomador possa pagar o emprestimo comprando a parte do financiador "

Os emprest imos familiares no zairesto quase sempre liveses de juros explicitos, mas incluem expectativas des reciprocidade futuran.

Emprest imos de moneylenders normalmente comerciantes ou individuos assalariados, chegam a custar até $70 \%$ ao mess. Na época da realizaco da pesquiga de Flammang, a inflaca no zalre estava em torno de $10 \%$ ao mês. Além da inflacko, a precariedade dos meios de transorte e comunicaca dificultam também o desenvolvimento dos mercados financeiros formats e informais no zaire.

Fato interessante que, mutas veres, recursos de pessoas que operam primariamente nos mercados informais säo cepositados em contas correntes abertas nas cooperativas Essas cooperativas, por sua very emprestam ta is recursos ao governo atraves da compra de obrigatoses do Tesouro. Nesse caso, o setor informal passa a financiar at:ividades do 
setor formal. o problema é que apesar da segurana proporcionada pelas tooperat ivas aos depositantes nág há

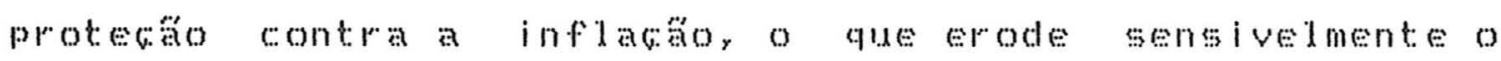
valor real dos recursosn

Essa parece ser a principad l igacáo entre os mercados

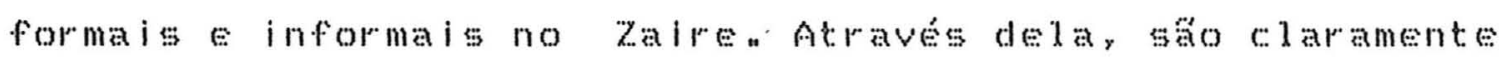
beneficiados o governo e o setor formal da economia às custas dos pequenos depositantes informats que perdem renda cespitaln

\subsection{2. $6 S I A$}

Considerando o tamanho expressivo e o baixo nivel de renda da populacác (principalmente a rupal), na maior parte

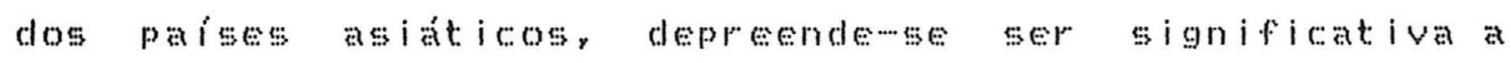
necessidade de recursos financeiros emateriais para o desenvolvimento da atividade economican Todavia saco raras as experiencias de financiamento formal hom sucedidas

Consequentemente, abrewse amplo espaco para a atuacáno dos intermediarios informas a habilidade em atrair cel ientes potenciais, mostrando flexibilidade e rapidez na concessá de empréstimos, coloca esses intermediarios em expressiva vantagem relativamente aos agentes formas de coredito. Tsso é verificado mesmo considerando o alto custo 
do dinheiro nos merados informats

\subsubsection{Bangladesh}

Dentre as experiencias de intermediacto financeira informat, uma das mais interessantes ereconhecidamente de efeitos positivos é a do Grameen Bank.

O Grameen Bank (OB) é uma organiazago originaria de iniciativa privada criada, em 1976, com o objetivo de fornecer coredito aos agricultores semprera e comerciantes de Bangladesh ${ }^{6}$ (RELATÓRTO, 1989).

Como forma de trabatho, o 0 atua atraves de grupos de agricultores interessados em corediton Além dissoy para que possam ter direito a emprest imotis todos os membros do grupo (constituido por cinco pessons) precisam demonetrar um comportamento regudar de poupanga semanaln

Os doisprimeiros individuos de cada grupo a receberem um emprestimo tém que pagar varias prestacoses semana atraso, para que os outros membros do grupo tenham, por sua verz, direito a credito. Esse sistema requer forte compromisso sociad entre os participantes n A maria dos

${ }^{6}$ Segundo PRABOWO (1989), muitas veses o termo Bank (Banco) \& utiliato no intuito de aumentar a confianca do usuário na instituic:áon 
emprestimos destinawe a financiar o comercio e a compra de gado. Saberse também que sto de curtoprazo os emprestimos e modestas as garantias exigidasn

O bom desempenho do bB pode ser verificado pelo crescimento e alcance conseguidosn fim fevereiro de $198 \%$, o QB mantinha 300 agencias bara o atendimento de 3400

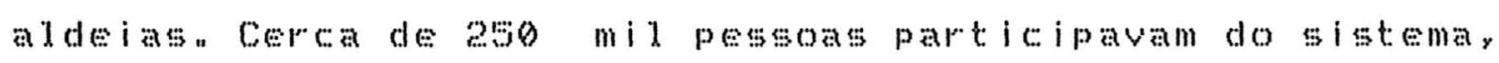
gendo as mulheres $75 \%$ do total de participantes. Em 1989 o

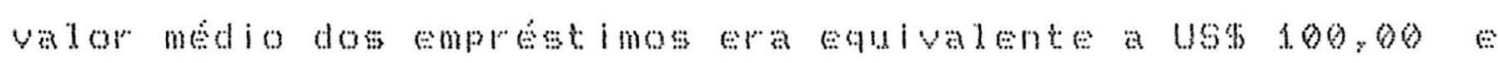
a tawa de reembolso das dívidas de 95\% (RELATORTO 1989)"

Os resultados satisfatorios conseguidos pelo GB devem

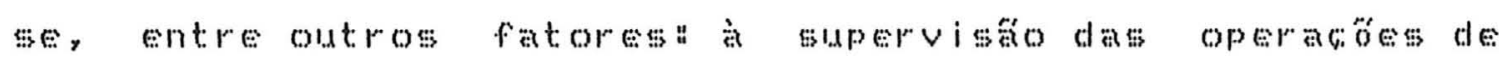
campo (feita através de contato semanal entre funcionarios do ob a mutuarios) y ao direcionamento dos empréstimos para fins que geram renda regularmentez a existencia de sol idar iedade entre os membros dos gruposy è fa frequencia semanal dos pagamentos"

Os recursos emprestados pelo oB tem custo operacional elevado. Entretanto, gracas a poupanca de cata mutuário e também à ajuda de agencias internaciona is de financiamento,

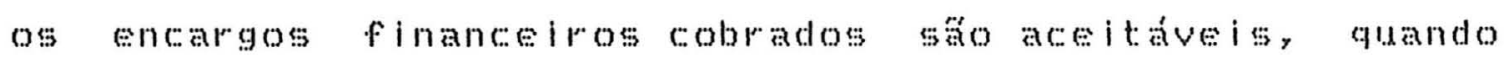
comparados aos praticados por outros agentes informa is " 


\subsubsection{Filipinas}

Nos mercados informats filipinos, parentes, amigose vizinhos sta fontes comuns de credito para consumo famli iar comerciantes e moedores/mauinistas realiam emprest imos preferencialmente para acuisica de insumose at:ividades produtivas (GERON, 1990 ).

Fato interessante ó que alguns dos agentes informats buscam recursos em outras fontes de credito para financiar seus c. lientes. Essa busca se da junto ao sistema bancárioy comerciantes, corporacónes chinesas ou, entoro, familiares e $\operatorname{amigosin}$

Com relacio às takas de juros cobradas nos financiamentos rurats informats, o autor est ima variem entre zero e $87,5 \%$ ao anon o limite inferior seria estabelecido, mais commente, por parentes/amigos/vizinhos e o superior por comerciantes e monestenders

Evidencias de financiamento informal nas Filipinas Găo, também, fornecidas por NAGARAJAN Et ali i (1991) ao analisarem os contratos de cessäo dos direitos de cultivo de terras entre proclutoresn Nesses contratos, um agricultor ceder temporariamentee o direito de cultivo de suas terrats a outro agricultor en troca de um emprestimon Rege esse 
acordo o compromisso de devolugăo desses direitos quando do pagamento da dividan

segundo esses autores, esse tipo de operactio té realizado, geralmentes por pequenos produtores com objetivo de levantar recursos para financiar investimentos produtivos fora da propredaden vale notar que a implantaca da reforma agraria nas Filipinas serviu de estimulo a esse procedimento.

Durante a vigência do emprestimo, o retorno líquido obtido pelo financiador no cultivo das terras do tomador equivale aos juros implícitos no empréstimon Essa prática obviamente, considera o risco de mercado do produto. fazendo com que os juros implicitos dos emprestimos variem sensivelmente os autores est imaram que os juros embutidos nos contratos de cessáo de direitos de uso de terras Variaram entre $17 \%$ e $37 \%$ a ano, no periodo 19961989. Houve, inclusive, evidencias de taxas de juros negativas, face ao elevado risco assumido pelo produtor que efetuou o emprestimon En caso de inadimplência comprovadar a transferencia definitiva das terras do tomador para o financiador pode ocorrer. 


\subsubsection{India}

Na rndia, o setor financeiro informal é bastante organizado e representado por uma grande diversidade de agentes financeiros por essa rayor seu alcance é maior que em outros paises em desenvolvimento (NAYAR, 1989)"

Dentre os agentes financeiros, os mais importantes

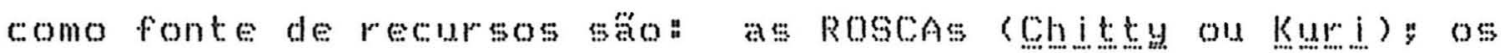
Fundos Mútuos (Nidnig); as Tnstituisós Finanoiadoras de Compras a prazog es as Financeiras Thformis.

A Chitty tem por objetivo a coleta edistribuicio de uma quantia presestabelecida, durante um determinado periodo de tempo, até que todos os participantes tenham Bdo contemplados a cada reunizo, o total arrecadador menos uma comissaro de g\% destinada ao organiandory é dado t:omo premio a um dos membros, selecionado por sorteio ou edeicano como o numero de subscricóses periódicas e o número de participantes sáo iguas, todos recebem seu prêmion

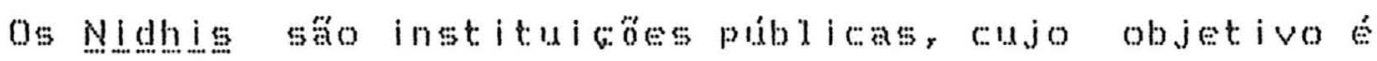
promover atividades de poupanga e emprestimo à taxas de

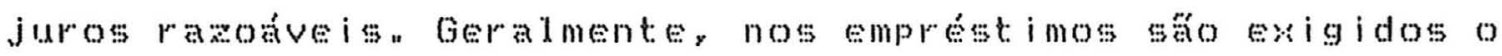
penhor de jóias ou a hipoteca de imóveis pertencentes aos 
tomadores de creditor comogarantia de pagamento da divida a

Na poupanca, os Nidhis oferecem, para varias categorias de depósitos, 3 a 8 pontos percentuats acima das taxas de juros prevalecentes nos bancos comereiais De outro lado, os encargos sobre os emprest imos variam de $18 \%$ a n i móveis) "

Existem também os penhoristas privados registrados e sob controle governamental que, apesar disso, cobram juros superiores aos $1 \mathrm{imites}$ estabelecidos na legislacton Em geral, esses penhoristas mantém joalherias ou ourivesarias aceitam apenas o penhor de objetos de ouro (Boumar \& BASTTAANSEN, 1989 ) "

Os penhoristas privados náo registrados, por sua veà,

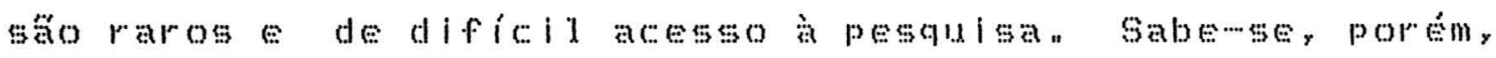
que dispóem de pequeno capital para operar e que atendem a cel lentes de baima rendan rais celientes têm acesso $1 \mathrm{imitado}$ ao credito de cooperativas e bancoser também, despertam pouco interesse dos penhor istas licenciados (BoumaN, 1989)"

Ass. Financiadoras de Compras a prazo sáo instituicács que real izam financiamentos para compra de bens de consumo e recuperam oprincipal e juros, em prestacóses, durante um 
determinado periodo de tempon os emprestimos tém prazo máximo de cinco anos"

Alguns agentes também financiam a compra de bens, em moldes semedhantes as instituicoses como suporte para sua atividade, ut i liam recursos proprios e depósitos recebidos de parentes e amigos n Tais depósitos recebem, geralmente, remuneracăo real de $18-2-20 \%$ ano ano.

As Financeiras sán firmas constituidas com o objetivo de obter lucros na realiancos de emprestimos Na mobilizacaro de depósitos, essas firmas exercem forte competicáo com o setor bancario comercial, aceitando depósitos correntes è prazon Tnelusive, nos depósitos à prazo chegam a pagar juros duas ou tres vezes superiores aos pagos pelos bancos. Mas, a ma ior vantagem em redaca ao setor bancario surge nas formas de emprestimos que elas podem realizar " rendo uma estrutura mas flexível e menos burocratianat tais firmas têm inovado, introduzindo esquemas de empréstimos ma is atrantes ao público (NAYAR, (1.989)"

\subsubsection{Indonésia}

Na Indonesia, a intermediactao financeira informal é readiada por grupos/associacos de produtores e por 
inst ituicóses financeiras semi formats

PRABOWO (1989) cassifica os agentes informas de credito em dois gruposa comerciais e năowomereiaisn om comerciats incluem moneydendersy comerciantes it inerantes, vendedores de insumos e penhoristas os financiadores nấn

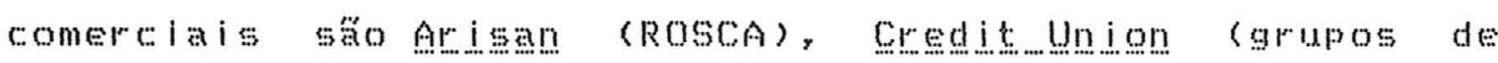
poupangas), amigos e parentes. Há, também, o sistema tojon caracteriato pela compra antecipada da producáo futura ("compra verde"). Nesse tipo de financiamento, o tomador cede ao financiador os direitos de colheita e venda da productáon

No caso da Arisan, cita o autor, a forma de atuacaco udtrapassa o modelo tradicional das Roschs operando inicialmente como um grupo de mobilizacaro de poupancar a associacio se desenvolve e passa a realizar emprestimos e/ou investimentos produtivos n Nesse estagio enguadram se associacóses identificadas como gimpan pinjam y ysang Bersamar e credit Un Ion

GERMTIS et alid (1991) c: itam a existencia do sewas, um sistema onde o tomador do emprestimo transfere os direitos de uso da terra para ofinanciacor "Esca transferencia se dá por lim periodo de tempo correspondente à duracáco do emprestimo. Nesse sistema, a renda liquida obtida no wso da 
terra é equivalente a taxa de juros cobraca pelos recursos emprestados lesquema semelhante a observado nas Filipinas)

Na Indonésia exister também, a presenca de agentes financeiros semi forma ss atuando como intermediarios de recursos n SEREL (1989) citar dentre outras, organiancós näowgovernamentats (ONGs), organizagos governamentais a algumas instituicoses privadas n

Seibed observa que essas organizacoses apesar de nă seguirem as normas oficiais do sistema financeiro, nä́ escapam ao controlefsupervisăo do governo tal como os agentes informats.

Finte as instituicós semi wormats governamentais merece destaque o Badan Kredit: Kecamatan -.. BKK \&RELATóRO, 1.989).

O BKK foi criado pelo governo da parte Central de Java com a finalidade de emprestar pequenas quantias à camponesas de meia idade, geralmente sem exigir garantias n

Uma grande vantagem do BKK é a rapider na decisăo sobre os emprestimosn os pedidos de financiamento tem resposta no prazo máximo de uma semana caso o primeiro 
emprestimo seja resgatado dentro do prazo, novos coreditos podem ser concedidos no mesmo dia em que sejam solicitacos Basta, para isso, que o chefe da aldeia autorizen Nán há exigencia de garantias a 0 sistema baseiane em referencias quanto ao carter do cliente fornecidas pelas autoridades locaise na pressás socialn

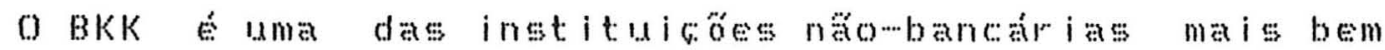
sucedidas do seu tipo em todo o mundon cerca de 3 no

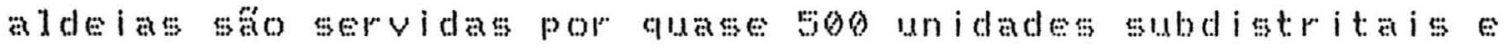
3 mil postos urbanos " Em 1.987, obanco tinha 5ib mil emprest imos, sendo $90 \%$ com valores inferiores a US\% 60,00 .

0) creditos concedidos pelo BKK sáo relativamente baratos (em torno de $7, \mathrm{sin}^{4}$ de juros reais ao mês) se comparados aos concedidos pelos moneylenders locas que ques chegam a cobrar juros reais de ate enom a dian

O Banco Regional de: Desenvolvimento da Parte Central de dava é a principal fonte de recursos do BKK. Além disso, c:ada emprestimo contém um componente de poupanga obrigatoria, que rende jurose pode ser retirada quando o c. liente quita of financiamenton.

o respeito conseguido junto ao publico pelo BKK fica evidentes quando se sabe que ao iniciar um programate 
poupanga voluntar i a em 9 de suas unidacesy a resposta foi tán positiva que em 7 meses foram levantados mais de usq 30.000,00. Tsso, através de contas cujo valor médio era de $\operatorname{US\$ } 9,00$

\subsubsection{Japão}

Segundo TzuMrDA (1989) vários tipos de associacoses informas de poupanca e credito sa mo mo populares.

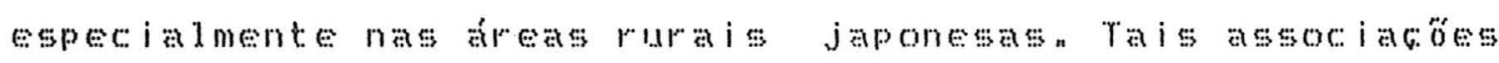

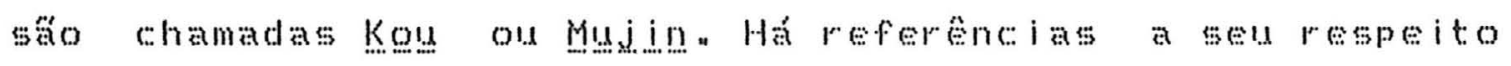
datadas do século XIT. o kou representou, também, importante fonte de recursos financeiros para pessoas pobres entre o periodo Meiji e a r T Guera Mundial. Além disso, exerceu forte influencia sobre a formacoso das cooperativas de coredito agricola no Japáon

Na verdade o Kou é uma associagaro de poupanga e chédito rotativo que se modernizou ao longo dos séculos sendo considerada, inclusive, a precursora do moderno e sofisticado sistema financeiro formal do Japón.

como pontos positivos dessas associacoses o autor destic: an
a) safo bastante conhecidas e faceis de organizary
b) a participacáde pessoas pobres for facilitaday 
(c.) estimulam a poupangay

d) oferecem oportunidades de emprestimo para todos os part icipant:esn

d) as taxas de juros säo mas baikas do que as taxas cobradas pedos moneylenders e penhor istas;

(E) geralmente năo exigem garantias reaisn

De outro lado, como pontos negativos säo relacionaclos" a) por serem facke is de organ izar, algumas vease tornam-se

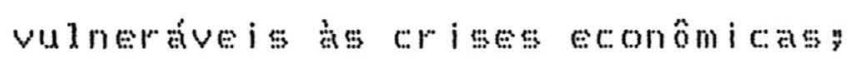

b) as taxas de juros variam expressivamentey alcancando, muitas veres, niveis bastante elevados; ey

(i) näo tem relacoses lega dificulta a resolucio de problemas entre os participantesn

Como exemplo da popularidade alcancada pelos koys podersecitar ofato de que em 1935, o Ministerio da Agricultura japonés registrou a existencia de 350 mil associacoses desse tipo no pais, com corca de ri milhós de participantes Atualmente, o numero de Kous é bem menor, mas anda importante no financiamento das atividades rurais japoness

\subsubsection{Papua Nova Guiné}

Os mercados informats de poupanca e credito em papua 
Nova Guine compreendemy principalmentey transacóses individuats de dinheiro, bens reais e de servigos entre familiares, class etribos (wantoks), amigos e comerciantes (FERNANDO, 1989 ) "

Eim se tratando de grupos ou associacoses a as at: ividades informats de poupanga e credito sáo feitas através de grupos (Wok Mer i) ou das Sandes (ROSCAs).

Os Wok Mer sá grupos formatos basicamente por mulheres e de carater predominantemente rural " lai as gandes têm carater urbanowrural e uma composicaro mista de homens e mulheres.

A busca por caredito informal em Papua Nova Guiné devese a fatores culturats, a economia de baixa renday ao baixo nivel educacional da populacto é dificuldade de acesso ao mercaco formal de ceredito.

Fato interessante é a ausencia de monesyenders Operando no setor rurad (FERNANDO, 1.989),

No que concerne aos juros cobracos nas transacobes Informas, chama a atencaso o fato das taxas serem, frequentemente, nulas ou muto baikas A reciprocidade parece ser o principal edo de 1 igacäo entre financiador e: 
tomador. A ausência de cobranga de juros é notada, inclusive, nos emprestimos real iacos pelos Wok Meri.

Quando o emprestimo e feito em especie năo há Evidências de que os comerciantes promovam ágios ou deságios nos precos dos insumosn contudo, a taxa de Inadimplência nesse tipo de credito é alta, salienta FERNANDO (1989).

\subsubsection{Sri Lanka}

Ainda que a participaca dos mercados financeiros informa is no sri l.anka tenha dectinado ao longo do tempor \$u importância é expressivan

Es:ses mercados, segundo SANDERATNE (1989), whegaram a ser responsaveis por 92\% do total de creditos concedidos em 1.957 naquele país. Em $1975 / 76$, apesar de perder espaco para o setor formal, os mercados informats ainda respondiam por $45 \%$ do total de coreditosn

Importantes e muto comuns no sr i l...nka como fontes financeiras sáo as cheety associacoses voluntarias de poupanga e códito rotativo -... (ROSCAs)

BOUMAN (1981) anal isando o funcionamento das chesteg 
observou que o sistema de definicádo do individuo que recebe a quantia recolhida mua conforme o ambienten Na agricultura de baina renda predomina o sistema de sorteio dos individuos Em regiós de agricultura comercial, o leiláo o método mas comm de estabelecer a ordem de corédio aos participantes o autor alega ger este lidtimo o sistema preferido pelos membros dos gruposa Esan preferencia se deve tanto a possibilidade de obter capital rapidamente, mesmo pagando altos presos (laneses) pela posicăo de recebimento como, tambem, pela possibillade de especulacion.

Outro tipo de financiamento informal bastante comum no sri l.anka é o emprestimo contra openhor de jó ias elou ouron

Esse sistema foi utilizado, inicialmente e durante longo tempo, apenas pela inieiativa privada Após a independênc: ia do sri l.anka, no entanto, com a adocáco de medidas para desenvolver a agricultura do paisy o governo resolveu ut iliar essa modal idade de creditor permitindo que os bancos aceitassem o penhor de objetos como forma de Garant i a dos Emprést imos (BOUMAN \& BAST TAASEN, 1989).

Além de permitir essa concorência o governo resolveu controlar os penhoristas privados, alegando que estes 
estavam explorando os tomatres de cretito atraves de elevadas taxas de jurosn Em consequencia m mitos penhoristas passaram a agir informamentey fugindo ao controle do Estadon Eses grupo cobra taxas de juros matores que as dos penhoristas registrados, devido ao risco adicional a que estáno submet i dos

Registrados ou näo, os penhoristas privados levam vantagem sobre o s istema bancario de penhor, atendendo a uma clientela numerosan bentre os motivos para essa popularidader Bouman \& Bastiansen citam dois como pricipais"

a) contato direto e diario com o publico interessacto; e, b) $\quad$ imites para emprestimos alcanoando até $50 \%$ (registrados) e 80\% (náko registractos) do valor da jóia ou do ouro penhoracos (contra apenas ps\% no setor bancario).

Bouman \& Houtman (1988) observaram que os penhoristas privados, a despeito das altas taxas impostas aos tomadores, chegam a ter, em média, volumes de emprestimos 1.2 a 18 veres matores que o volume total de coreditos do

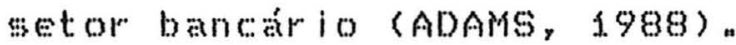

\subsubsection{Tailândia}

Apesar do forte crescimento do setor formal de cirédito 
a partir de 960, os mercatos informas na railândia continuaram importantes para os pequenos es médios agr ic:ultores (ONCHAM, 1.989),

Os MFRT ta ilandeses sás similares aos de outros páses asiaticos os recursos provem de parentes, amigos, moneydenders, comerciantes, proprietarios de terrat e produtores de arron

Quanto ass taxas de juros cobradas nos emprestimos informas, Oncham observa que, em geral, săo duas a quatro vezes superiores as takas do mercado formal.

Dutro aspecto interesentey devantado por oncham (1989), द a ocorencia dos emprestimos de usufruto, ou seda, a cessáco do direito de cultivo das proprias terras como forma de pagamento do financiamento obtidon Essas operacos săo semelhantes aquedas observadas nas experiências da Tndonesia re Fi ipinasn

Sobre o direito de usufruto, SHTBLI (1993) ressalta que, em alguns casos, ocorre a transferencia da posse da terra para o financiador com o compromisso verbat de devolucáo das mesmas ao tomador do emprestimo quando da quitacaro da dividan Essa transferencia da ao financiador o direito de venda das terrass porém, valores culturaise 
penalidades 500 iats impedem essa praticar a noo ser em casos de inad implencia comprovada.

\subsubsection{América do Norte e América Latina}

poucos sä́ os registros disponiveis gobre os mercados informa is na agricultura dos paises americanos o Dentre os existentes, apresentam-se aqui relatos sobre a atividade informa no México, na Republica Dominicana es de maneira destacada, no Brasil,

\subsection{1. México}

Dentre as modal idades de coredito informal podem ser destacadas as Tandas -.. associacoses de poupanca e crécito rotativo (ROSCAs) \& o crédito fornecido por moneslenders. comerciantes, agroindustrias e fornecedores de insumos (GERMTDTS et: a $1 \mathrm{i}, 1991$ )

Fator que influencia diretamente o desempenho das

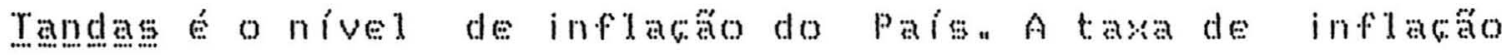
afeta basicamente a duracáto do grupo e o valor das contribuicoses dos participantes para combater os efeitos da inflaca exo ereservar o valor dos recursosy os grupos tendem a estabelecer periodos menores para distribuir o cirédito rotativo. Tsso também conduz a grupos com menor 
número de participantes

Outro procedimento é vincular as contribuicóse ao preco de um determinado produto cuja aquisicaro seja de interesse dos membros do grupon Assim, o valor da quotaparte é determinado segundo o preco do produto no mercado. acrescido de uma sobretaxa referente a expectativa de inflacáo no periodo e da comi ssăo do organizador "

Esse mecanismo significa uma préficaca do valor do produto ex consequentemente, da contribuicaro de ciaca membro. Eventuais erros na est imativa de inflaga podem implicar juros reais positivos ou negativos sobre os valores. se a taxa efetiva de inflaca for superior à estimativa, os juros implicitos serto negativos a a arrecadacto inferior ao preco do produto no mercadon Caso contrário, os participantes estaro pagando juros positivos sobre o valor do produto (GERMtors et ali y f9gf) "Neste ultimo caso, o excedente pode, inclusive, ser canalizado para outras finalidades de uso ou fundo de reservan

0 cordito oriundo de moneulendersy comerciantes. agroindustrias e fornecedores de insumosy alcano diferentes tipos de produtores moneslenders e comerciantes loca is servem a um publico modesto, composto bas icamente de pequenos e medios produtoresu As agroindustrias e os 
fornecedores de insumos têm interesse em trabalhar com produtores de nivel tecnológico elevado e, geralmente, or ientados para o mercado externon

\section{1-3.2. Repúb1 ica Dominicana}

o setor rural na República Dominicana é atendido, basicamente, por instituicóses oficialmente registractas o Banco Agricola e a credit Unionn o Banco Agricola é uma

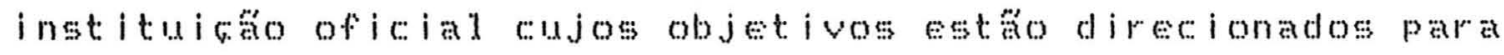
o desenvolvimento da agricultura A copedit. Union é uma entidade semi-norma destinada a mobiliarar poupanca rea 1 i ar empréstimos (USATD, f.991) "

Existem, também, intermediar ios financeiros informais (Finangeros) que trabadham à margem dessas instituicose atuam em pequenos mercados desconexos entre si " Esses agentes costumam pagar ecobrar juros superiores aos do sistema formal. Sua atuaga está mais direcionada para o setor urbano, onde é maior o fluso de recursos cusato, (.991).

\subsubsection{Brasil}

ARABUO (1967) estudando os fatores que afetam a demanda por coredito em nived de propriedade na regiádo de 
Ttapetininga (burei (sp), observa que existem dois mercados de coredito rural distintos" um governamental e outro livren o governamental é representado basicamente pelo Banco do Brasil e pelo Banco do Eatado de Săo Paulo - BANESPAn O mercado livere de dimenezo bem menory é constituido por bancos privados e outros agentes financeirosin

Nestecaso, a composicáno do mercado de crédito livre cons iderada por ARAuJo (1967) nabo coincide com a definica de mercados informats de credito adotada neste estudo devido a participacáo dos bancos privadosn Vales contudo, a observacăo sobre os emprestimos realizados pelos agentes individuats, cassificados pelo autor como de alto custo para o tomador, predominantemente de curto prazo e com

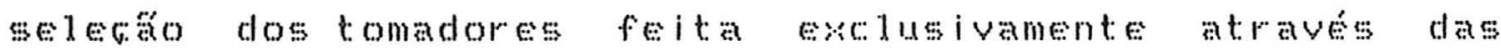
garant ias oferecidas.

Outra referencia aos mercados financeiros informas é feita por NEHMANN (1973) estudando o uso de eredito na regicio de rtapetininga (SP), o autor observa que pequenos proprietarlos (áreas inferiores a 20 ha) obtiveram $79 \%$ de seus emprestimos en fontes informats de crécito por outro lado, apenas 1.4\% dos emprest imos de proprietar ios com áreas superiores a 50 ha sá real i atos nesse tipo de fonten 
43\% para custeio da producaro, 37\% para consumo e $20 \%$ para invest imento (principalmente compra de terras)"

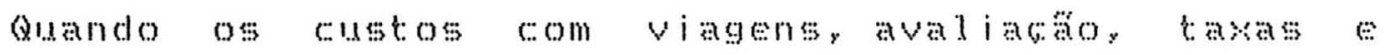

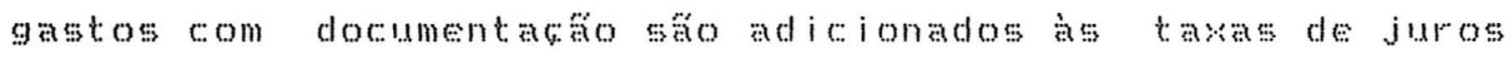
do crédito formal, o custo total dos empréstimos formats atinge eg\%, valor muto proximo das taxas de juros est imadas para o coredito informal.

BTSERRA (1978) analisando o credito tomado por produtores rupats no municipio de Caninde (ce) no ano agricola $1974 / 75$ nota que nesea regiag tipicamente de

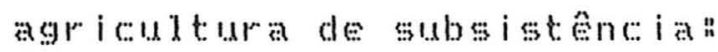

a) o crédito informal teve maior frequencia de uso e menor valor transacionado que o credito format, entre todos os grupos de produtores (proprietarios e/ou parceiros) :

b) parentes e amigos foram a principal fonte de crécito náno inst itucionaly

(.) a ma ioria dos emprestimos teve prazos inferiores a um ano:

d) as taxas de juros variaram entre $\quad$ arero (48\% dos emprestimos recebidos pelos parceiros e 33\% dos recebidos pelos proprietarios) e mas que $150 \%$ an ano ( emprest: imos a parceiros);

e) dentre os proprietarios, a maior parte do coredito informal (63\%) destinoumse a projetos de investimenton Em 
sequida, destacouse o consumo (35\%) e, em littimo lugar, o (:.ust:ei io (1\%);

f) os parceiros ut i i araram os recursos obtidos nos mercados informats preferencialmente para financiar o consumo fam i lar (76\% do valor total dos creditos)

segundo Biserra, em consequência dos compromissos assumidos com os agentes informas de coredito, os agricultores de Canindé viram-ine, mutas veres, forcados a vender parte da producfio (especialmente de algodíos a intermediarios etou "bodegueiros" locais, logo apos a colneita e, portanto, no momento de precos menos favoraved. Essa porda" de renda, se computada em termos de custos do emprestimo, elevaria as taxas de juros dos recursos informais

Ainda no Estado do ceará, desta feita na regiobo da Serra do Baturité, BESSER (1979) desenvolveu interessante pesquisa onde conclui que:

a) a menor tasa de atendimento pelas instituicóses formats de coedito da regiano estava relacionada aos nám. proprietarios e pequenos proprietariosy

b) as fontes informats concederam emprestimos com a finalidade de investimento para produtores näo-. proprietarios de terraze,

c. além dos nấoproprietarios e pequenos proprietários os 
mercados informats de credito atenderam, tamberm, a médios e grandes proprietár ios.

Besser anad isat também, a demanda por coredito informal naquela regiano o autor observa que a tawa de jurose os emprestimos forma is afetaram negativamente a funcero de demanda individual por credito informal " Por outro lado, o tamanho da familia cassociado possivelmente às necessidades de consumo) mostrou efeito positivo sobre essa demandan

Fiviencias mats recentes sobre as fontes informats de corédito săo fornecidas por ARAúdo et a di i (1989) e ARAúdo et

Esses estudos foram desenvoluidos em várias regiós do pais e analisaram diferentes tipos de atividades agropecuar ias froram escolhidas, intencionalmente, regiós de agricultura de subsistenciabaika renda e regioses de agricultura comercial, capital intensiva e altamente tecenificada.

A pesquisa de 1988 teve carter mais qual itativo, entrevistando 24 produtores. Já em 1990, a pesquisa foi ma agricolas do Brasil. Entre os agentes e formas de financiamento informal ut il iandos pelos produtores, em 1988 
e/ou em 1990, podem ser destacados alguns tipos principais, cujas coracteristicas estáco resumidas na rabela en e..

No Municipio de Porto Velho, Estado de Rondoniar praticase uma agricultura de subsistenciar sendo os peguenos produtores a grande maioria Mesmo assimy os entrevistacos dectararam let i izar, quando possível, financiamentos tanto de fontes forma se (BASA e Banco do Brasil) como informais (parentes) para viabiliar suas at:ividades de producăo e consumo.

Cruz das Almas, no Reconcavo Baiano, é caracter iaca pela presenca de pequenos produtores de fumo citros e mandioca Nessa regiáo foi detectada a diminuicádo do volume de: emprestimos formats e o crescimento do numero de operacoses informats envolvendo pequenos agricultorese comerciantes de fumo es citros

Os comerciantes de fumo, denominados "armazenistas" mantem um sistema informal de credito com base em emprestimos de sementes, fertiliantes, defensivose até mesmo dinheiro para despesas familiares. Em alouns casos, inclusive, garante-ne o pagamento do emprestimo através de nota promissória emitida pelo tomador, sem a necessidade de aval. 
Tabela 2.2.- Sinopse das formas de empréstimos nos mercados informais de crédito, em regiões 5elecionadas, Brasil, safra 1989-1990.

\begin{tabular}{|c|c|c|c|}
\hline $\begin{array}{l}\text { Forra de } \\
\text { Eaprésti ino }\end{array}$ & Regiäo & Agente & $\begin{array}{c}\text { Principais Caracteristicas } \\
\text { do Eupréstiono }\end{array}$ \\
\hline
\end{tabular}

\begin{tabular}{|c|c|c|c|}
\hline \multirow{5}{*}{$\begin{array}{l}\text { a) eapréstino en dinheiro } \\
\text { de particulares e/ou firmas }\end{array}$} & Porto Velho (RO) & parentes & $=$ ppara consuno fasiliar \\
\hline & Cruz das Alwas (BA) & armazenistas de funo & $=$ para consuno faniliar \\
\hline & Lajeado (RS) & compradores de fumo & \\
\hline & Rondonópolis (HT) & $\begin{array}{l}\text { cooperativas de } \\
\text { sojicultores }\end{array}$ & \\
\hline & Guaira (SP) & moageiras de 50ja & 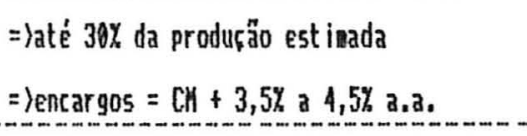 \\
\hline \multirow[t]{11}{*}{$\begin{array}{l}\text { b) operacones de escanbo tipo } \\
\text { insuno/produto e/ou } \\
\text { servico/produto }\end{array}$} & Cruz das Alwas (BA) & armazenistas de funo & 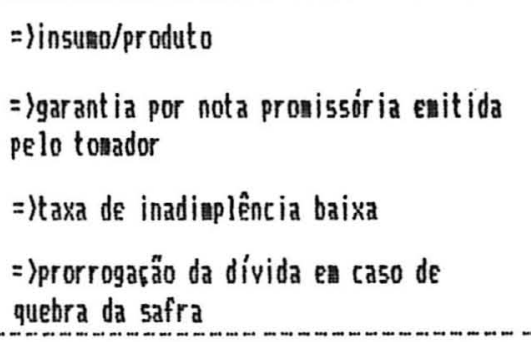 \\
\hline & Lajeado (RS) & $\begin{array}{l}\text { industria de aves } \\
\text { vendedores de selaentes } \\
\text { cooperativas }\end{array}$ & $\begin{array}{l}=\text { insumo/produto } \\
=\text { insuno/produto } \\
=\text { insumo/produto }\end{array}$ \\
\hline & Carazinho (RS) & $\begin{array}{l}\text { fornecedores de insunos e } \\
\text { serviç0s }\end{array}$ & $=$ linsumo/produto \\
\hline & & & $\begin{array}{l}\Rightarrow 20 \% \text { das lavouras de soja e milho, na } \\
\text { safra } 89 / 99 \text {, financiados des5a for ma }\end{array}$ \\
\hline & Ponte Nova (MG) & usinas de açúcar & $\begin{array}{l}=\text { lfertilizantes, wudas e servicos de } \\
\text { aáquinas }\end{array}$ \\
\hline & & & $\begin{array}{l}=\rangle \text { divida en toneladas de cana-de-açúcar } \\
=\rangle p r a z 0 s \text { entre } 12 \text { e } 18 \text { meses }\end{array}$ \\
\hline & & & $=)$ taxa de inadiuplência quase nula \\
\hline & Rio Verde $(60)$ & $\begin{array}{l}\text { interwediários na } \\
\text { exportaçáo de soja }\end{array}$ & $=\rangle_{5 e}$ lekãa rigorosa dos clientes \\
\hline & & & $=\rangle$ contrato de entrega futura registrado \\
\hline & & & 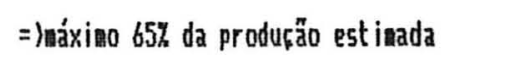 \\
\hline & & & $\begin{array}{l}\Rightarrow \text { conissano de } 1,25 \% \text { sobre o valor do } \\
\text { contrato }\end{array}$ \\
\hline
\end{tabular}


(cont inuação)

Tabela 2.2.- Sinopse das formas de empréstimos nos mercados informais de crédito en regiones selecionadas, Brasil, safra 1989-1990.

\begin{tabular}{|c|c|c|c|}
\hline \multirow[t]{7}{*}{$\begin{array}{l}\text { Forma de } \\
\text { Empréstino }\end{array}$} & Região & Agente & $\begin{array}{c}\text { Principais Caracteristicas } \\
\text { do Empréstio }\end{array}$ \\
\hline & & moageiras de oleaginosas & =〉รenentes/grão \\
\hline & & & $=3$ servicos de pós-colheita \\
\hline & Rondonópolis (ITT) & cooperativa & $=15$ sementes $50 \mathrm{ja} /$ produto \\
\hline & S.Gabriel D'Deste (MS) & moageira de 50ja & $\begin{array}{l}\text { =lpacote auplo: corretivos de solo, } \\
\text { fertilizantes, sementes, defensivos e } \\
\text { combust iveis }\end{array}$ \\
\hline & & & $\begin{array}{l}\text { = lexigênc ias contratuais con base en: } \\
\text { cadastro e deseapenho dos produtores en } \\
\text { contratos anteriores E penhor en } 10 \\
\text { grau da safra }\end{array}$ \\
\hline & Guaira (SP) & moageiras de soja & $=1$ seuentes/grão (1:2,5 sacas) \\
\hline \multirow[t]{4}{*}{$\begin{array}{l}\text { c) coupras/vendas } \\
\text { antecipadas de producão }\end{array}$} & Cruz das Aloas (BA) & interwediários de citros & 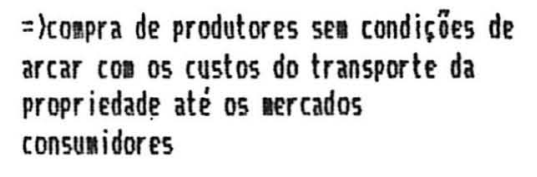 \\
\hline & & & $\begin{array}{l}=\rangle \text { preço pago é } 25 \% \text { menor do que o preso } \\
\text { do wercado }\end{array}$ \\
\hline & Lajeado (RS) & indústria de aves & $\begin{array}{l}\text { =ladiantamento referente à parte dos } \\
\text { custos de âá-de-obra e capital }\end{array}$ \\
\hline & & & $=$ base é o preco do quilo da ave viva \\
\hline \multirow{7}{*}{$\begin{array}{l}\text { d) consórcios, as5ociacones } \\
\text { informais de poupança/ } \\
\text { crédito e outras }\end{array}$} & Canindé (CE) & $\begin{array}{l}\text { grupo de pequenos } \\
\text { produtores }\end{array}$ & $\begin{array}{l}\text { =/pequena e obrigatória oensalidade } \\
\text { como poupanca }\end{array}$ \\
\hline & & & $\begin{array}{l}=\gamma \text { 'Hini- Posto Conunitário": adquirir e } \\
\text { eaprestar bens e servicos; e, juros de } \\
\text { 10\% a } 15 \% \text { no caso de senentes }\end{array}$ \\
\hline & & & $=$ leriaç̃a de una farmácia conunitária \\
\hline & & & $\begin{array}{l}\text { =)diversificacáo de at ividades: olaria, } \\
\text { para elevar a renda e eqpregar a } \\
\text { mão-de-obra fanilliar excedente }\end{array}$ \\
\hline & Rondonópolis (HT) & vendedores de ax́quinas & $\begin{array}{l}=\text { laceitavan quitacão de parte da divida } \\
\text { Ell produto }\end{array}$ \\
\hline & Guaira/Batatais (SP) & cooperativas leiteiras & $\begin{array}{l}=\text { Vuendas à prazo de até 90\% do total de } \\
\text { insuluos ut ilizados na produrão de leite }\end{array}$ \\
\hline & & & $=$ acerto da divida a cada 30 dias \\
\hline
\end{tabular}


A taxa de inadimplencia dos emprestimos junto aos armazenistas de cruz das Almas era extremamente baixan Ts50, devido, principalmentey da utilizacto de criterios seletivos baseados no relacionamento pessoal n Em casos de quebra de safra por estiagemy por exemploy a divida era aut omaticamente transferida para a safra seguinte e efetuado novo emprest i mon

Outra forma de financiamento informal nesea regiäo é

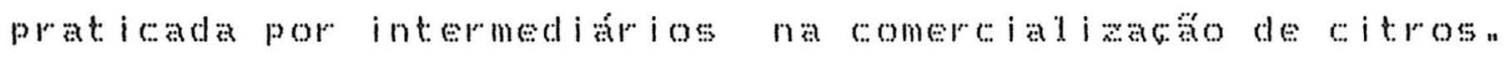
Estes compram, antecipadamente, a producio de daranda de produtores que, sabidamente, após a colneitay náo tem condicoes de arcar com os custos de transporte da propriedace até os mercados. o prego pago pelos intermediários na época das entrevistas era, em geral, 2yom menor que o preco de mercado (ARAúdo et ali i, 1991) "

No Municíplo de Canindé, Estado do Ceara, encontrouse em $1988 \mathrm{um}$ grupo informal de poupanca e credito, formado por 60 produtores, onde cada um dos integrantes fazia uma pequena e obrigatória contribuigáco mensal n Em determinada épocar esses produtores decidiram criar um nini posto Comunitario" com o objetivo de adquirire emprestar bense servigos aos membros do grupon A operaco ma is comum era o emprest imo de sementes com o compromisso de que o tomador 
devolvesser após a colheitar a quantidade desementes que recebeu do posto mals $10 \%$ a $19 \%$ de juros, pasos também em sacas de sementes/graso Estava anda previstor dentre as atividades do Mini mosto, o emprestimo em dinheiropara despesas de emergenciar principalmente em casos de doencan. Para diversificar suas atividates o grupo decidiu investir na constructo de uma olaria que inclusivey empregar ia o excedente de máowewobra familiar, sobretudo na entressafra

No Rio Grande do sul, os avicultores do municipio de Lajeado, além dos insumos em troca do produto futuror recebiam da industria o pagamento adiantado de um dado valor por quilo de ave vivar correspondente à remuneraca da mónowoba do capitaln da os produtores de fumo de 1...jeado, a semelhanga dos de Cruz das Almas, ut i l izavam recursos obtidos junto aos compradores de produton Foi também constatada a troca de sementes por produtor envolvendo firmas vendedoras de sementes elou cooperativas.

No caso das cooperativas de producáo, as operacóses financiadas com base em dinheiro obtido via coredito rural

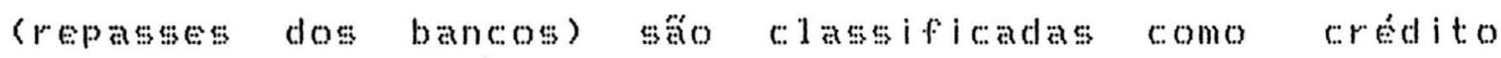
formal " Por outro lado, as operacoses de troca de insumos pela productio futura (escambo) ou de venda de insumos à 
prazo, financiadas pela propia cooperativar sá consideradas, neste estudo, como informaisn

0 escambo foi encontrado também em Carazinho (RS). Neste caso, os fornecedores de insumos eservicos recebiam dos agricultores pagmentos em produtos a tepoca da colheitan Desta maneira, um parametro muito importante era a relagaro de trocas insumomproduto FELDENS Et a 1 i i (1990) est imaram que equ das lavouras de sojar mitho e trigo foram assim financiacos na safrat $1989 / 90$.

Em Ponte Nova, zona da Mata de Minas Gerais e regiáo de agricultura de baixa renda, foi observada a pratica de escambo entre produtores de cana e usinas de acticar as agricultores recebiam fertilizantes, mudas eservicos de máquinas (principalmente durante a fase de preparo do a010) " 0 valor da divida era estabelecidocom base na

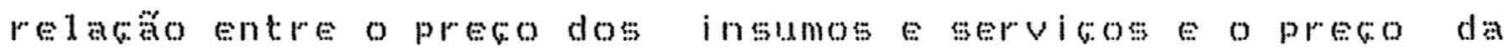
tonedada de canan Tais emprestimos eram formal iacas por contratos particulares de compra evenda, comprazos de 12 meses para canasoca e de 18 mesespara a canaplantan A taxa de inadimplência era praticamente nulan

Notewse que ofinanciamento informal serve nä́ apenas à pequena productán prova disso é que médios e grandes produtores, de regiós de agricultura comercial, também o 
ut: i li

Na agricultura comercial ex com elevado grau de:

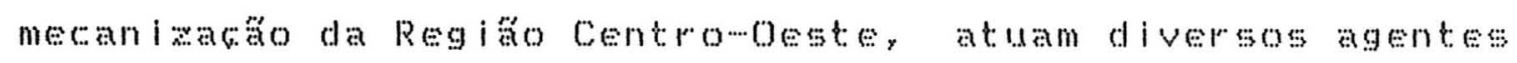
informa is de financiamenton compradores de soja, vendedores de insumos, prestadores de servicos e cooperativas de production, principalment:e

Nos Municípios de: Rio Verde em Ooiás, Rondonópolis no

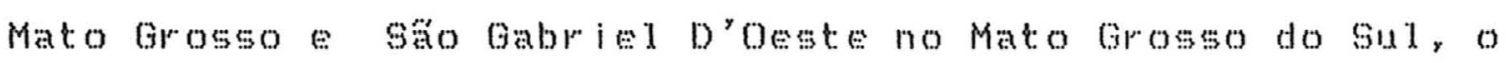
numero de contratos de creato forma em 1989/1990 foi bastante inferior ao de $1987 / 88$, apesar da elevaca do custo do dinheiron paralelamente, diversos tipos de financiamento informal foram utilizados nos mercados de insumose servicos e mesmo na negociactio de bens de capitad, o escamboy lastreado em simples acordos entre as partes, era prát ita comunn

Em Rio Verde, uma firma que atuava como representante de uma grande exportadora de soja estabedeces criterios bascicos para minimiar possiveis casos de inadimplêncian A selecáo dos beneficiários dos emprestimos era feita atraves de analise minuciosa do cadastro dos interessadosn A operacto de credito, por sua vez, era efetivada com registro do contrato, devidamente avaligadon o montante: contratado correspondia, no maximo, a $6 \% \%$ da producáo 
estimadan A remuneracto da firma pelo trabalho de intermediago entre exportadora eprodutor rurad era de 1. , $25 \%$ sobre o valor do contraton

As unidades de compra de produtos das moageiras de oleaginosas em Rio Verde também realizavam trocas diretas em 1990, Operacán comum era a troca de sementes por groson A prestaga de servigos póscolneita e ate mesmo adiantamentos em dinheiro para custear a colheitaty eram praticicasos

E.m Rondonopolis, a cooperativa fornecia sementes de soja e/ou adiantava recursos financeiros aos produtores mediante contratos de entrega futura da producian Algumas experiências informais de consorcios de másuinas e equipamentos foram também encontradas nestes possibilitavam à firma garantir o nived de vendas e ao agricultor renovar ou ampliar a maquinaria da fazenda firm ace itos desce o dance com equipamentos usados até a quitacasontecipada de parte da divida na época da colheitan

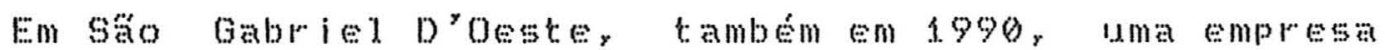
mogeira de soja praticava o escambo de forma bastante ampla no pacote de trocas estavam incluidos corretivos, fertilizantes, sementes, defensivos o ate mesmo combustived. As exigencias contratuais variavam em funcăo 
do candatro e do desempenho dos produtores em contratos anteriores, Em alguns cosos, Era Exigido o penhor da safra em primeiro grau, o que coriava problemas para o agriculor que necessitasse de emprestimo complementar oriundo dos bancess

No Estado de Säo paulo, a estrutura dos financiamentos agricolas, em 1990, foi estudada em dois municípiosa Batatais e Guaran En Batatais, a cooperativa local vendia, a prazo, 9o\% dos insumos ut i 1 i zados pelos produtoresn

Em Guarar importantes firmas agrowindustriais mantinham unidades de armazenamento, secagem es préc. limpeza de sojar principalmenten Representantes dessas firmas (corretores) eram responsaveis pela troca direta

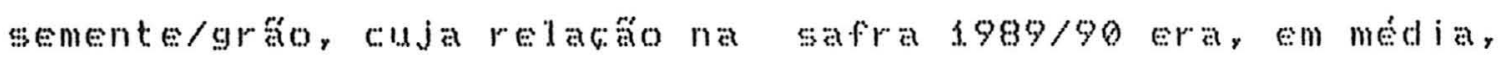

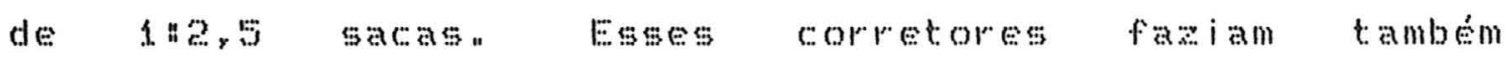
adiantamentos em dinheiro, geralmente até o $1 \mathrm{imite}$ de $30 \%$ do valor estimado para a futura safra cujas bases contratua is estabeleciam correcáto monetaria ma is uma taxa real de juros de $3,5 \%$ a $4,5 \%$ ao ano, Tnelusive, os corretores afirmaram ser esta modal idade a preferida pelos agricultores, diante da facilidade e rapidez na obtencáo dos recursosn Aparentemente, os riscos de inadimplencia eram minimiandos pelos $1 \mathrm{imites}$ de cada operacton 
Em relacko a citada troca direta semente por gró, deve-se estar alerta para a dificuldade de est imagáo da taxa real de juros embutida nessa operacto uma comparaco pura e gimples entre o valor monetario da quantidade de sementes tomada emprestada e o valor monetario da quant idade de grasos a ger devolvida nä permite determinar os custos financeiros embutidos nessa modalidade de financi amento. A diferenca na agregacta de valores durante os processos de producta do insumo (sementes) e do produto (grácios) inviabiliza esse procedimenton

Ademais, E preciso levar em conta que o agricultor recebe sementes no momento de preco mais elevado (pré... plantion e que o emprestaclor recebe graos no momento de precos tradicionalmente baimos (collesta). Ao emprestador apresentam-se como alternativas venda do produto aos precos vigentes no mercado ouy entajoy armazenamento, a fim de agurdar melhores pregos nesta ditima opgoy ede arca c.: om as despesas de estocagem.

Observerse que, na ausencia da operacto de troca, os custos embutidos nessas alternativas correriam por conta do produtorn tsso permite considerar que a transferencia de tais custos para o emprestador, associada boportandade de ter as sementes em más, representan uma forma de ganho para o tomador. Esse ganho pode ser contabilizado a seu 
favor, diminuindo o custo do financiamento via troca diretan Admitindo que nessa modal idade de emprestimo o custo de transacano para o tomador seja desprezived, o custo financeiro nấo será táo elevadon possivel até que o mesmo esteja em nivel próximo ao registrado no crédito formal. 


\section{METODOLOGIA}

Neste Capitulo säo apresentados os fundamentos teóricos e metodológicos da pesquisan

Tnicialmentes săo descritos os coritérios e parâmetros ut iliandos na avaliaço do crédito rupal formal Em seguida, discutersen oroblema da demanda por l i quidez nos mercados financeiros informas e desenvolve se modelo econômito correspondente. Finalmente y especifica se modelo econometrico apropriado para testar as redacoos emergentes do modelo econômico e definem-we as var iaveis selecionacasn

\subsection{Avaliação do Crédito Rural Formal}

com base em anal ise tabular de dados secundários,

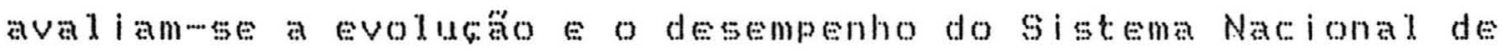
Credito Rural no Brasil entre 1970 e 1993. 
Para realizar essa tarefar sá consideradas informatós especificas sobre os emprestimos concedidos durante esse periodo, tais comon fonte de recursos, volume de coredito e taxas de juros das operacoses ratores de ordem macroceonômicar cuja influencia sobre o desempento do sistema tenha sido relevantes säo também considerados na

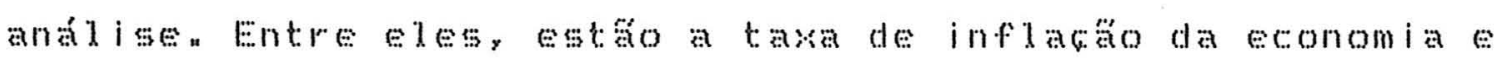
a compos i caro dos haveres monetarios na nowonetarios.

\subsection{Procura por Liquidez nos MFRIs}

\subsubsection{Introducão}

Considerando que uma unidade monetaria tomada por emprestino é idêntica a uma unidade monetar ia possuida pelo tomador, conclui we que os recursos emprestados podem ser aplicados em qualquer finalidade, independente da

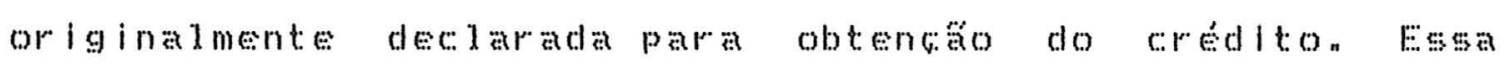
característica é denominada fungibilidade do dinheiron

SHTROTA (1988) Esciarece que o produtor rural pode apd icar os recursos tomados por empréstimo nas at ividades agricolas originalmente propostas " Todavia, pode ocorrer, também, a transferencia de parte desses recursos para outros setores da economia, adquirindo ativos náoaspicolas. Essa possibilidade desubstituicas, segundo o 
autor, está diretamente relacionada ao nivel de acesso a fontes financeiras alternativas e à possibilidade de investimentos à disposicaro do produtor-muturion

Nesse contexto, o terédito deve ser visto como meio de aumentar o volume de recursos imediatamente disponiveis para o tomador, ou seja, de ampliar sua liquidean recursos por ele obtidos podem ser gastos na compra de qualquer bem ou servico (VON PISCHKE \& ADAMS, 1980)"

Posto isso, tornase interessante direcionar esforcos no sentido de analisar as relacoses economicas entre a procura e a oferta de liquidea e alguns fatores economicos

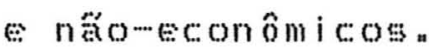

0 estuclo da oferta exige, porém, informato ôs sobre a atuaga dos intermediarios financeiros, näo disponíveis no momento. De um lado, os que tem como principal at ividade a concessăo de empréstimos cmoneydenders e penhor istas, por exemplo) evitam, costumeiramente, declarar o montante de recursos, custos e prazos das operacóes que realizam, De outro, nôno há informates suficientes sobre a estrutura operacional dos agentes cuja atividade principal é a comercializacto de insumos, produtos ou servicos eque, marginalmente, real iam emprestimos aos produtores a Sabense que, nestes casos, a concessa de coredito objetiva a 


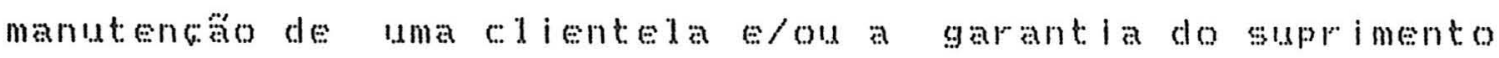
de materias aprimass

\title{
3.2.2. Modelo Económico
}

\begin{abstract}
Assumense que a demanda por liquidez em fontes informats de credito pode ser descrita por um modelo

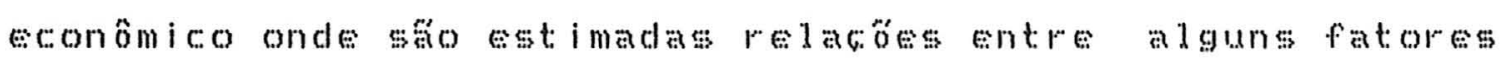
económicos e o montante de recursos obtidon Nos MFRTs, esses recursos podem ser concretizados na forma de dinheiro, insumos, produtos ou servicos"
\end{abstract}

b: importante salientar que o modelo economico, nesta pesquisa, referewse apenas a operacoses de financiamento de atividades agricolas, dada da fata de informacoses sobre a atividade pecuarian Adicionalmenter cabe observar que a especificacán dos fatores econômicos relacionados com a demanda por l iquidez nos MFRTs considerou, também, estudos anterlores sobre a demanda por liquidez via coredito rural, tais como o de ARAUJO (196\%), BESSER (1979) E BARROS \& ARAĹ. (1991) "

Esperatas que o montante de liquidezadicional tomado em fontes informats de creato num determinado periodo de tempo seja influenciaclo pelos seguintes fatoresa a) preco dos recursos nos mercados informas; b) volume de credito 
disponivel no mercado formal; (E) custo do dinheiro no mercado formal de creditor d) categoria ou porte to produtory e) valor das despesas operacionais tipicas da

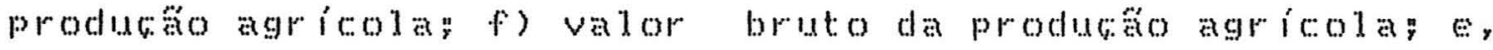
g) múmero de anos de educaca formal do produtor

Na transferencia de recursos do financiator para o tomador, admitewse que o primeiro cobre uma taxa de juros sobre o montante emprestadon Essa taxa de juros teria o sentido de compensar custos comon a) mobilizacäo do

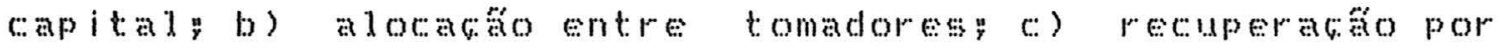
ocastân do pagamento da dividay ex d) risco de inad implencia (ARAúdo et a $1 \mathrm{i}$, $1990 \mathrm{~b}$ )

Do lado da demanda, o tomador tem interesse em maximiar o retorno liquido do montante obtido, sendo que a quantidade por ede procurada varia de maneira inversa ao preco dos recursos financeirosn Assim, à medida em que o preco se eleva, o valor do empréstimo tomado diminui e vicis:-verersan

Em boa parte das operacós informats de cordito, a taxa de juros nás é explicitan sán necessarios procedimentos sofisticados parato seu cilculog o que dificulta o conhecimento de sua exata magnitude pelo tomador "Agravante é fato de que nesses mercados as taxas 
flutuam livremente ey de maneira geral, sák bastante elevadas.

fí importante for sar que no preco dos recursos além da taxa de juros, deve ser tamberm considerado o custo de

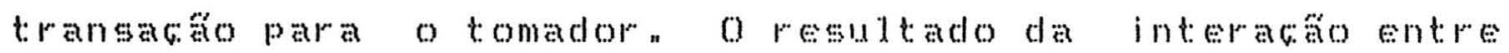
ambos corresponde ao custo financeiro efetivo da operaca de emprestimo?

Pressupóteses, também, que o crectito informal mantenha

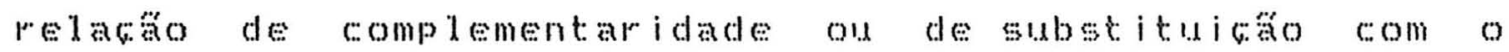
formal. Tsso faze com que a procura por recursos informas aumente à medida em que o cuedito formal para o tomador torne-we insuficiente ou excessivamente caron

No mercado formal, os recursos disponiveis tém sido insuficientes para atender a necessidade dos produtores rurats a Consequentemente, a grande matoria recebe apenas parte do valor que solicita. Para esses produtoresy os mercados informa is aparecemy entay como fonte alternativa cle 1 iquideran Assim, quanto maior o racionamento no volume de coredito formal, maior será a procura por coredito informal, indicando uma relacato de complementar idade entre

7 Para o tomador de coredito os custos de transatán correspondem aos gastos individuais com visitas ao agente financeiro, documentacko, reciprocidades financeiras es garantias oferecidas para a obtencaso do emprostimon 
ambos. A consideracăo desse fator contemplat tambémy o lado da oferta de recursos. Deserta formatenta captar o efeito da disponibilidade de recursos financeiros no mercado formal de coredito sobre a decisáo do produtor em tomar emplest imos nesses mercadon

A determinacato governamental de que as tacas de juros cobracas nos emprestimos formas sejam semedhantes para produtores da mesma categoria resulta em emprestimos de Valores diferentes à mesma taxa de juros e Esa semelhanca de taxas termina apenas quando computadosy individualmenter os custos de transacia para o tomador.

Segundo ARAUJO Et ali (1990b), o nived a a distribuicaro desses custos entre os participantes do mercacto formal variam conforme a tecnologia, as preferéncias do tomadory os controles das autoridades monetarias e o nived interno de eficiencia dos intermediár ios finance iros

como resultaclo desen especificidace, o custo financeiro efetivo (incluindo o de transactos dos emprestimos formats difere entre tomadores e mesmo entre empréstimos de um mesmo tomator " fe razóved esperar que o tomator seja sensivel a variacádo custo financeiro dos recursos forma is " Fa mo que issor frente a uma elevaca 
desse custo, que ede recorra a fontes informa is para suprir

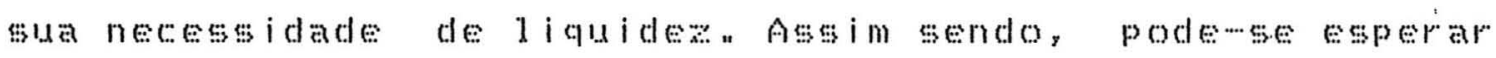
uma relacaro direta entre custo financeiro efetivo do curedito formal e o volume de liquidez adicional procurada nos mercados informais.

0 porte do produtor é outro fator fortemente relacionado à necessidade de liquidez adicionad. De maneira geral, agricultores de mitro e pequeno porte tem dificudades em arcar com of fuxo financeiro da divida oferecer garantias reais na tomata de credito formaln por esta rayar demonstram ma or afinidade com os mercados informa is, onde a variedace de arranjos operacionais e a aceitacaro de garantias pessoais facilita o acesso ao créditon Năo se descarta, porém, que a agilidade e a facilidade de acesso aos mercados informa is sejam atraentes também para médios es grandes produtores "

A questio principal se estabelece na maneira de c. 1 assificar o produtor "Entre os coritérios passive is de uso esta a a agricolan De qualquer modo, esperase que quanto maior o porte, menor seja a dependencia de recursos externos, formats ou informas, para custear a producáo agricolan Entretanto, se a projecto de despesas operacionais com máow dewobar máquinas ex insumos for corescente, o produtor 
poderá ter problemas de autowinanciamento "se nấo forem introduzidas mudancas no sistema de producăo visando à

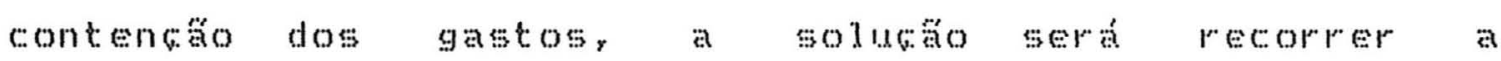
intermediarios financeiros formats e informats e E nesse caso, o volume de liquidez adicional estar at diretamente relacionado ao corescimento das despesas operacionais

A capacidade de gerenciar questobes do financiamento da producáo é influenciada pela habilidade em interpretar informacoses. E, essa habilidade pode ter como proxu o nivel de escolaridade do produtor. Neste contexto, duas reacoses distintas podem ser observadas como efeito da educaco formaln

De um lado, a maior escolaridade pode facilitar a negociacáo de empréstimos junto a agentes financeiros formag e diminuir o uso de arranjos informats para aumentar a diquidez. DELANCY (1989) salienta que o nivel educe aconal do individuo fac: i lita näo apenas o contato com as instituicoses formats de creditor permitindo o preenchimento de formularios e a negociacko dos emprestimos, como também a compreensago e absorcta de novas tecnologias oferecidas pelo s istema bancárion

Por outro lado, o maior nivel educacional pode ampliar o conhecimento sobre alternativas informats de 
financiamenton E istor possibitita ao tomador de credito complementar ou substituir o coredito formal racionadon

Diante desses aspectosy o valor da liatderadicional procurada nos mercados financeiros informats (LIQINF) pode ser representado por"

\section{IIQINF $=E($ JURINF, VALFOR, CSTFOR, CATPRD DESOPE, EDUFOR)}

onder

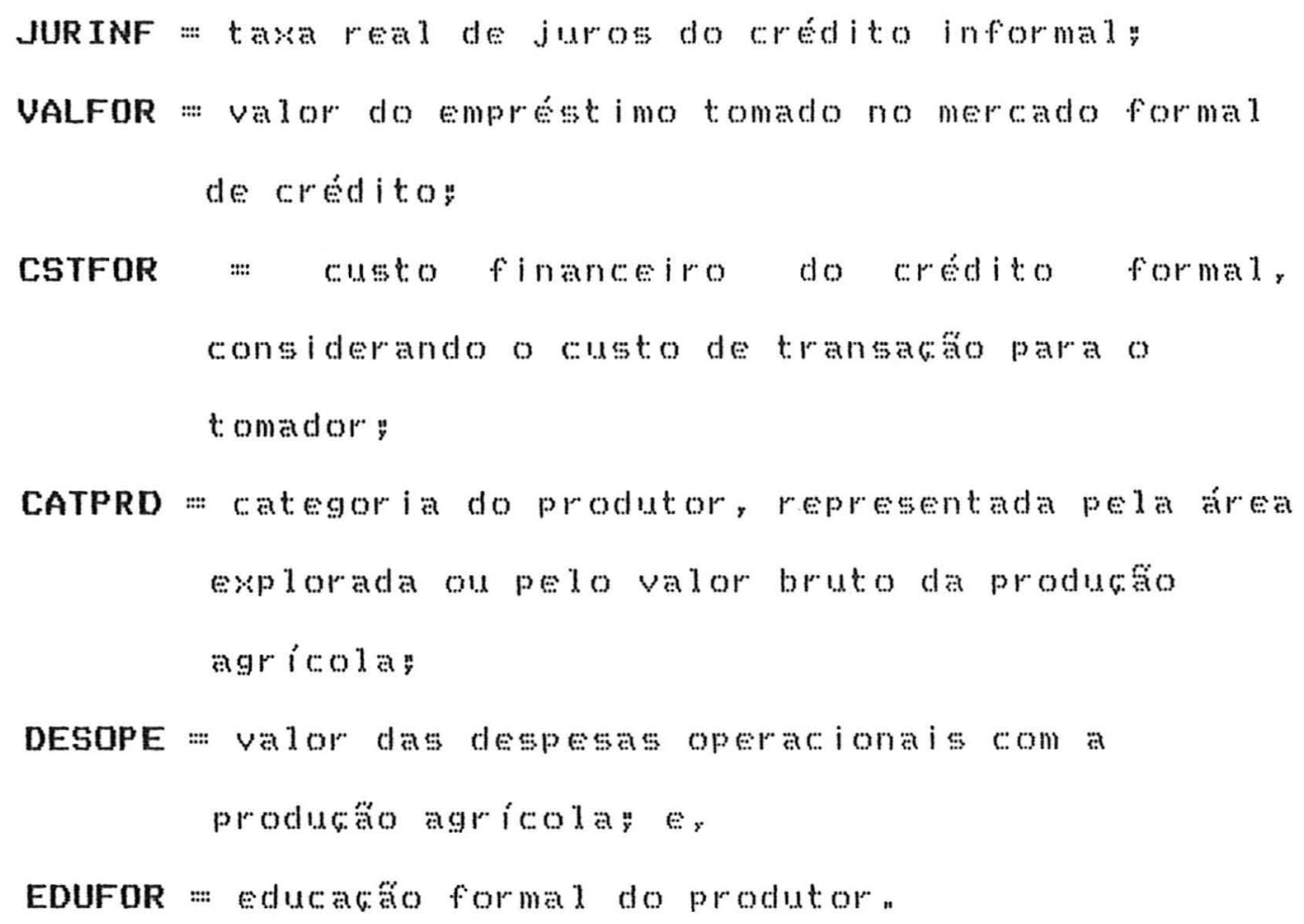


e a procura por l iquidez nos mercados informats define ase, a seguir, um modelo econometrico que est ima tais redacose testa as hipóteses sugeridas no modelo econômicon

\subsubsection{Modelo Econométrico}

0 interesse em obter liquidez adicional, num determinado momento do tempor pode ser colasificado conforme a redacto entre a disponibilidade de recursos financeiros propriose a necessidace de recursos para a cobertura de despesas operacionais, investimentos planejados e outras despesas eventua is 8

com base nessa redaco, podense classificar o interesse por liquidez adicional comon

a) negativo quando a disponibilidade de recursos de maior que a necessidade, havendo excedente financeiro que pode, inclusive, ser aplicado em outras at ividades/ativosy

b) nulo quando disponibilidade e necessidade gáo idênticas, näo havendo excedente financeiro ou necessidade de recursos externos;

8 Como recursos próprios e disponiveis para pronta

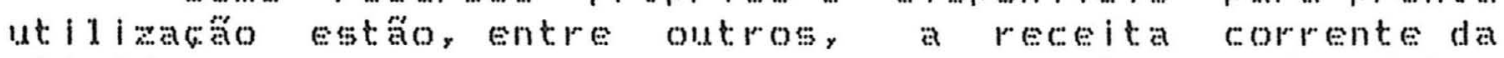
atividacle, a poupanca em dinheiro ou em insumos/produtos estocados es at ivos que podem ser desmobilizados no curto Prazon 
(i.) positivo = quando os recursos disponiveis no curto prazo să inferiores a necessidade de capital, exigindo complementacto externa Nesse casoy o proutor rural procura aumentar sua 1 iquidezerecorendo a intermediarios formais e/ou informais.

Ao estudarsen a procura por liquider nos mercados informats de credito parece razodved, a primeira vistay ut i 1 izar somente informaces sobre os individuos que se enca ixem no item (c) " Poremy a adocio desseprocedimento pode cassar serios problemas de estimagay discutidos a Hegir.

supondowe un modedo de regressto da forma

$$
y=\beta x+\mu
$$

ofato de que $y$ seja observado apenas quando $\mathbf{y}_{\mathbf{i}}>\theta_{\mathbf{y}}$ implica:

$$
\begin{array}{ll}
y=\beta x+\mu & \text { se } \beta x+\mu>0 \text { ou } \mu>-\beta x \\
y=0 & \text { nos demals casos }
\end{array}
$$

Nesse casor daco que apenas observacoses com $\mu_{i}>-B x_{i}$

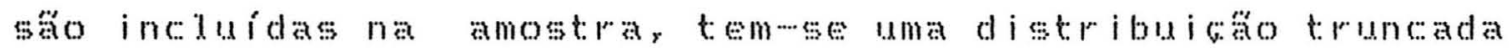




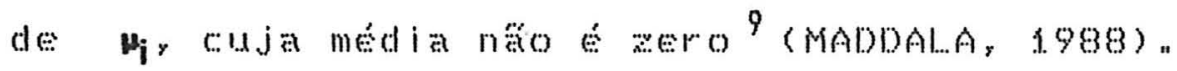

Por consequência, o método de mínimos quadracos ordinários năo se mostra adequado para a est imacăo da regressaro, uma vez que pressupoe $E(\mu)=0$, fato estenaso observadon logo, o uso indevido desse metodo pode causar vieses na estimativa dos parâmetros no caso de uma

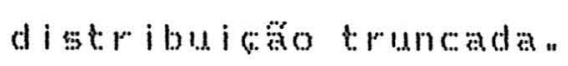

Frente a esse problema, ToBTN (1958) analisando gastos com a compra de automóveis. postulou um modelo com a seguinte forma"

$$
\begin{array}{cc}
y_{i}=\beta x_{i}+\mu_{i} & \text { se } \quad y_{i}^{*}>0 \\
y_{1}=0 & \text { se } y_{1}^{*} \leq 0
\end{array}
$$

Esse modelo ficou conhecido como tobit ou modelo de regressago consuradan

Quanto a estimacto do modelo, TOBTN (1998) propóe a ut i i zacáco do método da máxima verossimilhancan

${ }^{9}$ Na realidade, ofato da media de y náro ger zero,

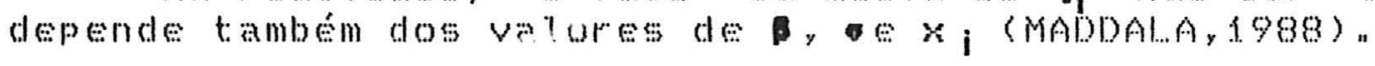


segundo KMENTA (1978), o método da máxima verossimilhanga baseiane na idéa de que diferentes popudacoses geram amostras diferentes e de que é mais provared que determinada amostra tenta origem en determinada populata do que em outras ainda que uma amostra possa vir de uma populaca cá caracterizada por

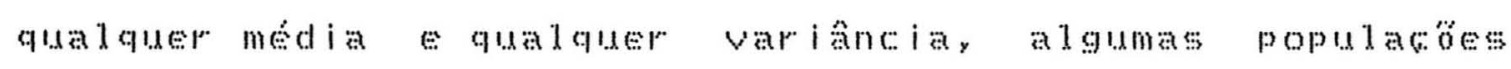
geram tal amostra com ma is frequencia do que outras.

De maneira ma is especifica, se uma variáced aleatór ia $x$ tiver uma distribuicto $f(x)$ ciarateriada pelos

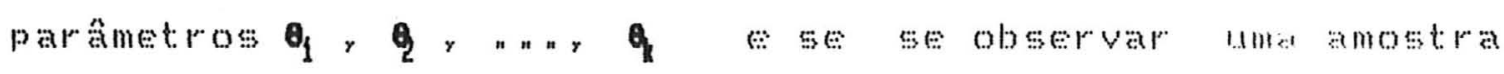
$x_{1}, x_{2}, n, x_{n}$ entio os estimadores de másima

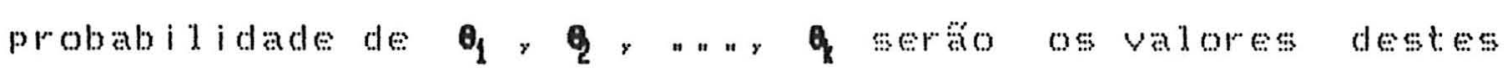
parametros que gerarem, ma $\mathrm{a}$, frequentementes a amostra observadan Em outras balavras, os estimadores de mámima probabilidade de $\theta_{1}$, 2 , " 9 sta valores para os qua is a probabilidade cou densidade de probabilidade) de determinaclo conjunto de valores amostrais están no másimon Tsto é para encontrar os estimadores de maxima

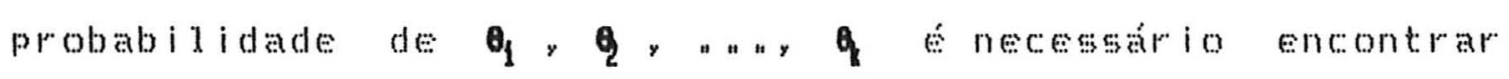
os valores que maximian $f\left(x_{1}, x_{2}, n n, x_{n}\right.$ ) (KMENTA, 1.978)

Esea maximizacto, no caso do modelo de regressá normal censurada, deve observar, segundo MADDALA (1988) 
a dons aspectos discut idos a seguir.

No caso do modelo tobity existem dois tipos de observacises:

a) com valores positivos de y, cuja funcio normal de densidade é a usual cobervecse que $\left(y_{i}-\beta x_{i}\right) / 0$ tem

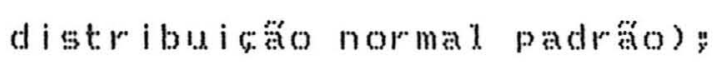

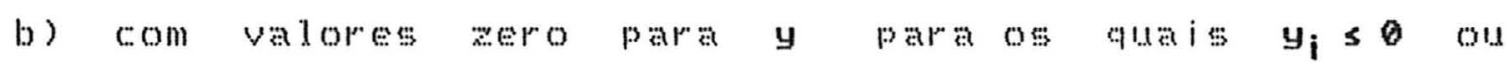

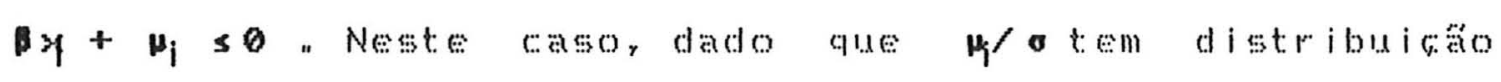

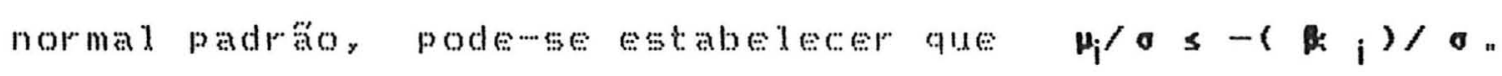
A probabilidade poder entäny ser escrita como Fr-

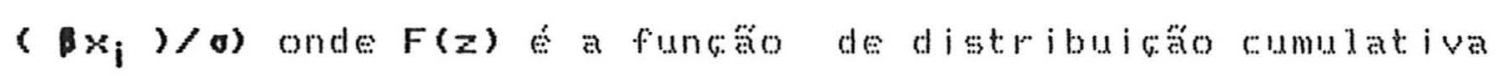
normal.

Tomandowe a funcaro de densidade normal por $f(a)$ e a

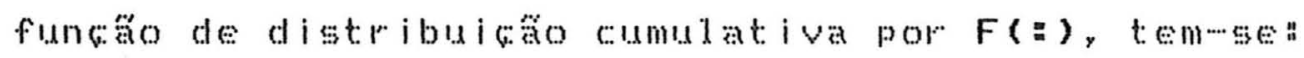

$$
f(t)=\frac{1}{\sqrt{2 \pi}} \exp \left(-\frac{t^{2}}{2}\right)
$$

E:

$$
F(z)=\int_{-\infty}^{g} f(t) d t
$$


que, por seu turno, permitem seja definida a functó de verossimithanca para o modelo tobit:

$$
L=\prod_{y_{1}>0} \frac{1}{\sigma} f\left(\frac{y_{1}-\beta x_{1}}{\sigma}\right) \prod_{y_{1} \leq 0} F\left(-\frac{\beta x_{1}}{\sigma}\right)
$$

Finalmente, a maximiango dessa functo com respeito a - a fornece as estimativas de maxima verossimithanca desses parânetros

Deve-we frisar que nem sempre a observacáo de um zero

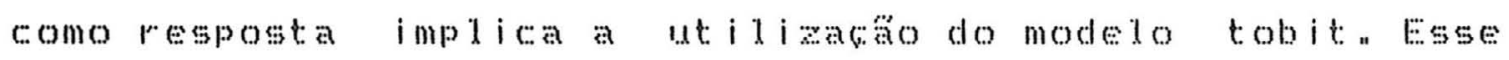
modelo, alerta MADDALA (1988), deve ser aplicado apenas nos casos em que a variaved dependente pode, em principio, assumir valores negativos e os valores aero sta consequencia da năo observacta do evento (censura) "Algumas variáveis, em principio, näo podem assumir valores negativos rgatos com automóveis, salario, horas trabalhadas, por exemplo), Nesses casos, o valor aero deven. se a decisöes individuais ená a problemas de censuran Diante dessa situactó Maddala recomenda que outros modelos, ao invés do tobit, sejam aplicadosn

Outra limitacác do modedo tobit apontada pelo referido autor dizrespeito ao caso em que a amostra é retirada de uma distribuicáo truncada, ou seja, náo säo observados 
valores para a variáced $\boldsymbol{y}_{\mathbf{i}}$ e também, para algumas das var i áveis $x_{\mathbf{i}}$ "

Neste caso, o modedo de regressáo censurada náo é adequado, pois seu uso pressupore a existencia de observacónes sobre todas as variaveis explanatón a isso năb ocorre, significa que abaixo ou acima de um determinado níved de $y_{\mathbf{i}}$ nä́o foram retiradas amostras, o que difere do fato da náowobervacáo de y

Issoposto, podense admitir que o modelo de regressao (iensurada (tobit) é adequado para o tratamento das informagoses disponiveis sobre a demanda por liquidez adicional junto a fontes financeiras informals porquen

a) o interesesem obter liquidez adicional pode ser, em principio, negativo:

b) ocorre una censura nas informacóses sobre a variável dependente, uma vez que se observa apenas $\mathbf{y}_{\mathbf{i}}>0 \%$ ex

c) há informacóes sobre as varidveis independentes ( $x_{i}$ ) para todas as unidades da amostran 


\subsection{Definicão das Variáveis}

As variáveis selecionadas na formatacio do modelo econômico, foram quant if icadas observando os procedimentos clesciritos a seguir.

a) a amostra de produtores agricolas originouse de levantamento feito em 10 regiones do paisy por ocasio do estudo desenvolvido por ARÁs.Jo et al $1 \mathrm{i}$ (1990a);

b) adotoune como unidacte de observacto o produtor rurad que tenha tomado ou näo emprestimos formats e/ou informas na safra de verto do ano agrícola $1989 / 90$ (compreendida entre mato de 1989 e junho de 1990$)$ :

(:) os valores monetarios foram reportados a setembro de

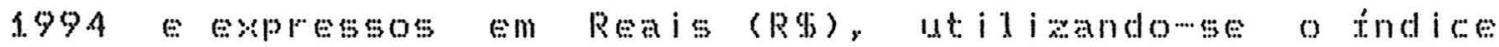

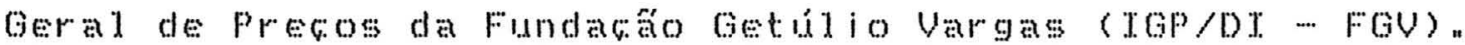

(e) para os náontomadores de créditor considerouns como custo de oportunidade do endividamento o custo financeiro médio regional ponderado pelo valor dos empréstimos formais/informais

(1) no caso de mas de uma operacta de emprestimo pelo mesmo 
tomadory foi considerada a soma dos valores principais e a taxa media de juros ponderada pelo valor do principal de c: ad a emprést imon

As var iaveis do modelo econométricosta definidas a $50 \mathrm{glin}$

Emprést imos Tomados nos Mercados Informais - LIQINF ( $Y$ )

Valor prineipal do emprestimo obtido pelo produtor rural em fonte informal de coreditor na safra de verádo ano agricola $1989 / 90$, em unidades monetarias (Rf) " Esse valor é uma prosed da liquideradicional obtida nos mercados informatse constitui a variáved dependente do modedon

No caso de empréstimo realiando em espécie cescambo produto/insumo, por exemplos alcangouse o valor do principal através da multiplicaga da quantidade de insumo adquirido ou do servico prestado pelo seu prego de mercado a época de abertura do corediton

Taxa Real de Juros do Crédito Informal - JURINF ( $\left.x_{1}\right)$

raxa real de juros, expressa em porcentagem, cobrada sobre as operacóses de emprestimo feitas junto aos intermediarios informa is 
Dado gue, na maria das operacoses informas a tara de juros näo estava explicita, houve a necessidade de sua estimacto caso a cason para tantoy nos escambos insumo/produto converteuse, primeiramente, o valor monetario do insumo em quantidade de produto equivalente. tomando por base o preco de mercado do produto na data de

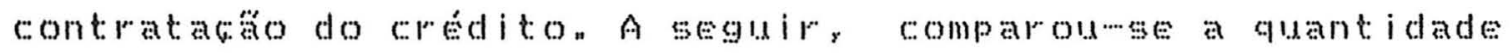
de produto obtida com aquela cobrada pelo financiador para entrega futura A diferenca percentuad entre as quantidades foi, entáro, considerada como a taxa real de juros da operaranon

Wa real idade, nák apenas a taka de juros dever a ser considerada mas, também, os custos de transacaro para o tomador, o que permitiria analisar o custo financeiro efetivo da operacano. Entretantor a fadta de dacos năo permitiu obter esses custos nas operacoses informas de crediton Por outro lado, a literatura sugere que os custos de transacáo para o tomador, nos mercados informats sáo

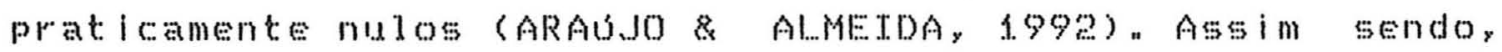
pode se argumentar que seu impacto sobre o custo financeiro informal näo seria significativon

\section{Empréstimo Tomado no Mercado Formal - UALFoR ( $\left.x_{2}\right)$}


rural junto a agentes forma is de credito, na safra de verán do ano agricola $1989 / 90$, en unidaces monetarias (RS).

No caso de mas de uma operacto de emprestimo pelo mesmo tomador, foi considerada a soma dos valores prineipas e a taxa média de juros ponderada pelo valor do principal de cada empréstimon

Essa variável tenta contar, também, a influenceia da oferta de recursos financeiros no mercado formal de coredito sobre o produtor rurad n

\section{Custo Financeiro Efetivo do Crédito Formal - CSTFOR ( $\left.x_{3}\right)$}

Custo financeiro dos recursos obtidos no mercado formal de credito, calculado a partir dos emprestimos realizados por agricultores na safra deverá do ano agricola 1989/90. Esse custo considera a taxa real de juros

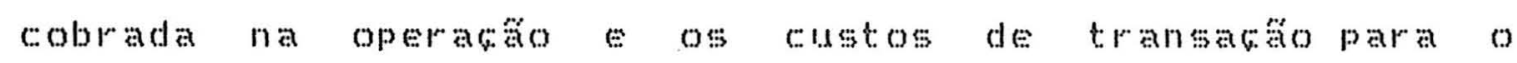
tomarar"

Os custos de transacto dos emprestimos, como definidos DOR MEYER \& CUEUAS (1990), säo Os gastos relacionados à transferencia de recursos financeiros entre mercados ou entre participantes de um mesmo mercadon 
A mensuraca do custo de transacáno para o tomador de emprestimo (CTR z) leva em conta gastos explicitos e implicitos n como explícitos, säo computados os gastos com transporte: al imentacto e hospedagem efetuados nas visitas

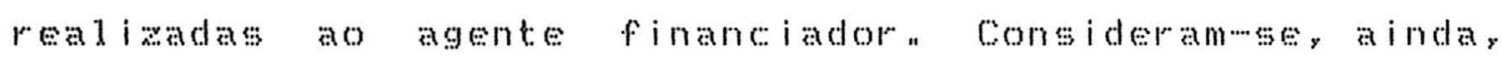

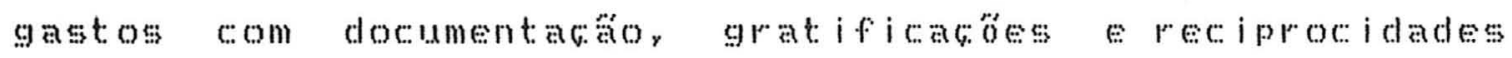
financeiras exigidos pelo agenten como gasto implicito admitewse o custo de oportunidade do agricultor para negociar o emprestimo, representado pelo valor de seu dia

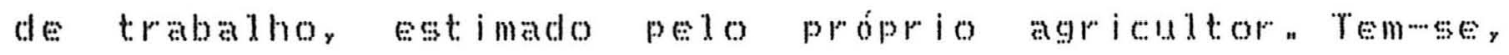
a 5 s 5 i m

$C T R=\frac{(N V I * T A H)+(D O C+G R A+R E C)+(D V I * E D T)}{V E M} \times 100$ (3.8.)

onde:

CTR \% :-: custo de transacáo para o tomador, em percentagem do valor principal do erétito:

NUI :: numero de visitas real iandas pelo produtor, até obter o emprest i mo:

TAH =: valor das despesas de transporte, al imentac áo e hospedagem, por visita feita ao agente financeiro (Rs) ;

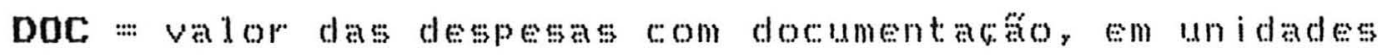
monet:ária ias (RS) ;

GRA :: valor das grat ificacoses, em unidades monetarias (Rq); 
REC :a valor das reciprocidades garantias exigidas para a concessa do emprést imo (RS) y

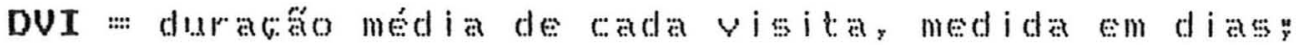
EDT :: estimativa de valor do dia de trabalho do produtor, em unidades monetarias (R⿻) : e:

UEM :-: valor principal do emprestimo formal (RG) :

Admitindo que o custo de transacto do pago antecipadamente pelo tomator, podewe considerar que o valor do empréstimo é de inicio, descontado de valor equivalente ao gasto para sua obtenction

Isso significa que o tomador recebe, efetivamente, valor menor que o principal estabelecido na operacanon rodavia, a taxa de juros incidesobre o principal do emprestimo, resultando em montante superior ao que seria encontrato caso fostas apl icada sobre o valor efet ivamente recebidon Essa composicácentre tawa de jurose custo de transaca para o tomador corresponde ao custo financeiro efetivo da operacáo de emprestimon Uma forma de calculato 10 ex seguinte:

$$
\operatorname{CSTFIN~}=\left(\left(\frac{1+\frac{\pi U R}{100}}{1-\frac{C T R}{100}}\right)-1\right) * 100
$$

onde: 


\section{CSTFIN :-: custo financeiro efetivo do emprestimo ( $/ n)$; JUR ::: taxa real de juros da operacta (\%) emprest imo.}

\section{Categoria do Produtor - CATPRD ( $\left.X_{4}\right)$}

Como indicador do porte do produtor duas alternativas sấ ut i l izadas área explorada (em hectares) e valor bruto da productáo agricola (em RG) "Ambas referentes à safra de verădo ano agricolar $1989 / 90$.

A área explorada considera terras proprias e teras tomadas/cedidas em arrendamenton o valor bruto da producáo agricola é determinado multiplicandowe a produca a colhida pelos pregos de mercados vigentes na colheitan

\section{Despesas Operacionais da Producão - DESoPE ( $x_{5}$ )}

sao computadas despesas operacionais tipicas com mow dewoba, máninas, defensivos e fertilizantes, necessarias para a manter a producta na safra de verao do ano agricola 1.989/1990. Essa varived é expessa em unidades monetarias (R W ) * 


\section{Educąão Forma1 do Produtor - EDUFOR $\left(x_{6}\right)$}

Esta variável é representada pelo mimero de anos de estudo formal dos produtores entrevistados sua inclusáó, de certa forma uma tentativa de captar o efeito da quad ificata do cap ital humano sobre o acesso do agricultor aos mercados financeiros n 


\section{RESULTADOS E DISCUSSÃO}

Nesta parte da pesquisa säo apresentadose discut idos os resultados obtidos segundo os objetivos propostos no Cap itulo 1.

Tnicialmente, avalianse a evoluca do mercado formal de coredto à aricultura, através do sistema Nacional de Créclito Rural -.. SNCR, entre 1970 E 1993.

A segur, sás est imatos indicadores economicos do desempenho de produtores, muturirios e nómotuários de credito, na safra de verán do ano agricola as89/90, em cl iferentes tipos de agricultura eregiós do país n No caso dos muturios sáo também descritas as caracteristicas dos

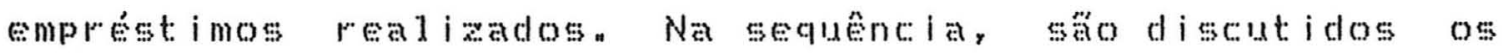
resultados do modelo econométricon 


\subsection{Crédito Rural Formal no Brasil: A Crise dos Anos 80}

Criado em 1965, o 5 istema Nacional de Crédito Rural -. SNCR constituiuse, segundo PATUA Et a di I (1973) numa "revolugaro total do credito a agricultura no pás"so" Dentre as vantagens dessesistema, os autores identificaram a participaca da rece bancaria no sistema de cócdito agricola, a ampliacaro da oferta de recursos financeirose a possibilidade de controlar o volume de dinheiro investido no setor agropecurion lese controle facilitariar inclusive, o direcionamento de recursos financeiros para regiones atividades especificas que necessitassem de apoion

A despeito do beneficio que essa orientacio possa ter oferecido. ARAúdo(1980) alerta para o fato de que sua excessiva utilizacano trangformou o credito rural em mecan ismo de planejamento do setor agricolabrasileiroy a invess de mantên apenas como instrumento de apoio finance iro ao produtorn

Nesse sentido, SHTROTA (1988) observa que devido à constante intervencăo governamental e to polition de curto prazo; a estabilidade do credito rural mostroune

10 Lei no 4.829, de $5 / 11 / 1965$, regulamentada pelo decreto no 58.380 , de $10 / 5 / 1.966$, 
vulneráved deso sua cor iacton

Ná bastassem os problemas advindos da interferencia diretay a politica de coedito rural foi também prejudicada pela instabilidade politicomeconomica que assolou o pais a partir dos anos 80. Aspecto marcante dessa fase foi a elevacto substancial e descontrolada do nivel geral de precos, resultando em altas taxas de inflacáanual, como pode ser visto na Tabela $A_{n}$. . Percebens que a partir de 1980 a inflacto atinge patamares cada ver mais edevacos, mesclados com algumas quedas provocadas pelos diversos

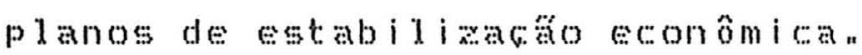

sobre o credito rurat, os efeitos negativos da inflaca foram sentidos nas principais fontes de recursos financeirosa depósitos à vista e recursos governanentais n

Os depósitos a vista nas instituigós financeiras representam dinheiro captaco relos bancos a baixo custo, náo havendo pagamento de remuneracăo pela sua permanência em contacorrenten Juntamente com o papel moeda em poder do publico constituem os ativos monetarios de maror liquider. na economian Parte dos depósitos a vista tem compulsoriedacte de aplicacouro na agricultura (exigibilidades), atraves de emprestimos aos produtores de acordo com as taxas de juros vigentes no SNCR 
Tabela 4.1.- Taxa Anual de Inflacăo na Economia, Medida pela Variąáo do Indice Geral de Precos (IGP-DI) da Fundacáo Getúlio Vargas, Brasil, 1970-1993.

\begin{tabular}{lr}
\hline Ano & $\begin{array}{c}\text { Variąâด } \\
(\%)\end{array}$ \\
1970 & 19,3 \\
1971 & 19,5 \\
1972 & 15,7 \\
1973 & 15,5 \\
1974 & 34,5 \\
1975 & 29,4 \\
1976 & 45,4 \\
1977 & 39,7 \\
1978 & 40,8 \\
1979 & 77,2 \\
1980 & 110,2 \\
1981 & 95,1 \\
1982 & 99,8 \\
1983 & 210,9 \\
1984 & 223,8 \\
1985 & 235,1 \\
1986 & 65,0 \\
1987 & 415,8 \\
1988 & $1.037,6$ \\
1989 & $1.782,9$ \\
1990 & $1.476,6$ \\
1991 & 150,2 \\
1992 & $2.708,5$ \\
1993 & \\
\hline
\end{tabular}

Fonte: Fundacấa Getúlio Vargas n 
rodavia, a indexacro da economia utilizada como protecá contra a inflacto, provocou o redirecionamento de recursos apdicados em ativos monetarios para apd icasoses em at:ivos námonetarios ${ }^{11}$ Com isso, o sistema passou a operar em nivel mais baixo de demanda por modan os clepósitos à vistar sujeitos d elevacio do custo de ociosidade da moeda, deixaram de ser atraentes col.tVETRA \& MONTEZANO, 1982), Registrouse, ent aro, forte migracaro de capital para os ativos nomomonetarios como pode ser observado na rabela 4nen lissa Tabeda apresenta a participacáo redativa dos principais haveres financeiros em poder do publico no total de haveres finanesiros da economia brasileira, entre 1972 e maio de 1993 .

observando a composicyo dos principais haveres perceberse que os monetarios perderam participacto significativa, declinando de $37 \%$ do total, em 197?, para $9,5 \%$ em maio de 1993. Por outro lado, os näomonetarios

11 Para cefeito de continuidade e comparactio de daclos,

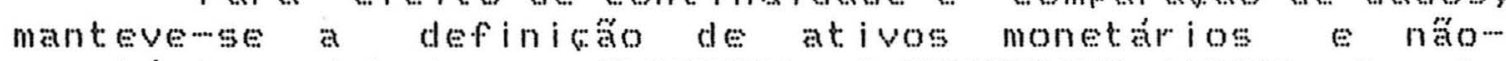
monetár ios adotada por OLIUETRA \& MONTEZANO (1982) "Pape 1 -... moeda em poder do publico es depositos a vista nos bancos comercia i compreendem os at ivos monetários "Depósitos de poupanar, depósitos à prazo, letras de importacaro e de exportacáo do Banco do Brasil, letras de cámbio, letras imobiliálas e títulos da divida publica federal sáso

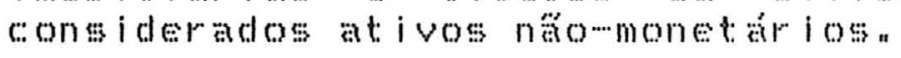


Tabela 4.2.- Participarão Relativa dos Principais Haveres Financeiros em Poder do Píblico no Total de Haveres Financeiros da Economia, Brasi1, 1972-1993. (emi percentagem) (1)

\begin{tabular}{|c|c|c|c|c|c|c|c|c|c|c|}
\hline \multirow[b]{2}{*}{ Ano } & \multicolumn{3}{|c|}{ Haveres Honetários } & \multicolumn{6}{|c|}{ Haveres Hẫo-monetários } & \multirow{2}{*}{$\begin{array}{c}\text { Total } \\
\text { Haveres } \\
\text { Financeiros }\end{array}$} \\
\hline & $\begin{array}{l}\text { Papel } \\
\text { Hoeda }\end{array}$ & $\begin{array}{c}\text { Depósitos } \\
\text { à Vista }\end{array}$ & Total & $\begin{array}{c}\text { Depósitos } \\
\text { de } \\
\text { Poupanca }\end{array}$ & $\begin{array}{c}\text { Depósitos } \\
\text { a Prazo } \\
\text { Fixo }\end{array}$ & $\begin{array}{l}\text { Letras } \\
\text { de } \\
\text { Canubio }\end{array}$ & $\begin{array}{c}\text { Letras } \\
\text { Hipotecá- } \\
\text { rias }\end{array}$ & $\begin{array}{l}\text { Tit.Div. } \\
\text { Publ.Fed } \\
\text { Resp.TH. } \\
\text { (2) }\end{array}$ & $\begin{array}{l}\text { Total } \\
\text { (3) }\end{array}$ & \\
\hline 1972 & 9,7 & 27,3 & 37,0 & 6,5 & 14,4 & 17,7 & 4,2 & 20,2 & 63,0 & 100,0 \\
\hline 1973 & 8,3 & 39,3 & 47,6 & 7,2 & 13,1 & 17,7 & 3,3 & 11,2 & 52,4 & 100,0 \\
\hline 1974 & 7,3 & 36,6 & 43,8 & 10,1 & 11,7 & 14,9 & 2,9 & 16,6 & 56,2 & 100,0 \\
\hline 1975 & 7,1 & 34,2 & 41,4 & 12,7 & 12,5 & 12,8 & 2,1 & 18,5 & 58,6 & 100,0 \\
\hline 1976 & 7,1 & 31,0 & 38,1 & 16,5 & 11,2 & 10,5 & 1,5 & 22,3 & 61,9 & 100,0 \\
\hline 1977 & 6,9 & 29,3 & 36,1 & 18,7 & 14,0 & 8,6 & 1,1 & 21,5 & 63,9 & 100,0 \\
\hline 1978 & 6,5 & 26,9 & 33,4 & 19,9 & 15,6 & 8,8 & 0,8 & 21,6 & 66,6 & 100,0 \\
\hline 1979 & 7,1 & 28,3 & 35,4 & 22,1 & 17,3 & 7,9 & 0,5 & 16,8 & 64,6 & 100,0 \\
\hline 1980 & 7,3 & 28,7 & 36,1 & 24,9 & 16,1 & 6,9 & 0,4 & 15,6 & 63,9 & 100,0 \\
\hline 1981 & 5,6 & 21,2 & 26,8 & 26,6 & 16,7 & 5,3 & 0,3 & 24,4 & 73,2 & 100,0 \\
\hline 1982 & 5,1 & 16,2 & 21,3 & 28,7 & 17,1 & 9,0 & 0,2 & 23,8 & 78,7 & 100,0 \\
\hline 1983 & 3,8 & 13,8 & 17,7 & 34,3 & 19,7 & 9,6 & $\theta, 2$ & 18,7 & 82,3 & 100,0 \\
\hline 1984 & 3,3 & 10,4 & 13,7 & 32,7 & 20,6 & 5,1 & 0,1 & 27,8 & 86,3 & 100,0 \\
\hline 1985 & 3,1 & 11,5 & 14,5 & 28,3 & 19,4 & 4,3 & 0,0 & 33,6 & 85,5 & 100,0 \\
\hline 1986 & 6,6 & 29,0 & 35,6 & 25,8 & 22,8 & 3,6 & 0,0 & 12,2 & 64,4 & 100,0 \\
\hline 1987 & 5,0 & 15,9 & 21,0 & 44,7 & 19,5 & 1,5 & 0,0 & 13,3 & 79,0 & 100,0 \\
\hline 1988 & 2,8 & 6,5 & 9,3 & 34,8 & 13,4 & 0,5 & 0,0 & 42,1 & 90,7 & 100,0 \\
\hline 1989 & 3,1 & 4,8 & 7,8 & 24,5 & 12,8 & 0,2 & 1,0 & 53,7 & 92,2 & 100,0 \\
\hline 1990 & 10,0 & 15,6 & 25,6 & 24,1 & 27,3 & 0,3 & 1,3 & 21,3 & 74,4 & 100,0 \\
\hline 1991 & 6,3 & 12,6 & 18,9 & 28,6 & 36,8 & 0,1 & 1,5 & 14,1 & 81,1 & 100,0 \\
\hline 1992 & 4,6 & 7,7 & 12,4 & 28,2 & 53,8 & 0,1 & 2,7 & 2,8 & 87,6 & 100,0 \\
\hline wai1993 & 2,8 & 6,7 & 9,5 & 31,1 & 54,2 & 0,1 & 2,4 & 2,7 & 90,5 & 100,0 \\
\hline
\end{tabular}

Fonte: Banco Central do Brasil - Boletim Mensal (vários números)

(1) Calculada sobre os saldos de dez. de cada ano, exceto para 1993.

(2) Nã̃o estão incluídos os títulos ên poder do BACEN.

(3) Nấo foram considerados 05 títulos da dívida pública estadual e municipal. 
aumentaram sua participacán em cerca de ey pontos percentua is no mesmo perído, passando de $63 \%$ para $90 \%$ do total. A diferenca na evolucato entre haveres monetariose nábononetarios fica evidente quando se observa a rigura 4.1.".

Fum inando individualmente a composica do dos haveres, notacise que os depósitos à vista perderam cerca de eo pontos percentuais no total de haveres financeiros entre dezembro de 1972 e mato de 1993 por outro lado, os depósitos de poupanca passaram de 6 a no mesmo periodo. comportamento semelhanter verificouse nos depósitos a prazo fino que elevaram sua representatividade de fA\% para GA\% do totad A Figura An n mostra a evolucio desses tres ativos, entre 1972 e 1993, em termos de participacte percentual no total de haveres financeiros na economian

Considerense que a politica monetaria restritiva, aliada aos controles e taxacos implicitas sobre a atividade dos bancos laplicacóes compulsórias em diversas atividades econômicasy por exemplos for am também responsaveis pela reducto significativa do total de haveres monetarios no sistema financeiro nacional " Diante das sanc:óses impostas, os bancos procuraram diversificar suas atividades no sentido de expandir as operacóses nán 
Figura 4.1.

Composiçao dos Principais Haveres

Financeiros, Brasil, 1972-1993.

(em percenlagem)

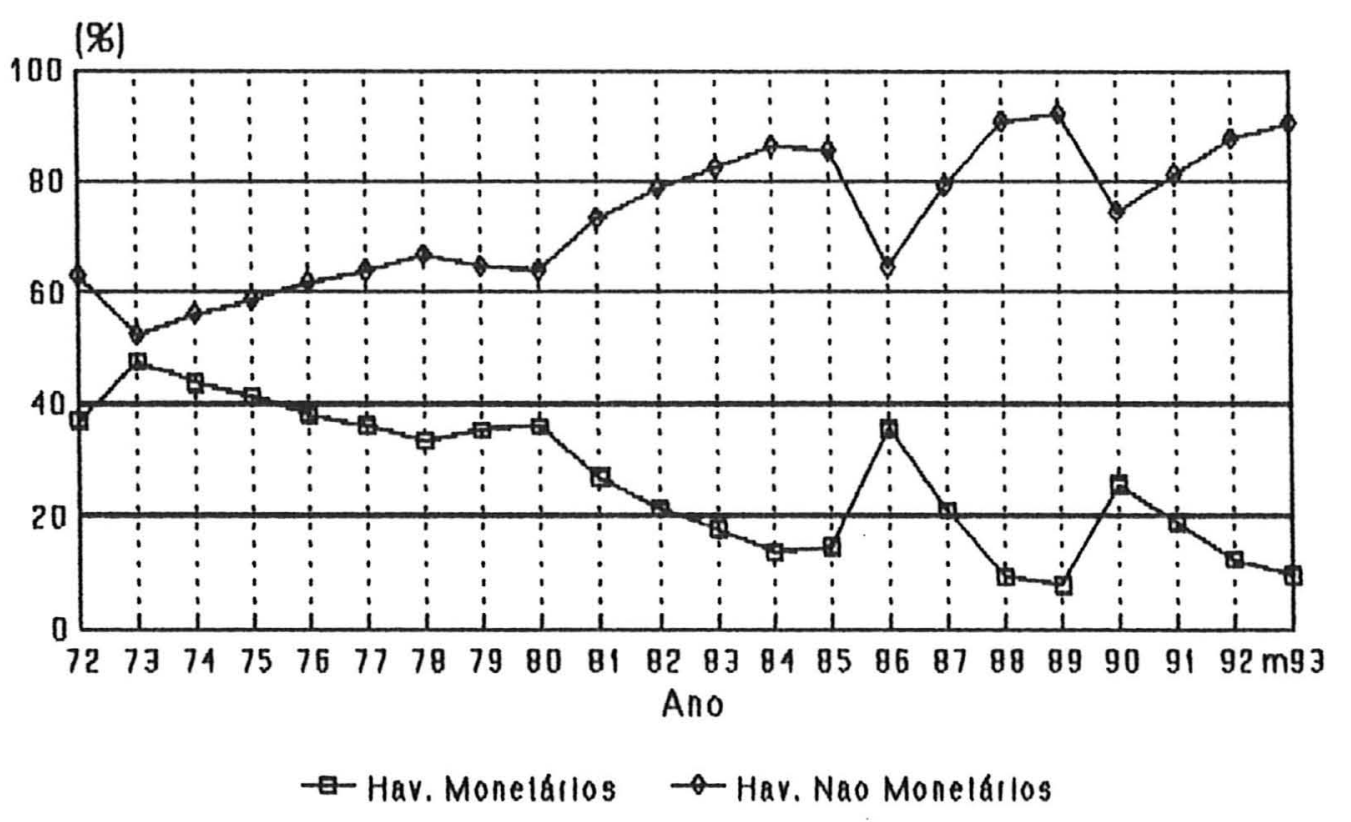

Fonte: Banco Central do Brasill. 
Figura 4.2=

Parlicipaçao dos Depósilos no Total de Haveres Financeiros, Brasil, 1972-1993 (em peicentagem)

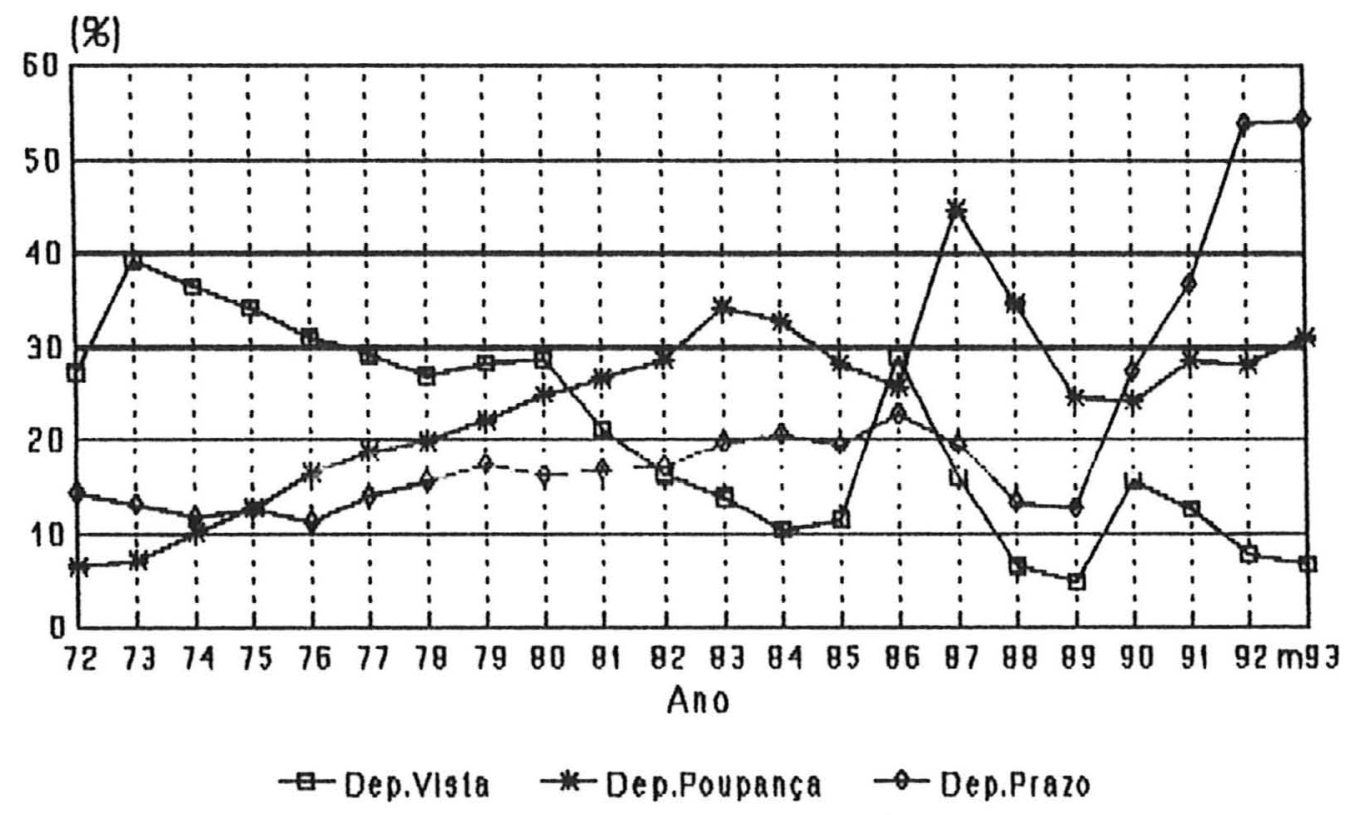

Fonle: Banco Central do Brasil 
monetarias que escapavam, na sua mariay das imposiobes

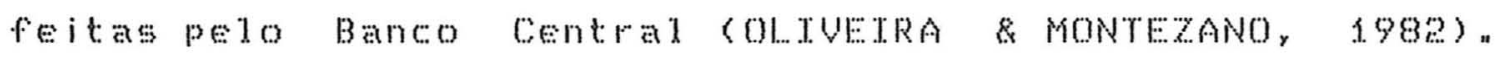
Issor contribuiu para deprimir ainda mas os valores mant i dos em contas correntes náromuneradas n

É importante lembrar que sobre os depósitos a vista

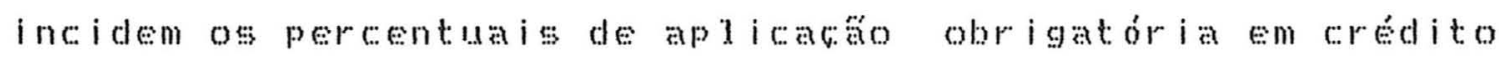
rupal denominados "exigibilidades" das instituicos financeiras que participam do sistema Nacional de credito Rural (BACEN, MCR - G 2 ), Assim, como conseguencia da drastica diminuicas dos saldos dos depósitos a vistar observou-se a diminuicaro do volume de recursos repassados à agricultura atraves das exigibilidades " Ressalte-ase que as autor idades monetarias a inda tentaram manter a capacidade de inversago de recursos via exigibilidaces mediante aumentos sistematicos nos percentuas determinados aos banc: os

A inflacko corecente teve efeitos danosos tamberm sobre os recursos governamentais destinados ao financiamento da agricultura neses valores timbam origem tanto na emissäo de moeda, como na colocago de titulos da divida pubica interna nos mercados financeiros (BARROS \& ARAU.JO, f991.)

o controle da oferta monetariar exercido com o intuito de atenuar o agudo processo inflacionario na economiar 


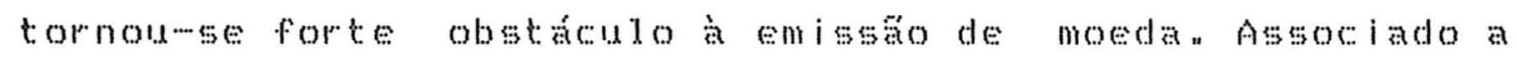
esse controle, foi adotado um conjunto de medidas que

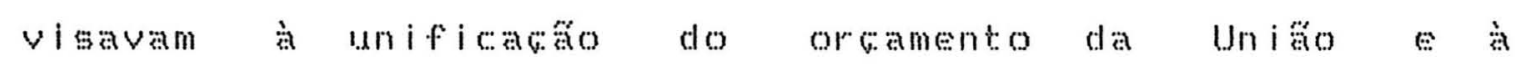
transferencia do controle sobre a expansăo da divida publica para o congresso Nacional. A extincago da conta de movimento", em 1986, foi uma deseas medidas"

0 recursos da conta de movimento tinham por finalidade cobrir, diariamentey a diferenca entre a

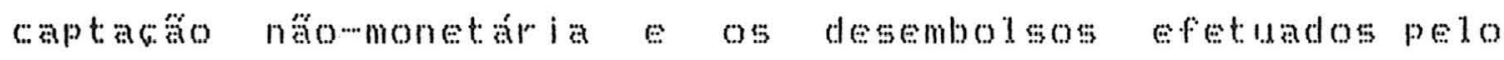
Banco do Braside Banco Central. Dentre os desembolsos estavam os emprestimos à agricultura feitos pelo Banco do Brasid, os repassese refinanciamentos feitos pedo BACEN E a execugaro financeira do resouro Nacional (NóBREGA, 1992)"

Como o próprio Nóbrega sugerey a conta de movimento era uma "roscansempim" al imentada pedo Banco central e pelo Banco do Brasil. De um lado, esse bancos aumentavam a liquidez do mercado através dos emprestimos e, de outro, o própro Banco Central eneugava essa liquideze vendendo titulos da divida publica mobiliaria interna da Uniân 0 as custos relativos aos juros eram, por sua vez, debitados ao resouro que necessitava langar mas titulos para cobrir esse onus como resultado, os recursos tinham custo asero tanto para o Banco Central como para o Banco do Brabil. 
BARROS \& ARAúdO (1991) observam que a desativacaro da conta de movimento redueiu a relacto entre a expansáda da oferta monetaria a oferta de credito rural. Apos $198 \%$, volume de crédito rural mostroune menos sensivel à taxa de inflack

Apesar disso, esses autores alertam que a relacáo volume de credito/taka de inflacko ná pode ser totalmente

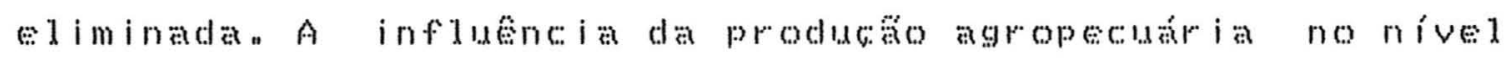
de preas faz com que as autoridades procurem, através da oferta de credito rural, evitar quedas na producáo e consequentes elevacoses nos precosn

Aspecto também relevante é que a conta de movimento ná apenas sobrecarregou o resouro Nacional, como tove Efeitos prejudiciais sobre outros instrumentos de apoio agriculturan por superesest imar a capacidade do sistema oficial de crédito rural, criando a imagem de que seus recursos eram i limitados deslocou para um segundo plano a pesquisa, o ensinor a extensforural eo seguro rural (NOBREOAA, 1992)"

Outra fonte utiliaga para angariar recursos com a finalidade de aplicacáno na agreultura foi a negociacáde títulos da divida publica interna nos mercados financeiros. Para serem atrativos no mercador esses titulos ofereciam 
remuneragos super fores de taxas de inflacan Entretantor com o avanco descontrolado do nivel geral de precosy a divida atrelada a taxa de juros também coresen mensivelmentey restringindo o uso desse instrumento de politica monetarian Alids, o incremento da divida teve consequencias diretas sobre os custos dos recursos financeiros, prineipalmente daquedes cuja finalidade era o emprestimon

Na media em que a dívida publica interna precisava ser pasar os recursos emprestados deveriam retornar com taxas de juros preferencialmente superiores dis de captacta no mercacion Isso contrariava a politica de concessáde

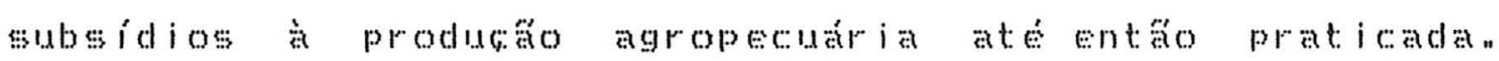
Emprestimos subsidiados tornaramsen pois, um empecitho à emissaco te titulosn

No caso da agricultura, ficou dificil para o governo suportar uma diferenca muto significativa entre os custos de captacto e de emprestimon Em raza disso, decidiuse incorporar gradativamente a correcto monetaria aos valores emprestados pelo SNCR.

Apesar do reconhecido efeito perverso sobre a manutencato do valor dos recursos do SNCR, existiam argumentacós de que face aos elevados riscos inerentes à 


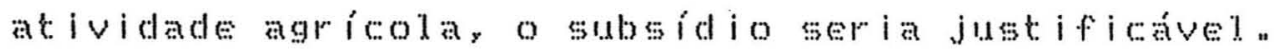

1...evewse en conta que o montante de subsidios a agricultura chegou a representar aprowimadamente $22 \%$ do PIB do setor agricola e e, $4 \%$ do P TB totad brasideiro, no ano de 1980 (SHTROTA, 1988)"

LOPEs (1992) salienta que esea politica durou até momento em que se tornou insuportável manter o déficit: públ ico cansado pelos subsidios de crediton

Devido à interferêne i de varios planos económicos ques tentaram a estabilizacaro da economia nos anos 80, o processo de retirada dos subsín ios năb foi contínuon Quando cotejada a evolucăo dos indexadores do credito e da

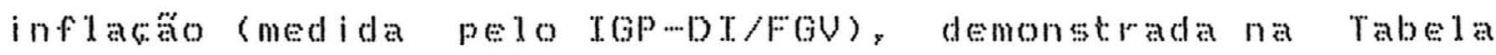
4.3n, registramose taxas de juros reate positivas apenas em tres anos do periodo $1980 \cdots 1993$, quais sejam" 1984, 1991 e 1.99312. Ainda que oscilantes, notase tendencia de aumento das tawas principalmente a partir de 1987.

12 Vários indexadores for am utilizados ao longo do tempo para corrigir monetariamente o coredito rural Cobrigaceoses Reajustáve is do Tesouro Nacional … ORTN, Letras

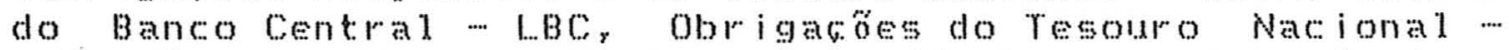
OTN, Bônus do Tesouro Nacional … BTN, Taxa de Referencia -.. TR e, mais recentemente, a Unidade de Referencia Agr icola es Industrial -- UREF), Porém, apenas em alguns momentos a evolucaro desses indicadores foi igual ou superior à inflaca ấo medida pelo TSPAT. 
Tabela 4.3.- Taxa Noninal e Real de Juros do Crédito Rural, Brasil, 1970-1993. (1) (\% ao ano)

\begin{tabular}{|c|c|c|c|c|c|c|c|}
\hline & & Noninal & & & & Real & \\
\hline 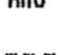 & Custeio & Invest inento & Conercializaқãa & 10 16 & Custeio & Invest imento & Comercializaķ̃̃o \\
\hline 70 & 17 & 17 & 17 & 19,2 & $-1,85$ & $-1,85$ & $-1,85$ \\
\hline 71 & 17 & 17 & 17 & 19,8 & $-2,34$ & $-2,34$ & $-2,34$ \\
\hline 72 & 15 & 15 & 15 & 15,5 & $-0,43$ & $-0,43$ & $-0,43$ \\
\hline 73 & 15 & 15 & 15 & 15,7 & $-8,61$ & $-0,61$ & $-0,61$ \\
\hline 74 & 15 & 15 & 15 & 34,5 & $-14,50$ & $-14,50$ & $-14,50$ \\
\hline 75 & 15 & 15 & 15 & 29,4 & $-11,13$ & $-11,13$ & $-11,13$ \\
\hline 76 & 15 & 15 & 15 & 46,2 & $-21,34$ & $-21,34$ & $-21,34$ \\
\hline 77 & 15 & 18 & 18 & 38,8 & $-17,15$ & $-14,99$ & $-14,99$ \\
\hline 78 & 15 & 18 & 18 & 49,8 & $-18,32$ & $-16,19$ & $-16,19$ \\
\hline 79 & 15 & 21 & 21 & 77,2 & $-35,10$ & $-31,72$ & $-31,72$ \\
\hline 80 & $? ?$ & 38 & 29 & 110,3 & $-36,76$ & $-34,38$ & $-38,66$ \\
\hline 81 & 45 & 45 & 45 & 95,2 & $-25,72$ & $-25,72$ & $-25,72$ \\
\hline 82 & 45 & 71,9 & 45 & 99,7 & $-27,39$ & $-13,92$ & $-27,39$ \\
\hline 83 & 117,3 & 181,6 & 117,3 & $211, \theta$ & $-30,13$ & $-9,45$ & $-3 \theta, 13$ \\
\hline 84 & 226,8 & 226,8 & 226,8 & 223,8 & 0,93 & 9,93 & 0,93 \\
\hline 85 & 230,6 & 230,6 & 230,6 & 235,1 & $-1,34$ & $-1,34$ & $-1,34$ \\
\hline 86 & 6,5 & 6,5 & 6,5 & 65,0 & $-35,45$ & $-35,45$ & $-35,45$ \\
\hline 87 & 212,1 & 212,1 & 212,1 & 415,8 & $-35,78$ & $-35,78$ & $-35,78$ \\
\hline 88 & 889,7 & 889,7 & 899,7 & 1037,6 & $-13,00$ & $-13,00$ & $-13,00$ \\
\hline 89 & $1.639,6$ & $1.639,6$ & $1.639,6$ & 1782,9 & $-7,61$ & $-7,61$ & $-7,61$ \\
\hline 90 & $1.276,0$ & 1276,0 & 1276,0 & 1476,6 & $-12,72$ & $-12,72$ & $-12,72$ \\
\hline 91 & 542,2 & 542,2 & 542,2 & 480,2 & 10,70 & 10,70 & 10,70 \\
\hline 92 & 904,0 & 904,0 & 904,0 & 1157,9 & $-11,54$ & $-11,54$ & $-11,54$ \\
\hline 93 & $2.784,1$ & $2.784,1$ & $2.784,1$ & $2.708,6$ & 2,69 & 2,69 & 2,69 \\
\hline
\end{tabular}

Fontes: 1) 1970 a 1996 - SHIROTA, R. Crédito rural no Brasil: subsídios, distribuicão e fatores associados à oferta. ESALQ/USP, Piracicaba, 1988.

1987 a 1993 - Cálculos da pesquisa para recursos or iundos das exigibilidades.

2) Manual de Crédito Rural

3) Conjuntura Econômica - vários números

(1) Considerando empréstimos para médio-produtores do Centro-Sul.

(2) Variação entre dez/dez de cada ano. 
lé preciso ter contela ao se examinar as tawas apresentadas nessa Tabela, uma vez gue elas säo referentes apenas aos recursos oriundos das exigibilidades

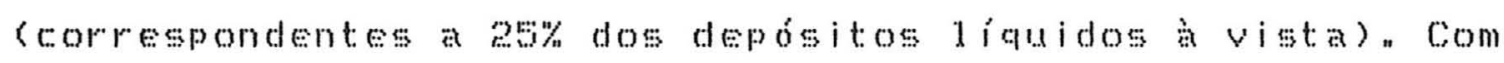
a coracato da caderneta de poupana rural, passou a vigorar um sistema de nix" de taxas de jurosa as taxas dos emprestimos săo ponderadas caso a caso, segundo a participacio das fontes de recursos financeiros tresto dificulta a estimaka precisa dos juros reais para o chedito como um todo ${ }^{13}$

Quanto aos subsidios, NAKANO (1992) acrescenta que estes năo se convertem em elevacto da renda dos produtoresy uma vere que acabam sendo trantererdos via mecanismo de preas para outros

setoresn fim liltima instancia, quem se beneficia deses sistema sato os bancos cobrando as reciprocidades o os vendedores de insumos que determinam os próprios precoson Ademais, o dinheiro barato é sempre fungived, podendo ser apl icado em outras at ividades

Frente d exautăo das fontes tradicionats de recursos

13 A titulo de exemplo desea diversidade defontes e taxas de juros, podewe consultar a Resoluciso BACEN no 2. n102, de 24/08/94, que di spóe sobre o direcionamento de recursos enencagos financeiros do credito rural " 
para o coredito rurad, o governo viunse obrigado a buscar novas fontes, preferencialmente nacoinflacionarias, para o financiamento da agricultura Nesse sentido, foi cor aday em 1.986, a caderneta de poupanca rural, cujos recursos captados junto ao publico deveriam ser aplicados, principalmente: no setor ruraln

Iniciadmente, apenas o Banco do Brasil foi autoriando a operar com a poupanca rurad Depoisy o Banco da Amazonia e o Banco do Nordeste do Brasil também receberam essa

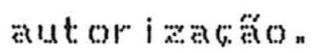

A taxa read de juros incidente sobre os recursos depositados na caderneta rural foi estabelecida em $6 \%$ ao ano, semelhante a remuneracáa paga pela caderneta de poupanga common

Descles seu surgimento, a poupanga rural desempenhou papel significativo como suporte para o credito ruraln A Tabela 4na mostra o volume de creditos concedidos segundo a origem dos recursos no primeiro ano de operaca (1987) recursos de poupanca representaram cerca de $23 \%$ do volume total desembodsado. Em ago, mesmo sob efeito do plano collor, a poupanga rural transferiupara a agricultura montante equivalente a $20 \%$ do total de cordito Nos anos 
Tabela 4.4.- Crédito Concedido pelo Sistewa Nacional de Crédito Rural, segundo a Fonte de Recursos e Participação Percentual de Cada Fonte (entre parenteses) no Total Anual, Brasil, 1987 - 1993. (R milhão de 5etembro de 1994) (1)

\begin{tabular}{|c|c|c|c|c|c|c|c|}
\hline \multirow{2}{*}{ Fonte } & \multicolumn{6}{|c|}{ Ano } & \multirow[b]{2}{*}{1993} \\
\hline & 1987 & 1988 & 1989 & 1990 & 1991 & 1992 & \\
\hline $\begin{array}{l}\text { Tesouro } \\
\text { Hacional }\end{array}$ & $\begin{array}{c}9.216 \\
(37,3 \%)\end{array}$ & $\begin{array}{c}4.377 \\
(25,1 \%)\end{array}$ & $\begin{array}{c}3.817 \\
(24,0 \%)\end{array}$ & $\begin{array}{c}2.431 \\
(26,7 \%)\end{array}$ & $\begin{array}{c}2.270 \\
(24,2 \%)\end{array}$ & $\begin{array}{c}2.391 \\
(23,0 \%)\end{array}$ & $\begin{array}{c}2.383 \\
(26,9 \%)\end{array}$ \\
\hline $\begin{array}{c}\text { Recurs05 } \\
\text { Obrigat órios }\end{array}$ & $\begin{array}{c}8.488 \\
(34,3 \%)\end{array}$ & $\begin{array}{c}5.982 \\
(34,3 \%)\end{array}$ & $\begin{array}{c}2.302 \\
(14,5 \%)\end{array}$ & $\begin{array}{c}2.491 \\
(27,4 \%)\end{array}$ & $\begin{array}{c}2.101 \\
(22,4 \%)\end{array}$ & $\begin{array}{c}1.948 \\
(18,7 \%)\end{array}$ & $\begin{array}{c}987 \\
(10,6 \%)\end{array}$ \\
\hline $\begin{array}{l}\text { Poupanca } \\
\text { Rural }\end{array}$ & $\begin{array}{c}5.574 \\
(22,6 \%)\end{array}$ & $\begin{array}{c}6.523 \\
(37,4 \%)\end{array}$ & $\begin{array}{c}8.221 \\
(51,6 \%)\end{array}$ & $\begin{array}{c}1.821 \\
(20,0 \%)\end{array}$ & $\begin{array}{c}3.032 \\
(32,3 \%)\end{array}$ & $\begin{array}{c}4.738 \\
(45,5 \%)\end{array}$ & $\begin{array}{c}3.863 \\
(43,7 \%)\end{array}$ \\
\hline $\begin{array}{l}\text { Recurs0s } \\
\text { Liures }\end{array}$ & $\cdots$ & $\ldots$ & $\begin{array}{l}1.243 \\
(7,8 \%)\end{array}$ & $\begin{array}{c}1.810 \\
(19,9 \%)\end{array}$ & $\begin{array}{c}969 \\
(10,3 \%)\end{array}$ & $\begin{array}{c}703 \\
(6,8 \%)\end{array}$ & $\begin{array}{c}1.049 \\
(11,5 \%)\end{array}$ \\
\hline $\begin{array}{c}\text { Fundos } \\
\text { Const itucionais }\end{array}$ & $\cdots$ & $\cdots$ & $\begin{array}{c}124 \\
(0,8 \%)\end{array}$ & $\begin{array}{c}407 \\
(4,5 \%)\end{array}$ & $\begin{array}{c}303 \\
(3,2 \%)\end{array}$ & $\begin{array}{c}327 \\
(3,1 \%)\end{array}$ & $\begin{array}{c}493 \\
(5,5 \%)\end{array}$ \\
\hline $\begin{array}{r}\text { Governos } \\
\text { Estaduais }\end{array}$ & $\cdots$ & $\cdots$ & $\begin{array}{c}43 \\
(0,3 \%)\end{array}$ & $\begin{array}{c}8 \\
(0,1 \%)\end{array}$ & $\begin{array}{c}12 \\
(0,1 \%)\end{array}$ & $\begin{array}{c}7 \\
(0,1 \%)\end{array}$ & $\begin{array}{c}9 \\
(0,1 \%)\end{array}$ \\
\hline Qutras Fontes & $\begin{array}{l}1.438 \\
(5,8 \%)\end{array}$ & $\begin{array}{c}558 \\
(3,2 \%)\end{array}$ & $\begin{array}{c}177 \\
(1,1 \%)\end{array}$ & $\begin{array}{c}131 \\
(1,4 \%)\end{array}$ & $\begin{array}{c}702 \\
(7,5 \%)\end{array}$ & $\begin{array}{c}293 \\
(2,8 \%)\end{array}$ & $\begin{array}{c}154 \\
(1,7 \%)\end{array}$ \\
\hline Total & 24.716 & 17.440 & 15.926 & 9.099 & 9.387 & 10.409 & 8.938 \\
\hline
\end{tabular}

Fonte: Banco Central do Brasil.

(1) Ut ilizando o IGP/DI - FGV (média anual) como inflator. 


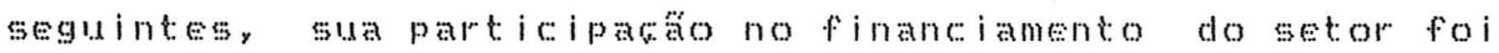
corescenter alcancando $43,2 \%$ do total de creditos concedidos em 1.993

Ainda que tenha se mostrado una fonte expressiva de recursos para o ceredito rurad, a poupanga rupal näo foi suficiente para compensar a forte diminuicáo ocorrida nas demais fontesn o volume total de creditos do SNCR, apresentou sensivel declinio anual no periodo 1979-1993.

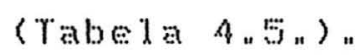

Considerando 1979 cano da ma ior oferta read de credito formal) como base, percebewe que ovolume de 1993 foi equivalente a apenas eng do total de recursos emprestados

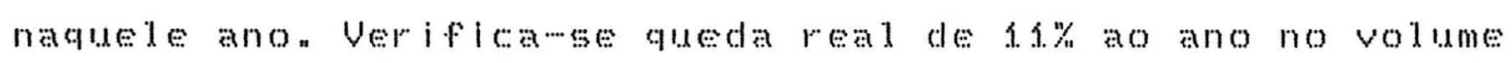
de credito conedido no periodo 1979 - 1993 como bem ilustra a Figura $4,3,14$

Quanto à finalidade dos empréstimos, o custeiofoi a que teve a menor reducaro real de recursosn entre 1979 e 1993 o volume de credito concedido com esse objetivo decresceu cerca de $9,0 \%$ ao ano. 0s financiamentos para

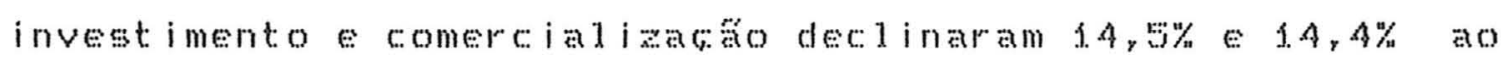
ano, respectivamente.

14 As taxas de crescimento do crétito rural total e por final idades for am calculadas sesundo procedimentos teoricos (I $\mathrm{i}$ scut: i dos em NEGRT NETO et a $1 \mathrm{i}$ (1993)" 
Tabela 4.5.- Financiamentos Concedidos a Produtores e Cooperativas, através do SNCR Segundo a Finalidade, Brasil, 1970-1993. (Rg milhao de setembro/1994) (1)

\begin{tabular}{|c|c|c|c|c|c|c|c|c|}
\hline \multirow{2}{*}{ Ano } & \multicolumn{2}{|c|}{ Custeio } & \multicolumn{2}{|c|}{ Invest inento } & \multicolumn{2}{|c|}{ Comercializacao } & \multicolumn{2}{|c|}{ Total } \\
\hline & Valor & indice & Valor & indice ! & Valor & indice & Valor & indice \\
\hline 1970 & 4.202 & 21 & 2.557 & 26 & 2.662 & 27 & 9.422 & 24 \\
\hline 1971 & 4.741 & 24 & 3.214 & 32 & 2.940 & 30 & 10.896 & 27 \\
\hline 1972 & 5.610 & 28 & 4.457 & 45 & 3.408 & 35 & 13.474 & 34 \\
\hline 1973 & 8.136 & 41 & 6.304 & 63 & 4.613 & 47 & 19.053 & 48 \\
\hline 1974 & 10.609 & 53 & 7.132 & 72 & 5.821 & 59 & 23.562 & 59 \\
\hline 1975 & 15.056 & 75 & 10.735 & 108 & 8.560 & 87 & 34.351 & 86 \\
\hline 1976 & 14.861 & 74 & 11.416 & 115 & 8.938 & 91 & 35.215 & 88 \\
\hline 1977 & 14.859 & 74 & 7.623 & 77 & 8.941 & 91 & 31.423 & 79 \\
\hline 1978 & 15.234 & 76 & 7.978 & 80 & 8.732 & 89 & 31.944 & 80 \\
\hline 1979 & 20.024 & 100 & 9.946 & 100 & 9.842 & 100 & 39.811 & 100 \\
\hline 1989 & 21.543 & 108 & 7.142 & 72 & 9.388 & 95 & 38.073 & 96 \\
\hline 1981 & 19.367 & 97 & 5.104 & 51 & 8.552 & 87 & 33.024 & 83 \\
\hline 1982 & 20.570 & 103 & 4.194 & 42 & 7.214 & 73 & 31.978 & 80 \\
\hline 1983 & 15.024 & 75 & 4.034 & 41 & 5.104 & 52 & 24.163 & 61 \\
\hline 1984 & 10.393 & 52 & 1.815 & 18 & 2.537 & 26 & 14.745 & 37 \\
\hline 1985 & 14.950 & 75 & 2.725 & 27 & 3.350 & 34 & 21.026 & 53 \\
\hline 1986 & 17.540 & 88 & 10.047 & 101 & 3.766 & 38 & 31.353 & 79 \\
\hline 1987 & 17.340 & 87 & 4.226 & 42 & 3.150 & 32 & 24.716 & 62 \\
\hline 1988 & 11.863 & 59 & 2.794 & 28 & 2.783 & 28 & 17.440 & 44 \\
\hline 1989 & 12.739 & 64 & 1.674 & 17 & 1.514 & 15 & 15.926 & 49 \\
\hline 1990 & 6.811 & 34 & 997 & 10 & 1.290 & 13 & 9.099 & 23 \\
\hline 1991 & 7.718 & 39 & 798 & 8 & 872 & 9 & 9.387 & 24 \\
\hline 1992 & 6.558 & 33 & 1.244 & 13 & 2.607 & 26 & 10.409 & 26 \\
\hline 1993 & 4.969 & 25 & 1.837 & 18 & 2.132 & 22 & 8.938 & 22 \\
\hline
\end{tabular}

Fonte: Banco Central do Brasil - Anuários do Crédito Rural, vários números.

(1) Ut ilizando o IGP/DI - FGV como inflator. 
Figura 4.3.

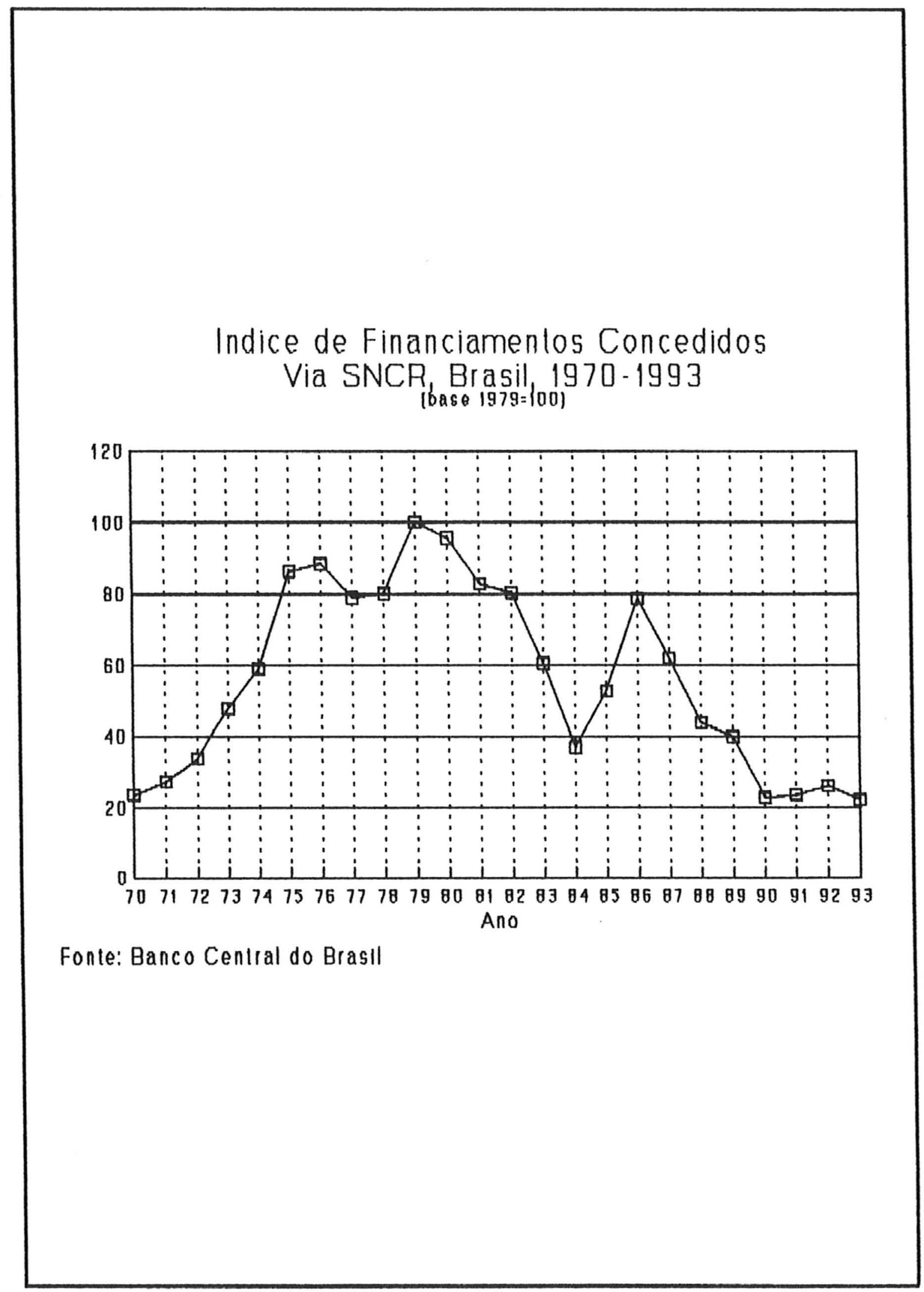


le possivel admitir que a queda no volume de emprestimos rurate concedido seja resultante nábo apenas da diminuicáo no montante ofertado mas y também, da gueda na quantidade demandada de recursos financeiros n

A reducáo do volume ofertado deriva dos problemas enfrentados pelas fontes de recursos que sustentam o SNCR, apontados anteriormente " A retraga no corécito demandado deve-we a combinacáno de mudancas na estrutura de producta agricola e, ao aumento do risco de endividamento para os agricultoress

A adocáo de novas tecnitas de producto, com mator

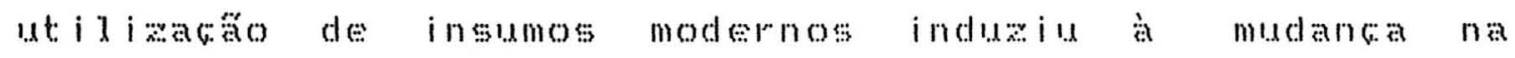
composicáco da producáno agr ícola finarciada, inclusive, pelo própro coredito rurad p principalmente nas regióses mais desenvolvidas, os produtos exportaveis foram favorecidos, provocando o des locamento dos produtos de mercado internon Segundo CARUALHO (1.986), essas mudangas foram est imuladas por alteracos nos precos redativos dos produtos e/ou fatores, "resultando em maior lucratividade dos produtos e/ou técnicas em expansao" tsso acabou por alterar a necessidade de recursos externos para financiamento das atividades agricolas 
Quanto ao endividamento devenge considerar que a combinagáco de fatores como a necessidade de indexacta das dividas frente à inflacko crescentey o comportamento aleatorio da productio esos precos agricolas bem como a frequente interferencia governamental na economia pode aumentar de maneira significativa or isco de endividamento

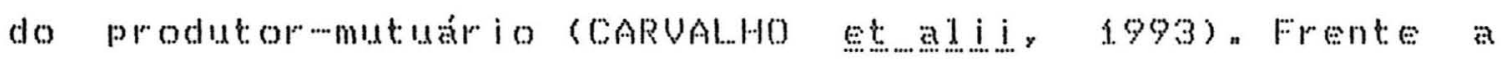
esse tipo de expectativa, o agricultor procura diminuir a tomada de financiamento externo, a despeito das taxas de juros cobradas no crétito rupal serem subsidiadas ou preferencia i is

Gutro ponto, náo menos importante, é o tradicional atraso nas liberacose do credito oficial, prejucicando, muitas vezes, o desenvolvimento das at ividades agricolas n

Tnclusive, esse atraso afronta dispositivo da lei 4.829 que determina que o coredito rural deveria atender ao requisito da oportunidade (CASTro, 1970) " Entendase a oportunidade como a conceseño dos recursos na boca em aue estes såo efetivamente necessar ios

Essa questac tornase mase relevante quando considerada a naturean irreversivel da producáogricolan Como lembra REZENDE (1989), uma vez iniciado o cicio produtivo, dificilmente a producto pode ser interrompida 
sem incorrer em attos custos " fe pois importante que os recursos estejam disponiveis ao produtor no momento adequado.

No setor agricolar tanto o volume de recursos por unidade de valor gerado como o prazo para obtencián do produto sáo matores que na productio industrial " o setor exige, portanto, tratamento diferenciado daquele dedicado a industriar, principalmente no que tange a fornecimento de capital degiron

No Brasil a náo observacaso a esses aspectos tem contribuido para a precariedade dos mecanismos forma $\mathrm{s}$ de financ: iamento rural, Em consequencia, os produtores tem que otimizar o uso dos proprios recursos e busear novas fontes elou formas de financiamento nos mercados fimanceiros muraisn

0 uso eficiente do capital proprio diminui a dependencia de recursos financeiros externos " por outro 1ado, novas fontes e/ou formas de financiamento permitem complementar ou mesmo substituir prontamente os recursos do corédito rural formaln

Nos mercados financeiros rurats os produtores podem recorrer a emprestimos informats para obter dinheiro ou, 
entäo, realizar operacoses de troca direta cinsumos, produtos e servitos) com agentes do setor privado.

\subsection{Desempenho Econômico dos Agricultores}

A amostra anal $\mathrm{i}$ sada foi obtida de dados levantados por ocasiano de estudo desenvolvido sobre varias regións agricolas do País (ARAúdo et alii. 1990a) " Das 330 entrevistas realizadas com produtores na safra de veráo do ano agricola $1989 / 90$, foram selecionadas 279 para a elaboracaro desta parte da pescuisan As demais por deficiencia de informacoses, foram descartadas

Admitindo que o desempenho economico e reflexo do tipo de tecnologia separouse a amostra em tres grupos de produtores distintos"

a) grupo 1. (61) -.. produtores de pequeno porte e baika renda, localizados nos Municipios de Caninde no Ceará, cruz das Almas na Bahia, Lajeado no Rio Gande do Sul e ponte Nova em Minas Gerais:

b) grupo 2(Ge) -o produtores que desenvolvem sistema de producáo agricola comercial e intensivo no uso de capital (daqui em diante denominados agricultores comerciais) situados nos Municipios de Carazinho no Rio Grande do Sul, 
Guara e Batatais em sao Paudo e Petrolina em Pernambucoy (s.

(:) grupo 3 (03) -.. produtores que desenvolvem exploracto agricola comercial e em larga escala congi em diante (lenominados agricultores em larga esca1a), estabelecidos nos Municipios de Rio Verde em Goids. Rondonópolis no Mato Grosso sato Gabried Doeste no mato brosso do sul.

Eise agrupamento segundo o tipo de exploracato agricolar levou em conta as corraterísticas dos produtores, da regito agricola do sistema de producto desenvolvido, descritos por ARAUJO et a d i 1990 a)

Para fins analiticos, a amostra é também dividida em dois tipos de produtoress muturios e näomutuarios de

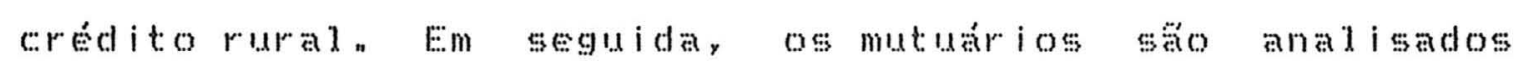
segundo a fonte de recursos externos a exelusivamente formal, exclusivamente informad e, ainda, simultaneamente formal e informal "

Combase em anal ise tabular dos dados, registrame, primeiramente, a participacato de cada grupo de produtores na amostran Em segulda, aval iamse alguns indicadores de desempenho tais comon areas possuida e exploradan valor

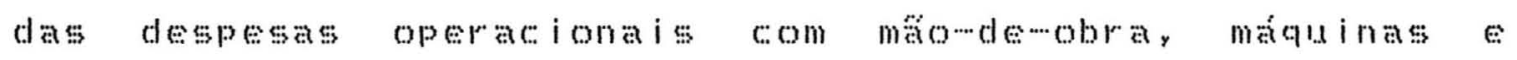


insumos: valor bruto da productocolnida a precos de mercador receita operacional liquida cralor productoro -.. valor das despesas)y e nivel de escolaridace dos produt oress n

A Tabela $4 b_{n}$ apresenta o numero de produtores anal isados, segundo os grupos de produtores, o mun cipior a

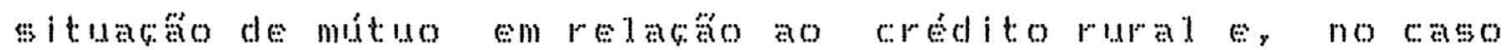
dos mutuarios, a or igem dos recursos.

Da analise dessa Tabela, percebense que o total de produrores estudados comporewsen na marora, de agricultores de baxa renda $(40 \%)$, Fim seguida aparece o grupo de agricultores comerciats (31\%) ey por lidtimo, o grupo de agricultores em larga escala (po\%), outro aspecto é que, do total de produtores, Aa\% eram muturios de algum tipo de (.) rédito em 1.989/90.

Como esperado, os produtores do grupos saco matoria (57\%) dentre os muturios n 0 s produtores do grupo a mostram

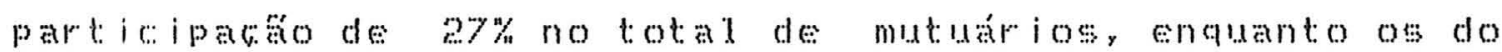
grupo f. representam apenas $16 \%$ daquele total nesa situaga se inverte no caso dos námotuarios passando o grupo 3 a ser minoria $(9 \%)$ e grupo 1 a maioria $(5 \% \%)$ da amostan 
Tabela 4.6. - Número de Produtores Analisados, Segundo o Tipo de Agricultor, Município, Situacão de Mútuo de Crédito Rural e Fonte de Recursos, Brasil, Ano Agrícola 1989/90, Safra de Verão.

\begin{tabular}{|c|c|c|c|c|c|c|}
\hline \multirow[t]{2}{*}{$\begin{array}{c}\text { Tipo de Agricultor } \\
\text { E } \\
\text { Hunicípio }\end{array}$} & \multirow[t]{2}{*}{$\begin{array}{l}\text { Avostra } \\
\text { Total }\end{array}$} & \multicolumn{4}{|c|}{$\begin{array}{l}\text { Mutuário } \\
\text { de Crédito } \\
\text { Rural }\end{array}$} & \multirow{2}{*}{$\begin{array}{c}\text { Não } \\
\text { Mutuário } \\
\text { de Crédito } \\
\text { Rural }\end{array}$} \\
\hline & & Formal & Inforwal & Alubos & Total & \\
\hline Pequeno Porte e Baixa Renda (G1) & 111 & 3 & 14 & 1 & 18 & 93 \\
\hline Canindé, CE & 20 & 0 & 1 & 0 & 1 & 19 \\
\hline Cruz das Aladas, BA & 35 & 3 & 7 & 1 & 11 & 24 \\
\hline Lajeado, RS & 32 & $\theta$ & 1 & $\theta$ & 1 & 31 \\
\hline Ponte Nova, HG & 24 & 0 & 5 & $\theta$ & 5 & 19 \\
\hline Comercial E Capital-Intensiva (G2) & 86 & 21 & 5 & 6 & 32 & 54 \\
\hline Carazinho, RS & 37 & 10 & 1 & 5 & 16 & 21 \\
\hline Guaíra/Batatais, SP & 22 & 8 & 1 & 1 & 10 & 12 \\
\hline Petrolina, PE & 27 & 3 & 3 & $\theta$ & 6 & 21 \\
\hline Em Larga Escala (63) & 82 & 39 & 14 & 14 & 67 & 15 \\
\hline Rio Verde, 60 & 23 & 9 & 5 & 4 & 18 & 5 \\
\hline Rondonópolis, HT & 30 & 15 & 5 & 4 & 24 & 6 \\
\hline São Gabriel Doeste, HS & 29 & 15 & 4 & 6 & 25 & 4 \\
\hline Total Brasil (n) & 279 & 63 & 33 & 21 & 117 & 162 \\
\hline
\end{tabular}

Fonte: Dados da Pesquisa. 
lintre os tomadores de credito, observans que $53 \%$ buscam recursos unicamente em fontes formats, ag\% o fazem

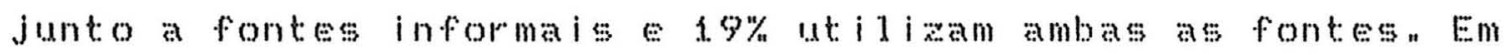
termos de terédito formal, os produtores do grupo 3 sä́ os que ma $\mathrm{i}$ s tomam emprest imos (6o\%), seguldos pelos do grupo $(33 \%)$ e do grupo 1. (5\%) " Em se tratando de uso exclusivo de fontes informas os produtores dos grupos a e 3 mostram participacoses identicas (As\%) enquato os do grupo respondem por 16\% do total desse tipo de crediton No uso simultâneo de recursos de fontes formats e informats, os produtores do grupo 3 săo maioria (64\%) seguidos pelos do

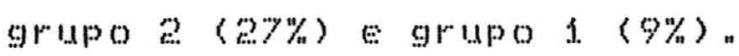

De maneira geral, os resultados apresentados na rabela 4. on permitem algumas constatacoses e i acoses sobre o uso de coredito no ano agrícolat $1989 / 90 \%$

a) a matoria dos produtores náo toma emprestimos, seja por opcro próprat, seja pelo inacesso aos mercados financeiros;

o racionamento no crédito formal e o risco das operacoses informats se refletem em elevado custo do dinheiro e exigencia de garantias e de reciprocidades pessoais e/ou financeiras " Tsto restringe o acesso de maior mumero de produtores aos mercados financeiros e provoca a 


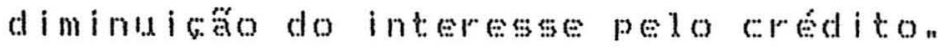

b) dentre os muturios, os agricultoresem larga escala (grupo 3) mostram maior interesse em obter recursos externos, independentemente da or igem dos recursos;

lisse comportamento é reflewo do maior volume de recursos financeiros exigidos em functo da escala de producia e do investimento para a incorporacán de novas

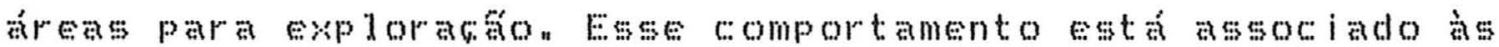
regioses de fronteira agricola do centrowoesten

(:) os pequenos agricultores (grupo f) săo os que menos ut i l i ram coredito rural e, quando ofarem, preclominam os emprestimos obtidos de fontes informats:

Razoses para isso seriam o baixo nived de renda proporcionado pela agricultura de pequeno porte e a falta de garantias reais a oferecer nos emprestimos do SNCR " Como consequência de sua redua da capacidade de pagamento, esses produtores ficam mais ligados as fontes informas de financ: iamenton

d) os agr icultores comercia is (grupo es) ocupam posicáto ma is confortáved que os demais no que respeita à decisáo de tomar emprést i mos: 
A estabilidade dos sistemas de producto e do fluko de rendar bem como a posse de garantias reais a oferecer, de um lado, facilita o acesso deseses produtores aos mercados de credito. De outro, permite 1 hes autowinanciar com maior frequencia suas atividades.

\subsubsection{Indicadores de Desempenho Econômico}

A rabela 4.7 "mostra alguns indicadores econômicos médios da atividade agricola e fatores associados ao desempenho dos produtores da amostra total (279), dos mutuarios de crédito rural inclusive segundo a fonte de recursos (1.17) e dos näo-mutuár ios (162)"

Essa Tabela revela que, em média, os produtores da amostra exploram area superior a possuida (1.73 contra 126 ha), o que enfatiza a prática do arrendamento de terras de terceiros além disso, alcancam uma receita operacional liquida (valor bruto da producio c.. despesas operacionais) positivan Isto é verificado tanto em termos absolutos (RS

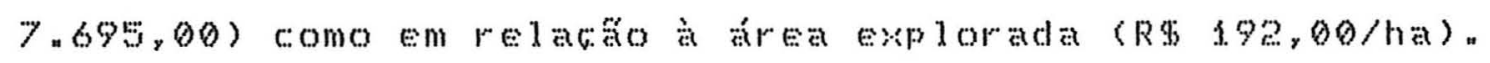

outro ponto que chama a atencia te o baiso nived de escolaridade detectado entre os produtores apenas seis anos de educacto formal. Essa informatăo näo considera a 
Tabela 4.7.- Indicadores Econônicos Médios da Atividade Agrícola e Fatores Associados ao Desempenho Econômico dos Produtores da Amostra, Segundo a Situação de Mútuo e o Tipo de Crédito Rural Recebido, Brasil, Ano Agrícola 1989/90, Safra de Verão. (1)

\begin{tabular}{|c|c|c|c|c|c|c|}
\hline \multirow[t]{2}{*}{ Indicador } & \multirow[t]{2}{*}{ Amostra } & \multicolumn{4}{|c|}{$\begin{array}{l}\text { Mutuário } \\
\text { de Crédito } \\
\text { Rural }\end{array}$} & \multirow{2}{*}{$\begin{array}{l}\text { Não } \\
\text { Mutuário } \\
\text { de } \\
\text { Crédito } \\
\text { Rural } \\
\\
\langle n=162)\end{array}$} \\
\hline & & $\begin{array}{l}\text { Formal } \\
(n=63)\end{array}$ & $\begin{array}{l}\text { Informal } \\
(n=33)\end{array}$ & $\begin{array}{l}\text { Ambos } \\
(n=21)\end{array}$ & $\begin{array}{c}\text { Total } \\
(n=117)\end{array}$ & \\
\hline - Area Possuida (ha) & 126 & 242 & 68 & 106 & 172 & 94 \\
\hline .Area Explorada (ha) & 173 & 315 & 137 & 298 & 262 & 110 \\
\hline $\begin{array}{l}\text {. Despesa Operacional } \\
(R \Phi 1,00)\end{array}$ & 36.254 & 64.511 & 34.648 & 76.574 & 58.253 & 20.366 \\
\hline $\begin{array}{l}\text {. Valor Bruto da Produrão } \\
(R \$ 1, \theta 0)\end{array}$ & 43.949 & 88.680 & 34.301 & 74.600 & 70.816 & 24.547 \\
\hline $\begin{array}{l}\text {.Despesa/Area Expl. } \\
(\mathrm{RS} 1,00 / \mathrm{ha})(2)\end{array}$ & 250 & 272 & 229 & 270 & 260 & 242 \\
\hline $\begin{array}{l}\text {.Valor Producfão/Área Expl. } \\
(\mathrm{R} \$ 1,00 / \mathrm{ha})\end{array}$ & 442 & 391 & 404 & 303 & 379 & 489 \\
\hline .Educação Formal (anos) & 6 & 7 & 5 & 8 & 7 & 5 \\
\hline
\end{tabular}

Fonte: Dados da Pesquisa.

(1) Valores monetários expressos Em RS de setembro de 1994.

(2) 0s resultados foram obtidos mediante a divisão do valor total das despesas/ha e da producão/ha individuais pelo número total de produtores da amostra ou sub-amostra (n). Esse procedimento difere, substancialmente, da divisão do valor médio da despesa/producão pela área média explorada. 
possibilidade de reprovacăo escolar, mas sugere a existencia de altos indices de evaso esocolar, principalmente no meio rural"

Especificamente em relaca a a credito rupal, observan se que os resultados médios da atividade desenvolvida pelos mutuários ság ma iores que os dos násomutuarios em termos de area explorada, despesas operacionaise valor da producáon Eim termos absolutos, a receita operacional lípuda dos

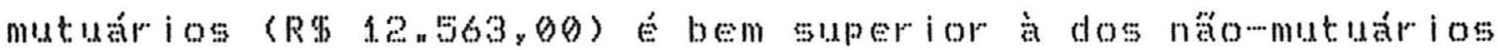

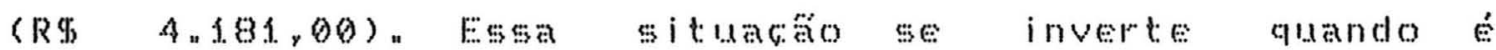
considerada a receita operacional liquida por hectare

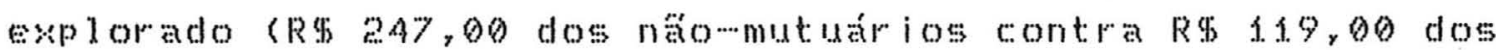
mutuários)"

Por sua vez, dentre os mutuarios, os de ceredito formal săo os que obtém a maior receita operacional liquida em

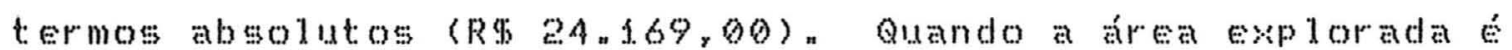
ut i l ianda como denominador, os tomadores exclusivos de fontes informats demonstram o melhor resultado (R\$) $175,00 / h a)$. 0 s que ut i 1 i zam ambas as fontesexibem receita mais estreita $(R \% 33,00)$.

Relativamente ao nivel de escolaridade media dos produtores notase que o dos mutuarios (y anos) é superior ao da amostra como um todo (b anos) a ao dos nábomuturios 
(s anos) n Esta evidencia pode ser indicativa de que o nível

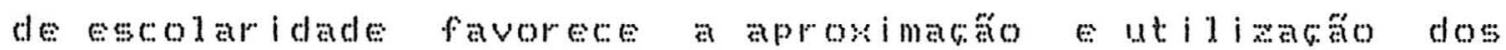
mercados de crediton corrobora esta afirmaco o fato de o nivel medio de escolar idate dos mutuar ios que ut i i anm ma de uma fonte de crétito, simultaneamente, ser de 8 anos de educat: formaln

Após anal isar as caracteristicas da amostra como um todor e interessante observar e comparar aspectos referentes aos grupos de produtores em cada tipo de agricultura com este propósito, apresentamsenas rabedas 4.8. a 4.10. alguns indicadores medios da atividade agricola fe fatores associados ao desempenho economico dos produtores dos grupos f. (pequeno porte e baika renda), e (comerciais) e 3 ( 1 arga escala) "

0 exame das rabelas revela que tanto a área méclia possuida como a explorada aumentam do grupo f para o 3 . Além disso, percebewse que os produtores do grupo exploram apenas a área que possuem, náo recorrendo ao arrendamento de outras terrasn 0 s produtores do grupo 3 exploramy em médiar área 60\% maior que a possuidan Em estágio intermediario, os do grupo es detem uma relacáo area explorada/rea possuida em torno de f, 4 n 
Tabela 4.8.- Indicadores Econômicos Médios da Atividade Agricola e Fatores Associados ao Desempenho Econômico dos Agricultores de Pequeno Porte e Baixa Renda (Grupo 1), Segundo a Situarão de Mútuo e o Tipo de Crédito Rural Recebido, Brasil, Ano Agricola 1989/90, Safra de Verão. (1)

\begin{tabular}{|c|c|c|c|c|c|c|}
\hline \multirow[t]{2}{*}{ Indicador } & \multirow[b]{2}{*}{$(n=111)$} & \multicolumn{4}{|c|}{$\begin{array}{l}\text { Mutuário } \\
\text { de Crédito } \\
\text { Rural }\end{array}$} & \multirow{2}{*}{$\begin{array}{l}\text { Năo } \\
\text { Mutuário } \\
\text { de } \\
\text { Crédito } \\
\text { Rural } \\
\\
(n=93)\end{array}$} \\
\hline & & $\begin{array}{l}\text { Formal } \\
(n=3)\end{array}$ & $\begin{array}{l}\text { Informal } \\
(n=14)\end{array}$ & $\begin{array}{l}\text { Ambos } \\
(n=1)\end{array}$ & $\begin{array}{l}\text { Total } \\
(n=18)\end{array}$ & \\
\hline - Area Possuida (ha) & 56 & 9 & 10 & 10 & 9 & 64 \\
\hline . Area Explorada (ha) & 56 & 9 & 10 & 10 & 11 & 65 \\
\hline $\begin{array}{l}\text {.Despesa Operacional } \\
(\mathrm{R} \$ 1, \theta 0)\end{array}$ & 2.260 & 2.813 & 1.100 & 3.173 & 1.590 & 2.408 \\
\hline $\begin{array}{l}\text {.Valor Bruto da Producão } \\
(R \$ 1,00)\end{array}$ & 3.641 & 5.629 & 1.881 & 6.431 & 2.991 & 3.767 \\
\hline $\begin{array}{l}\text {.Despesa/Area Expl. } \\
(\mathrm{RS} 1,00 / \mathrm{ha})(2)\end{array}$ & 120 & 352 & 163 & 317 & 204 & 103 \\
\hline $\begin{array}{l}\text {. Valor Producão/Area Expl. } \\
(R \$ 1,00 / \mathrm{ha})\end{array}$ & 266 & 541 & 350 & 643 & 399 & 240 \\
\hline -Educacãa Formal (anos) & 3 & 3 & 3 & 1 & 3 & 3 \\
\hline
\end{tabular}

Fonte: Dados da Pesquisa.

(1) Valores monetários expressos em RS de setembro de 1994.

(2) 0s resultados foram obtidos mediante a divisão do valor total das despesas/ha e da produçäo/ha individuais pelo número total de produtores da amostra ou sub-amostra (n). Esse procedimento difere, substancialmente, da divisão do valor médio da despesa/produção pela área média explorada. 
Tabela 4.9.- Indicadores Econômicos Médios da Atividade Agricola e Fatores Associados ao Desempenho Econômico dos Agricultores Comerciais (Grupo 2), Segundo a Situakão de Mútuo e - Tipo de Crédito Rural Recebido, Brasil, Ano Agricola 1989/90, Safra de Verão. (1)

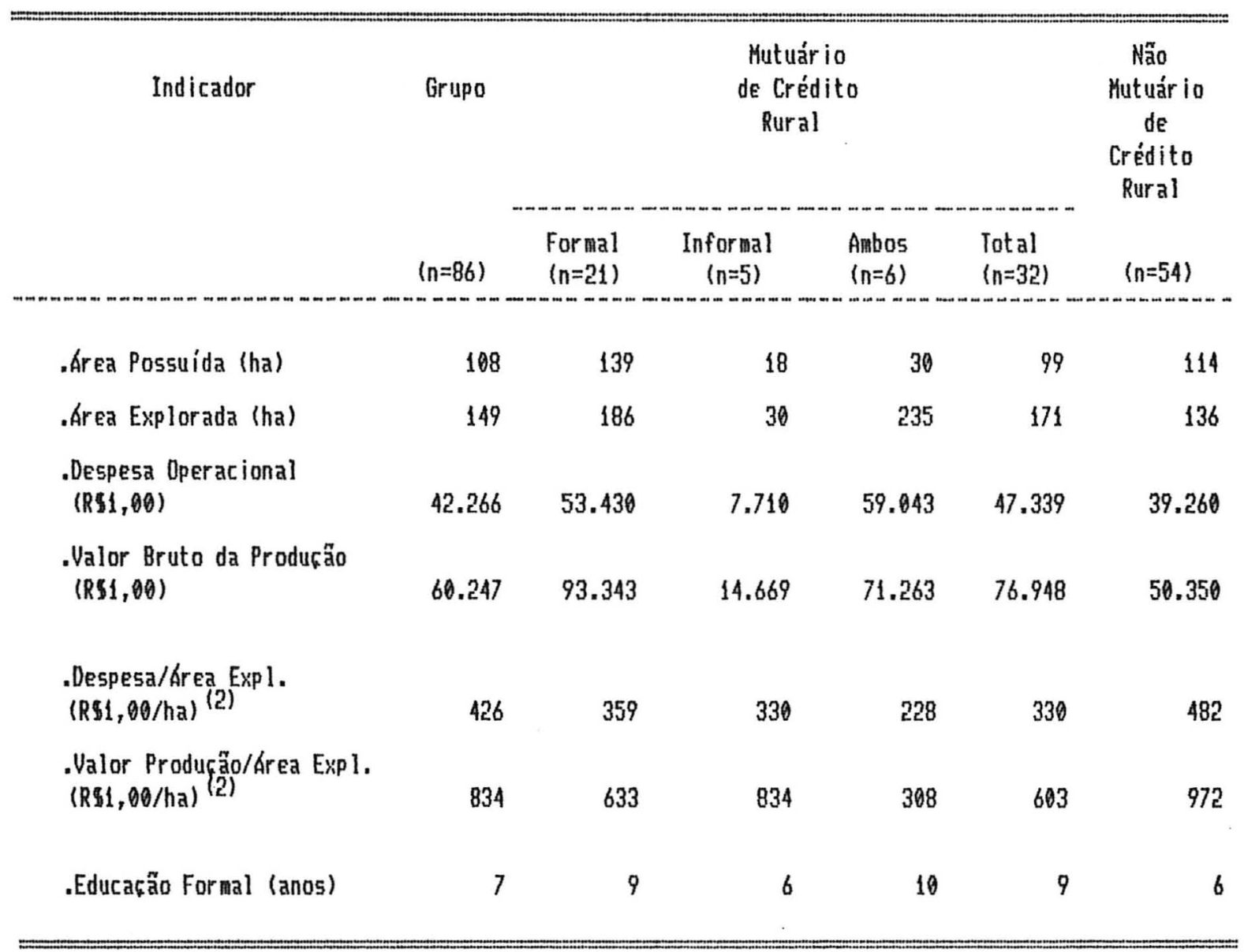

Fonte: Dados da Pesquisa

(1) Valores monetários expressos ell R\$ de setembro de 1994.

(2) Os resultados foram obtidos mediante a divisẫo do valor total das despesas/ha e da producão/ha individuais pelo número total de produtores da amostra ou sub-amostra (n). Esse procedimento difere, substancialmente, da divisão do valor médio da despesa/produção pela área média explorada. 
Tabela 4.10.- Indicadores Econômicos Médios da Atividade Agrícola e Fatores Associados ao Desempenho Econômico dos Agricultores Comerciais em Larga Escala (Grupo 3), Segundo a Situação de Mútuo e o Tipo de Crédito Rural Recebido, Brasil, Ano Agrícola 1989/90, Safra de Verão. (1)

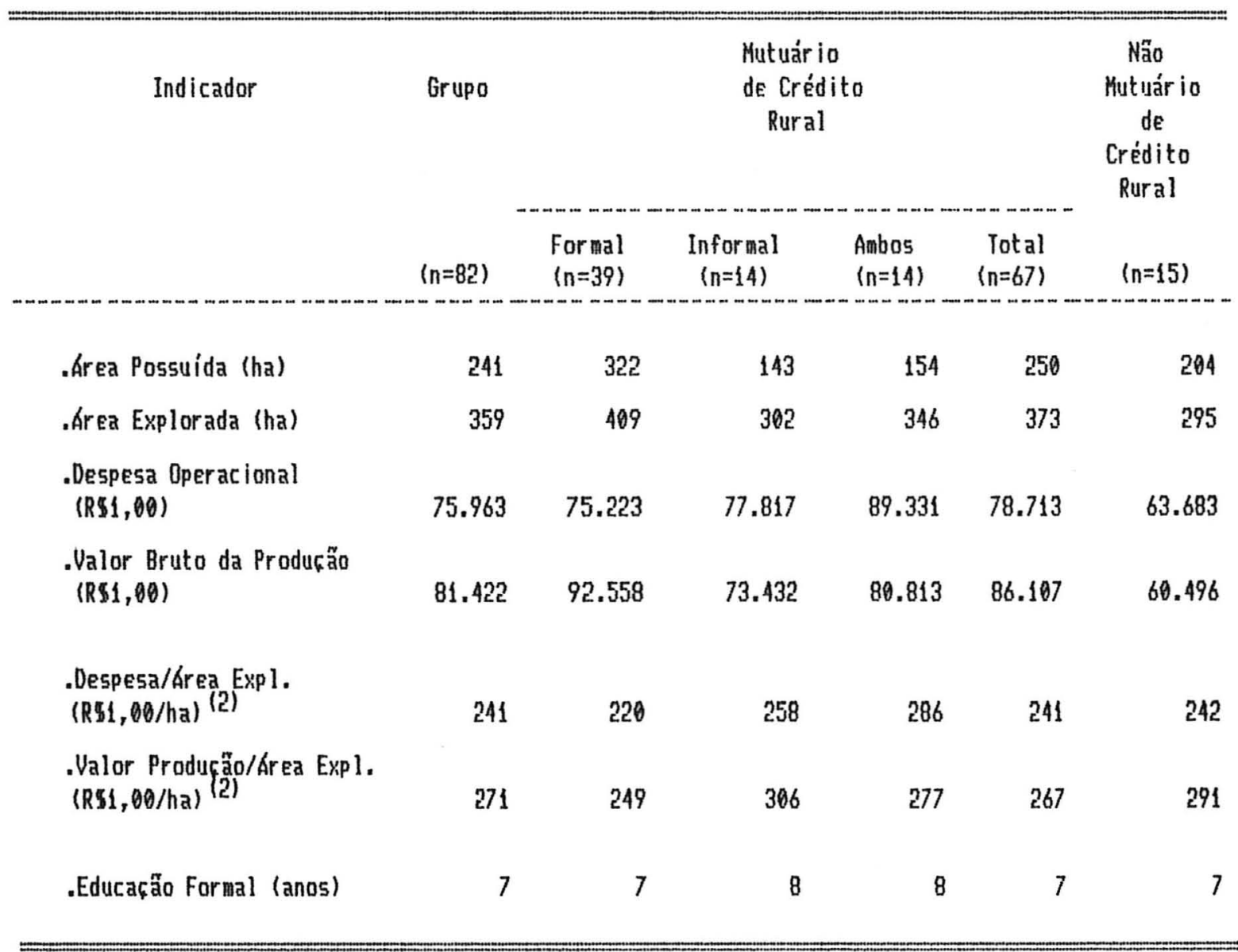

Fonte: Dados da Pesquisa.

(1) Valores monetários expressos EN RS de setembro de 1994.

(2) 05 resultados foram obtidos mediante a divisão do valor total das despesas/ha e da produçäo/ha individuais pelo número total de produtores da amostra ou sub-amostra (n). Esse procedimento difere, substancialmente, da divisão do valor médio da despesa/produção pela área média explorada. 
Quanto às despesas operaciona is a a valor da producăo colnida, nota-3e posicionamento semelhante ao da area valores adcancados pelo grupo 3 sta superiores aos do grupo e. que, por sua vez, superam os do grupo f.

Da andise das despesas operacionais/ha do valor

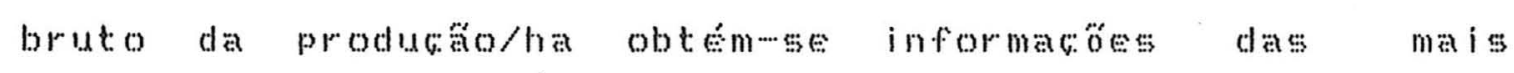
interessantesn Na médiay a receita operacional liquida do grupo ge expressivamente superior (R\$ $408,00 /$ a $)$ a dos

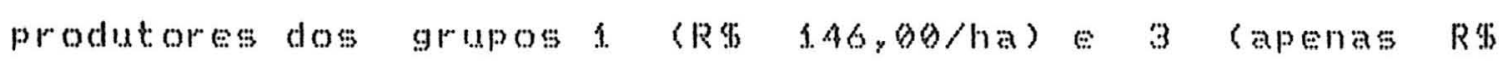
$30,00 / \mathrm{h}$ ) situacto tipica dos produtores anal isados, pode se concluir que: a) os produtores comercias que utilian cam atal intensivamente tem maior capacidade de autowinanciamentop b) os pequenos produtores por ut i lizarem, basicamentey mán dewobra familiar tem custos reduzidos por hectarey o que thes proportiona methor nivel de receitan c) os agricultores em larga escala enfrentam eseros problemas de l iquidezer por isso, tem ma or propensâno a endividamenton

Considerando, agoray os indicadores de desempenho entre mutuarios e nátomutuar ios de coredito, observacse que 8en dos produtores do grupo 3 sámo muturios de qualquer tipo de ciedito, contra $37 \%$ do grupo e e apenas $16 \%$ do grupo f. Tsso ratifica o gue foi discutido anteriormente com relacáto de demanda por liquidez dos produtores em larga 
escalan Adicionalmente, verificase que a receita operacional liquida dos mutuarios é superior a dos náon mutuart os nos três grupos

Anal iando apenas os tomadores de emprest imosy notane que nos tress grupos, como esperado, os tomadores de emprestimo formal säo os que operam a maior escala de

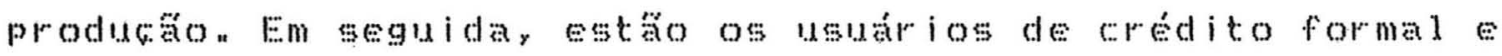
informal simultaneamente es por filtimo, aqueles que buscam (iredito apenas em fontes informas n Nesesesentidoy vale sempre lembrar que o acesso ano coredito formal está 1 igaco a uma estrutura operacional que, normalmente, exige garantias reats do tomador.

A esta altura pocesse, portanto, acomitir que a liquidez adicional obtida nos mercados financeiros rurais é um dos fatores que contribuem para o melhor desempenho economico dos proutores.

\subsubsection{Características dos Empréstimos}

A seguir, saco apesentados e discutidos os resultados sobre as caracteristicas dos emprestimos formas e informa 5 , em termos da amostra como um todo e dos grupos de produtores agricolas 
A rabela 4 1. 1. apresenta a final idade dos emprestimosy tomados pelos produtoresmmtuarios ${ }^{15}$ "Nota a que que tanto na amostra como nos grupos, o custeio da producaso a finalidade predominante em emprestimos formats es informats 0s invest imentos säo prineipadmente financiados através do SNCR , Fato interessante é que näo foram identificados emprestimos de comercializagón Apenas um empréstimo para consumo famili ar foi realiandon

A rabeda Ande apresenta as prineipais fontes formais e: informals de financi iamento ut i l iadas pelos tomadores de coredito no ano agricola $1989 / 90$.

o exame da referida Tabela evidencia que, no mercado formal os bancos oficiais respondem por $95 \%$ dos emprestimosn 0s bancos privados e as cooperativas tem participacto mu to rectuzidan

Entre os agentes informas, merecem destaque as firmas que comercializam insumos e/ou produtos, respondendo por cerca de 7on do total de emprestimos n Em seguida estäo as

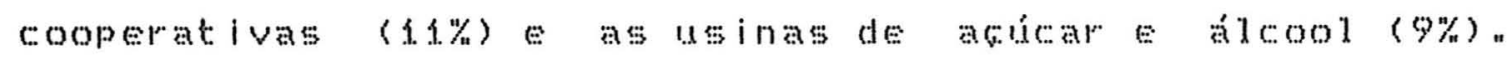

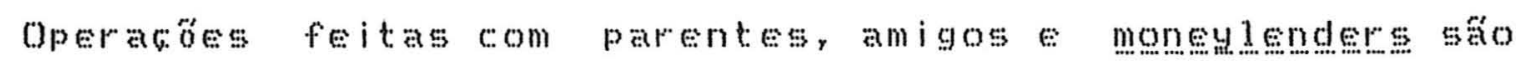
minoria.

15 E.:m se tratando de finalidade dos emprestimos, năo se deve perder de vista a questa da fungibilidade do dinheiroy discutida no capitulo 3 . 
Tabela 4.11.- Empréstimos Formais e Informais, Segundo Grupos de Produtores e Finalidade dos Empréstimos, Brasil, Ano Agrícola 1989/90, Safra de Verão. (1)

\begin{tabular}{|c|c|c|c|c|c|c|c|}
\hline & \multicolumn{3}{|c|}{$\begin{array}{c}\text { Empréstinos } \\
\text { Formais }\end{array}$} & \multicolumn{4}{|c|}{$\begin{array}{l}\text { Empréstinos } \\
\text { Informais }\end{array}$} \\
\hline & Custeio & Invest inento & Total & Custeio & Invest inento & $\begin{array}{l}\text { Consuno } \\
\text { Faniliar }\end{array}$ & Total \\
\hline Amostra & 74 & 10 & 84 & 49 & 4 & 1 & 54 \\
\hline Grupo 1 & 4 & 0 & 4 & 14 & 0 & 1 & 15 \\
\hline Grupo 2 & 23 & 4 & 27 & 8 & 3 & $\theta$ & 11 \\
\hline Grupo 3 & 47 & 6 & 53 & 27 & 1 & 0 & 28 \\
\hline
\end{tabular}

Fonte: Dados da Pesquisa.

(1) Os grupos de produtores sâo os seguintes: a) grupo 1 = agricultores de pequeno porte e baixa renda; b) grupo 2 = agricultores comerciais; $E$, c) grupo $3=$ agricultores en larga escala. 
Tabela 4.12.- Empréstimos Formais e Informais, Segundo Grupos de Produtores e Origen dos Recurs05, Brasil, Ano Agrícola 1989/90, Safra de Verão.(1)

\begin{tabular}{|c|c|c|c|c|c|c|c|c|c|}
\hline & \multicolumn{3}{|c|}{$\begin{array}{c}\text { Emprésti ios } \\
\text { Formais } \\
(n=84)\end{array}$} & \multicolumn{6}{|c|}{$\begin{array}{l}\text { Eaprést inos } \\
\text { Informais } \\
\text { (n=54) }\end{array}$} \\
\hline & $\begin{array}{c}\text { Bco. } \\
\text { Oficial }\end{array}$ & $\begin{array}{l}\text { Bco. } \\
\text { Privado }\end{array}$ & Cooperat & Cooperat & $\begin{array}{c}\text { Firua } \\
\text { Insuga } \\
\text {-Produto }\end{array}$ & Agiota & $\begin{array}{l}\text { Awigo } \\
\text { E/ous } \\
\text { Parente }\end{array}$ & $\begin{array}{c}\text { Assoc. } \\
\text { de } \\
\text { Produtor }\end{array}$ & $\begin{array}{c}\text { Usina } \\
d e \\
\text { Alcool }\end{array}$ \\
\hline .Amostra & 80 & 1 & 3 & 6 & 39 & 1 & 2 & 1 & 5 \\
\hline Grupo 1 & 4 & 0 & 1 & 1 & 8 & 0 & 0 & 1 & 5 \\
\hline Grupo 2 & 23 & 1 & 3 & 4 & 7 & 1 & 0 & 0 & 0 \\
\hline Grupo 3 & 53 & 0 & 0 & 1 & 24 & 1 & 2 & 0 & 0 \\
\hline
\end{tabular}

Fonte: Dados da Pesquisa.

(1) Os grupos de produtores são os seguintes: a) grupo 1 = agricultores de pequeno porte e baixa renda; b) grupo 2 = agricultores comerciais; $\varepsilon, c)$ grupo $3=$ agricultores e larga escala. 
Mencăo especial deve ser feita ao grupo dos agricultores em larga escalan sua participacán no total de emprestimos formats e informais ésignificativa sa $63 \%$ e :en, respectivamente. No mercado formal, os financiamentos desses produtores estaco concentrados em bancos of icia is

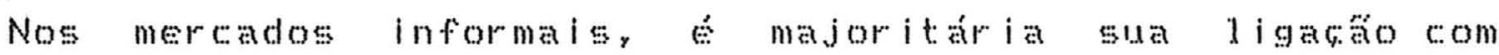
firmas de insumo/produton

Nos mercados informats, um apresivel numero de unidaces de valor/conta é utilizado nos empreste imos n Tabeda 4ns3n apresenta as unidades utilizadas nos emprest imos informats no ano agricola $1989 / 90$. Dentre as observadas, a saca de soja é a ma s ut i ianda, superando ligeiramente as operacoses feitas em dinheiron

Para o tomador, a utilizacáco um produto agrícola especifico como indexador físico das operacose informais ér. em parter reflexo da instabi 1 idade economica que o país tem atravessadon fí grande orecelo de que taxas de juros crescentes, devido à inflacáro, resultem en redaço preso do produto, indexador financeiro decrescente Recentemente, esse sistemat comum nos mercados informas, foi absorvido com algumas variacoses pelo mercado formal na chamada "equivalênci i aprocotuto" 
Tabela 4.13.- Empréstimos Infornais, Segundo Grupos de Produtores e Unidade de Valor, Brasil, Ano Agrícola 1989/90, Safra de Verão.(1)

\begin{tabular}{|c|c|c|c|c|c|c|}
\hline \multirow[t]{2}{*}{ Produt or } & \multicolumn{6}{|c|}{$\begin{array}{l}\text { Unidade } \\
\text { de } \\
\text { Valor }\end{array}$} \\
\hline & Dinheiro & $\begin{array}{l}\text { Saca } \\
\text { de } \\
\text { Soja }\end{array}$ & $\begin{array}{c}\text { Saca } \\
\text { de } \\
\text { Milho }\end{array}$ & $\begin{array}{l}\text { Arrob่ } \\
\text { de } \\
\text { Algodaึo }\end{array}$ & $\begin{array}{l}\mathrm{Kg} \\
\mathrm{de} \\
\text { Fumo }\end{array}$ & $\begin{array}{c}\text { Tonelada } \\
\text { de } \\
\text { Cana-de-Acúcar }\end{array}$ \\
\hline Amostra $(n=54)$ & 20 & 21 & 2 & 1 & 7 & 3 \\
\hline Grupo $1(n=15)$ & 4 & 0 & 1 & 0 & 7 & 3 \\
\hline Grupo $2(n=11)$ & 5 & 6 & 0 & $\theta$ & 0 & $\theta$ \\
\hline Grupo $3(n=28)$ & 11 & 15 & 1 & 1 & 0 & 0 \\
\hline
\end{tabular}

Fonte: Dados da Pesquisa.

(1) Os grupos de produtores são 05 seguintes: a) grupo 1 = agricultores de pequeno porte e baixa renda; b) grupo 2 = agricultores comerciais; E, c) grupo $3=$ agricultores en larga escala. 
Em relacaro aos emprestimos, pode se observar na rabela 4.1.4. os valores máximoy mínimo e médio para o montante principal, prazo da operaga taxa real de juros dos empréstimos formats e informals "Adicionalmente, no caso dos emprestimos formais, a rabela exibe o custo de transacáo para o tomador. o mesmo näo acontece para os emprestimos informa is devido a falta de informacoses

Convém notar que o mímero de emprestimos forma is é ma ior que o de informa emprestado e prazo das operacoses o credito formal supera o informal nos tress niveis analisados cmásimo, minimo e. medio) "Tais resultados sto coerentes com a descricáco feita no Capitulo e (vide Tabela en. n)"

Como reflexo da liberdade financeira nos mercados informats e da administracto das taxas de juros no mercado formal, o juro read dos emprestimos informats mostra maior amplitude de variaga (96 pontos percentuates que a dos formas (29 pontos percentuais). Fom termos medios, a taxa real de juros nos emprestimos informas é 3 vezes superior a taxa registraca nas operacoses forma

Näo se deve esquecer, porém, que ao credito formal está associaclo um alto custo de transacán para o tomador 
Tabela 4.14.- Caracteristicas dos Empréstimos Formais e Informais Tomados pelos Produtores da Amostra, Brasil, Ano Agrícola 1989/90, Safra de Verão.(1)

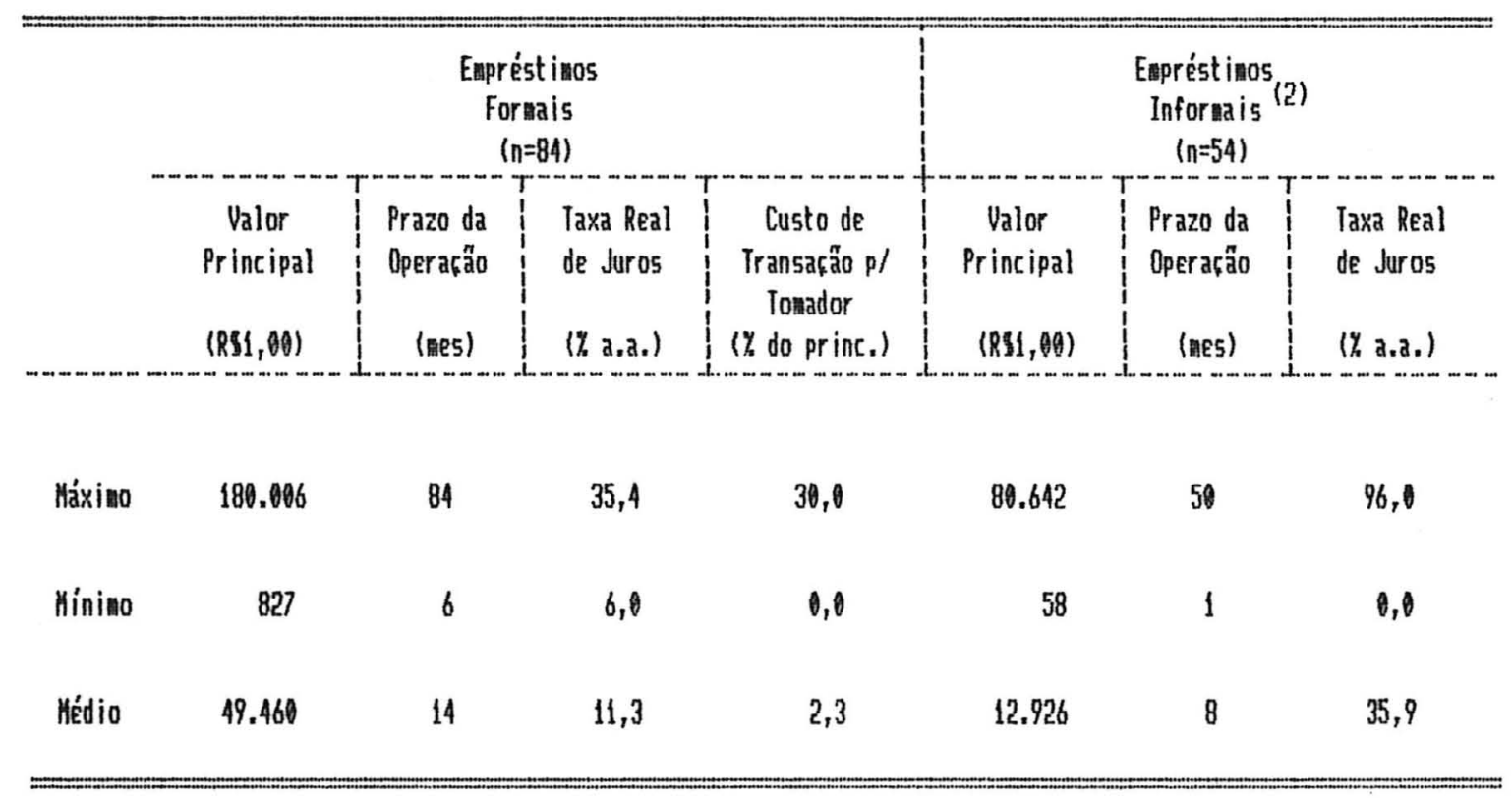

Fonte: Dados da Pesquisa.

(1) Valores monetários expressos Em R\$ de setembro de 1994.

(2) A falta de informaçóes não permitiu a obtenção de estimativas dos custos de transaçấ para o tomador. 
Na rabela 4.1.4. observace que, no valor másmo, o custo de transaca para o tomador do emprestimo at inge $30 \%$ do valor principal tsto significa gus para cada unidade monetaria pleiteada o tomador recebe, efet ivamente, 70 centavos . Mesmo em termos mediosy näo sáo despreziveis os 2.3\% de custo de transactio que o tomador de emprestimos formats desembolsa para obter recursos do SNCR.

Em média, os emprestimos de cada grupo de produtores

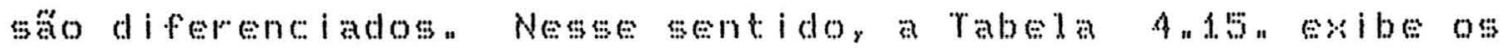
Valores másimo, mínimo e medio referentes ao principal, prazo e taw real de juros dos emprestimos forma s e informas de cada grupon os custos de transacáo na tomada de emprést imos forma is sâo também apresentados n

Em termos de valor principal, observace calaramente que os produtores comerciais săo os que obtêm emprest lomos de ma or valor nos tres niveis apresentados cmaximo, mínimo e medio) nos mercados financeiros

Nos tres grupos de produtores os emprestimos informats têm prazo menor, prineipalmente pelo risco e custo envolvidosn Os produtores do grupo f obtém prazo medio anda menor que os dema is os mutuarios dos grupos e? 3 conseguem prazos mais longos, possivelmente por efeturem investimentos em bens de capitaln 
Tabela 4.15.- Características dos Empréstimos Formais e Informais, Segundo Grupos de Produtores, Brasil, Ano Agrícola 1989/90, Safra de Verão.(1)

\begin{tabular}{|c|c|c|c|c|c|c|c|}
\hline Grupos (2) & & & $\begin{array}{l}\text { rést inos } \\
\text { ornais } \\
1=84)\end{array}$ & & & $\begin{array}{l}\text { préstimos } \\
\text { nforma is } \\
(n=54)\end{array}$ & \\
\hline & $\begin{array}{c}\text { Valor } \\
\text { Principal } \\
(R 31,39)\end{array}$ & $\begin{array}{l}\text { Prazo da } \\
\text { Operabão } \\
\text { (mes) }\end{array}$ & $\begin{array}{l}\text { Taxa Real } \\
\text { de Juros } \\
(\% \text { a.a.) }\end{array}$ & $\begin{array}{l}\text { Custo de } \\
\text { Iransarâa } \mathrm{p} / \\
\text { Touador } \\
\text { (\% do princ.) }\end{array}$ & $\begin{array}{c}\text { Valor } \\
\text { Principal } \\
(R \$ 1, \theta 9)\end{array}$ & $\begin{array}{c}\text { Prazo da } \\
\text { Operacano } \\
\text { (acs) }\end{array}$ & $\begin{array}{l}\text { Taxa Real } \\
\text { de Juros } \\
\text { (Y a.a.) }\end{array}$ \\
\hline Grupo $1(n=4)$ & & & & & Grupo $f(n=15)$ & & \\
\hline Máxino & 5.224 & 12 & 12,0 & 1,4 & 2.154 & 11 & 83,4 \\
\hline Hinimo & 910 & 12 & 7,0 & 0,1 & 58 & 1 & $\theta, \theta$ \\
\hline Médio & 2.947 & 12 & 10,7 & 0,5 & 621 & 6 & 50,1 \\
\hline Grupo 2 (n=27) & & & & & Grupo $2(n=11)$ & & \\
\hline Máxino & 180.006 & 84 & 35,4 & 30,0 & 23.934 & 50 & 87,7 \\
\hline Mínilu & 827 & 6 & 6,0 & 0,0 & 70 & 1 & 0,0 \\
\hline Hédio & 50.796 & 16 & 11,5 & 1,2 & 5.461 & 12 & 29,8 \\
\hline Grupo $3 \quad(n=53)$ & & & & & Grupo $3(n=28)$ & & \\
\hline Háxino & 157.387 & 60 & 29,5 & 29,6 & 80.642 & 11 & 96,0 \\
\hline Minimo & 1.906 & 6 & 8,0 & 0,0 & 78 & 4 & 0,0 \\
\hline Hédio & 52.290 & 13 & 11,2 & 3,0 & 22.449 & 8 & 30,7 \\
\hline
\end{tabular}

Fonte: Dados da Pesquisa.

(1) Valores monetários express0s en RS de setembro de 1994.

(2) Os grupos de produtores são os 5eguintes: a) grupo 1 = agricultores de pequeno porte e baixa renda; b) grupo 2 = agricultores comerciais; E, c) grupo 3 = agricultores ent larga escala.

(3) A falta de informaçôes não permitiu a obtenção de estimativas dos custos de transą̧ão para o tomador. 
Em relacáo as taxas de juros, os emprest imos informa mostram variacta ampla e manitude superior as registradas nos emprestimos formais nos niveis maximo es médion

Especialmente em relacăo aos financiamentos informats vade a pena ressaltar a sua importancia nos sistemas de producfo agricola desenvolvidos pelos produtores da amostran A rabela 4.1.6. demonstra a participacáo média do coredito informal no total de ceredito recebido, nas despesas

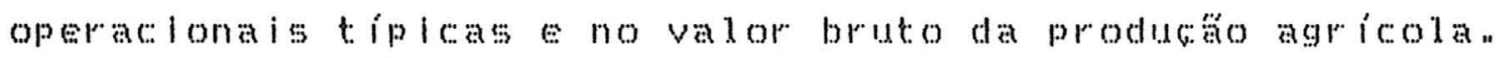
Quanto ao crécito total recebido for am coneiderados apenas os casos em que oprodutor utilizou, simultaneamente. fontes formais e informais.

De modo geral, o financiamento informal representar em médiar 29\% dos creditos obtidos pelos produtores da

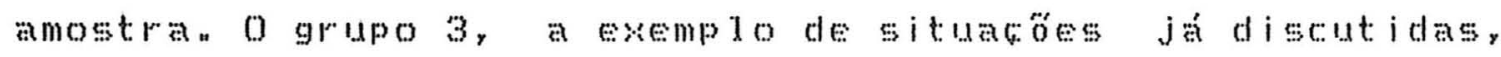
revela maior uso de eredito informal, reflexo provavel da general iacata do escambo soja por insumos e/ou servi gosn

Em se tratando das despesas operacionais tipicas Verificanse, na amostra como um todo, que os emprestimos obtidos informalmente equivalem a $39 \%$ dessas despesas Notanse ainday que entre os agricultores de ba (G1) os emprest imos informa is corpespondem a by do total das despesas 
Tabela 4.16. Participação Percentual Média do Crédito Informal Recebido por Produtores Rurais no Crédito Total Recebido, Valor Bruto da Produçäo Agrícola e Despesas Operacionais Típicas da Producão, Segundo Grupos de Produtore5, Brasil, Ano Agrícola 1989/90, Safra de Verão. (1)

\begin{tabular}{|c|c|c|c|}
\hline Grup05 & $\begin{array}{c}\text { Informal } \\
/ \\
\text { Crédito Total (2) } \\
(\%)\end{array}$ & $\begin{array}{c}\text { Informal } \\
/ \\
\text { Despesas } \\
(\%)\end{array}$ & $\begin{array}{l}\text { Informal } \\
\text { U. Produkão } \\
(\gamma)\end{array}$ \\
\hline Amostra & 29 & 39 & 30 \\
\hline Grupo 1 & 25 & 57 & 26 \\
\hline Grupo 2 & 25 & 28 & 19 \\
\hline Grupo 3 & 32 & 34 & 36 \\
\hline
\end{tabular}

Fonte: Dados da Pesquisa.

(1) Os grupos de produtores são os seguintes: a) grupo 1 = agricultores de pequeno porte e baixa renda; b) grupo 2 = agricultores comerciais; $\varepsilon_{r}$ c) grupo $3=$ agricultores em larga escala.

(2) No crédito total recebido foram considerados apenas casos em que o produtor utilizou, simultaneamente, fontes formais e informais. 
Tomando-me o valor da producta como base de cáleulo, observa-se que o crédito informal equivale a $30 \%$ do valor do produto agrícola médio da amostra Dentre os grupos, o ma ior percentual corresponde ao grupo $3(36 \%)$. Em seguida, aparecem os grupos $1.26 \%)$ e $2(19 \%)$ n

Esses valores médios indicam a manitude e sugerem a importancia do financiamento informal para os agricultores das regióes estudadas, principalmente no caso dos de pequeno porte baika rendan

\subsection{Análise da Demanda por Liquidez em Fontes Informais}

A fim de testar o modelo econometrico tobit especificado anteriormente, foram realizados po ajustamentos, considerando formas alternativas de mensurar algumas das variáveis selecionadas (vide Apéndice),

o fato de a tawa de juros do créclito informal näo estar explicita em boa parte das operacoses dificulta ao produtor conhecer sua exata magnitude "por esse motivo, a var iavel taka real de juros do credito informal (JURTNF) foi mensurada e testada em termos mensais e anuais. A variável custo financeiro do crédito formal (CSTFor) também foi submetida ao mesmo tratamento. No presente estudo, os resultados revelam que, a taka real de juros do crédito 
informal (JURTNF) E o (usto financeiro do coredito formal (CSTroR) mostram melhor ajuste quando em base mensal n

Outra varivel testada foi a categoria do produtor (CATPRD)" Na proposicaro do modelo economico duas poss ib i idades for am consideradas a area explorada (AREXPL) evalor bruto da producáto agricola (UALPRD)" Os melhores resultados estatisticos sâo obtidos quando a categoria do proclutor é medida pela área exploradan

Para o ajustamento do modedo foi ut il iado o programa

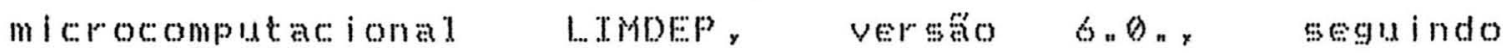
procedimentos indicados em (BREENE (1991) n A estimacín do modelo foi realiada para a amostra como um todo e para os três grupos de agricultores (o1, Ge e G3)"

A analise dos resultados baseouseser principalmenter na coerencia das relacóses economicas no sinal e estabilidade dos toeficientes de regressato er tambem, na sua significancia estat: istican

A Tabeda 4. 17. apresenta o ajustamento selecionaclo com as estimativas dos coeficientes das variaveis e respectivos valores do teste "to para a amostra de eqg agricultores. 
Tabela 4.17.- Estimativa dos Paranmetros das Relaçôes entre o Valor dos Empréstimos nos Mercados Informais e Fatores Condicionantes da Demanda por Liquidez na Amostra de Produtores, Brasil, Ano Agrícola 1989/90, Safra de Verão. (1)

\begin{tabular}{|c|c|c|}
\hline \multirow{2}{*}{$\begin{array}{c}\text { Variável } \\
\text { Independente } \\
\text { (Xi) }\end{array}$} & \multicolumn{2}{|l|}{ Amostra } \\
\hline & Coeficiente & $\cdot t \cdot$ \\
\hline Termo Constante & $-32255, \theta$ & $-4,189$ \\
\hline $\begin{array}{l}\text { Juros Reais do Crédito } \\
\text { Informal (JURINF) }\end{array}$ & $-535,99$ & $-0,384$ \\
\hline $\begin{array}{l}\text { Valor do Crédito Formal } \\
\text { (UALFOR) }\end{array}$ & $-0,0047$ & $-0,060$ \\
\hline $\begin{array}{l}\text { Custo Financeiro do } \\
\text { Crédito Formal } \\
\text { (CSTFOR) }\end{array}$ & 1821,5 & 0,306 \\
\hline $\begin{array}{l}\text { Categoria do Produtor } \\
\text { Medida pela Área Explorada } \\
\text { (AREXPL) }\end{array}$ & $-31,193$ & $\begin{array}{r}-1,684 \\
(9,2 \%)\end{array}$ \\
\hline $\begin{array}{c}\text { Despesas Operacionais } \\
\text { da Producão Agricola } \\
\text { (DESOPE) }\end{array}$ & 0,2251 & $\begin{array}{r}2,899 \\
(0,4 \%)\end{array}$ \\
\hline $\begin{array}{l}\text { Educafão Formal } \\
\text { (EDUFOR) }\end{array}$ & 584,29 & 0,982 \\
\hline
\end{tabular}

Fonte: Dados da Pesquisa

(1) A amostra é constituida de 279 observaçőes.

(2) Os valores entre parênteses representam o nível de significância do teste "t" para os coeficientes significativamente diferentes de zero. 
f: importante ressaltar que para a amostra como um todo, o modelo mostrou ajustamento cons iderado apenas como regudar Entre os fatores que podem ter contributo para esse resultado destacase a precariedade nos dados quant itat ivos obtidos sobre as operacose informats uma ver que os questionarios aos produtores näo tinham por objetivo principal levantar dados sobre esse tipo de operagar informacoses preciosas para sestruturar um modelo mais adequado ficaram comprometidas ou, mesmo, ausentes. A limitacán nos registros sobre a oferta de recursos nesses mercedos, por exemplo, impossibilitou a inclusăo de variáveis que pudessem captar a influencia da disponibilidade de credito informal sobre a deciano do produtor

Outro fator importante \& a asencia de procedimento econometrico similar na literatura sobre intermediacáa informal, que pudesse orientar a consolidacto do presente modelo. Por esse motivo, a inda que a naturezaxploratoria do estudo justifique a tentativa, observacse algum prejúgo nos resultados.

Apesar disso, verificase pelos resultados que os coeficientes da regressta do modelo tobit mostram sinats

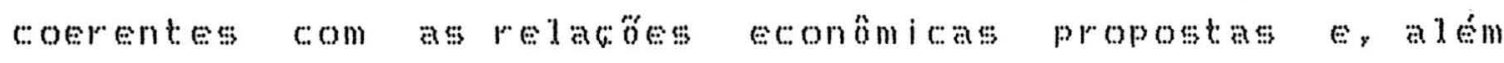
disso, sugerem uma estabilidade aceitavel " 
Anadisando os niveis designificheia, verificanse que

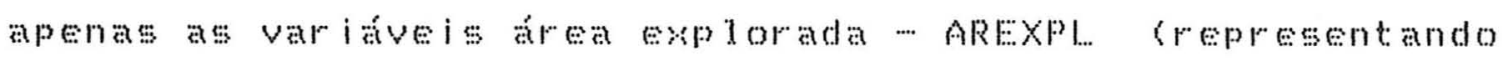
a categoria do produtor) e desesas operacionais tipicas a... DESOPE, mostram coeficientes significat ivamente diferentes

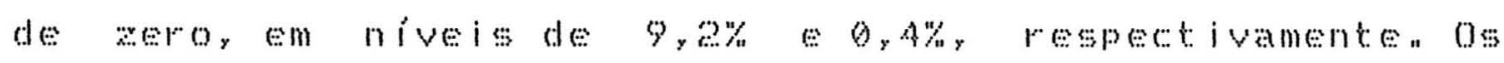
resultados indicam que o valor dos emprestimos informats diminu à medida em que a area explorada comese vicen versan Alem disso, observanse relacto direta entre as despesas operacionas tipicas da producaso agroda e o montante emprestado em fontes informa is de crediton

As demais variácis näsăo significativas do ponto de vista estatioticon No caso da taka real de juros do credito

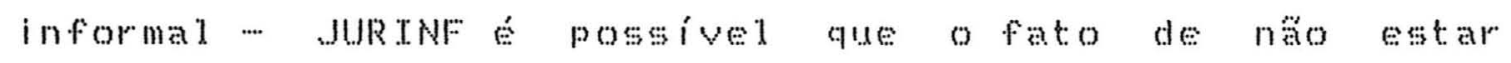
explicita na ma ior das operacose tenha mascarado o seu verdadeiro efeito na functa de demanda por l i guideza

As variáveis relativas ao credito formal (WAl..For e: Corfor) também näo contribuiram para explicar a demanda por l iquides informan Ainda que os sinats dos coeficientes tenham indicado o comportamento esperado em redaço a var iaved dependente: os respectivos niveis de eignificancia náo puderam ser aceitos. Assim sendor nenhuma reacaro de substituicaro ou complementaridade pode ger atribuida a essas var iaveis independent:es 


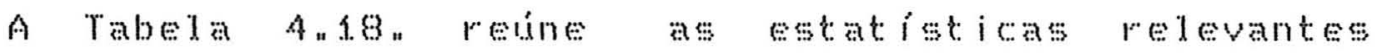
est imadas para a functán de demanda por l i quider nos mercados informa is do grupo f (agricultores de baixa renda) egrupos (agricultores em larga escala),

Para o grupo e? (agricultores comerciats) os resultados

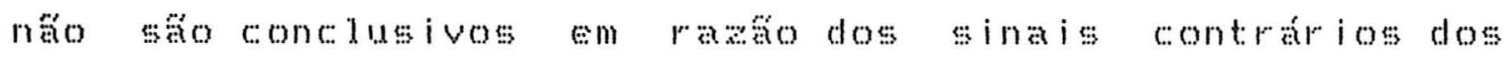
coeficientes de regressao e dos baimos niveis de gignificancian Uma eventual expl icacápara esse resultado seria o fato de os produtores desse grupo apresentarem uma receita operacional liquida media bem superior a dos produtores dos grupos a e 3 , o que thes possibilitaria ma ior capacidade de autowimanciamenton Essa parece ser uma explicacăo plasived, a julgar pela menor participacăo desses agricultores nos MFR Is (vide Tabeda $A_{n} G_{n}$ ),

No modedo economérico do grupo f. o preso dos recursos financeiros e a categoria do produtor sáo variaveis importantes na decisac de buscar liquidez adicional nos mercados informa is nostram-ges gonificativos a taxa read de juros cobracta no coredito informad -... JURTNFM $(10,9 \%), \quad$ o custo financeiro do coredito formal em base

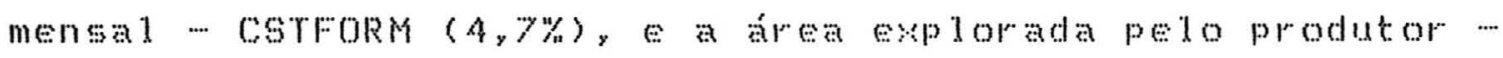
AREXPL... (1.5, 8\%) , 
Tabela 4.18.- Estimativa dos Parantetros das Relaçỏes entre o Valor dos Eapréstinos nos Hercados Informais e Fatores Condicionantes da Demanda por Liquidez nos Grupos de Produtores, Brasil, Ano Agrícola 1989/99, Safra de Verão. (1)

\begin{tabular}{|c|c|c|c|c|}
\hline \multirow{2}{*}{$\begin{array}{c}\text { Variável } \\
\text { Independente } \\
\text { (Xi) }\end{array}$} & \multicolumn{2}{|l|}{ Grupo 1} & \multicolumn{2}{|l|}{ Grupo 3} \\
\hline & Coeficiente & "t" & Coeficiente & "t" \\
\hline Termo Constante & $-2274,1$ & $-1,770$ & -13933 & $-0,901$ \\
\hline $\begin{array}{l}\text { Juros Reais do Crédito } \\
\text { Informal (JURINF) }\end{array}$ & $-199,65$ & $\begin{array}{r}-1,598 \\
(10,9 \%)\end{array}$ & $-4975,7$ & $\begin{array}{r}-1,493 \\
(13,5 \%)\end{array}$ \\
\hline $\begin{array}{c}\text { Valor do Crédito Formal } \\
\text { (VALFOR) }\end{array}$ & 0,0888 & 0,378 & $-0,0429$ & $-0,320$ \\
\hline $\begin{array}{l}\text { Custo Financeiro do } \\
\text { Crédito Formal } \\
\text { (CSTFOR) }\end{array}$ & 2765,0 & $\begin{array}{r}1,978 \\
(4,7 \%)\end{array}$ & $-3336,3$ & $-0,369$ \\
\hline $\begin{array}{c}\text { Categoria do Produtor } \\
\text { pela Area Explorada } \\
\text { (AREXPL) }\end{array}$ & $-26,043$ & $\begin{array}{r}-1,499 \\
(15,8 \%)\end{array}$ & $-99,15$ & $\begin{array}{l}-2,206 \\
(2,7 \%)\end{array}$ \\
\hline $\begin{array}{c}\text { Despesas Operacionais } \\
\text { da Produção Agricola } \\
\text { (DESOPE) }\end{array}$ & 0,0106 & 0,170 & 0,4615 & $\begin{array}{r}2,800 \\
(0,5 \%)\end{array}$ \\
\hline $\begin{array}{l}\text { Educaçăo Formal } \\
\text { (EDUFOR) }\end{array}$ & $-10,410$ & $-0,145$ & 1669,3 & 1,223 \\
\hline
\end{tabular}

Fonte: Dados da Pesquisa

(1) Os grupos de produtores såo os seguintes: a) grupo 1 = agricultores de pequeno porte e baika renda $(n=111) ; \varepsilon$, b) grupo $3=$ agricultores em larga escala $(n=82$ ).

(2) Os valores entre parênteses representam o nível de significância do teste "t" para os coeficientes significativamente diferentes de zero. 
liste grupor composto por pequenos produtores. apresenta uma reduzida capaciade de endividamenton 0 s produtores tendem a compensar o aumento do custo finance iro do credito formal com maior volume de financiamento

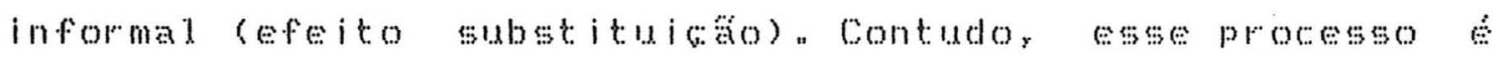
condicionato aos juros cobrados pelos intermediarios informats Ey a despeito da nog do distoreida que possam ter dos juros implicitos na operaga informal de credito, os tomadores reagem a elevara das takas com a diminuicao do Valor emprestadon

O modelo econométrico do grupo 3 sprodutores em 1 arga escala) evidencia que săo significativamente diferentes de anco os coeficientes das variveis taxa real de juros do cordito informat -... JUR TNFM (13, g\%), area explorada pelo

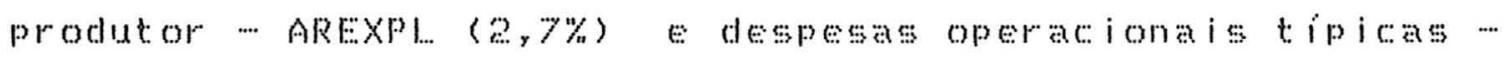
DESOPE $(0,5 \%), E s s e s$ resultados indicam que o valor dos emprestimos informas yaria em sentido contrario ao preco dos recursos financeiros e ao tamanho da exploractan Indicam, também, variacobes de mesmo sentido entre as despesas operacionas tipicas a a liquidez procurada nos MFRI:

Faz sentido imaginar que aumentos na escala de: produca sáo acompanhados por aumentos nas despesas 
operacionats tipicas a partir de determinado nivedr poremr maior liquider é necessariay o que estimula a buscar de finaneiamento externo, inclusive nos mercados informats o volume de 1 i quider demandado, será corescente deste que o preco cobrado pelos recursos varie em sent ido inverson 


\section{CONCLUSöES}

A excssiva intervenctio governamental na economia -.. particularmente quando caracterizada pela imposicádo de pesada carga tributaria, sistemas de fiscaliagáco controle deficientesy escasseze de recursosfinanceirosy rigideze demora nos procedimentos institucionats oficiais ... fomenta a chamada "economia informal"

Dentre as diversas atividades informas, a intermediate financeira tem papel bem definido no desenvolvimento das atividades de individuos e firmas servindo de edo de ligato entre co capital proprios os recursos obtidos nos mercados formats

Interessante é que, em boa parter o estimulo a intermediacto financeira informal, principalmentes no que se refere a emprestimos destinados a atividade agricolas 
decore das dificuldades operacionas do propriosetor finance iro formaln

Há registros sobre o funcionamento dos mercacos financeiros rurats informals (MFres) em diversos paisese diferentes tipos de economian Esses mercados, entretantor parecem ter especial importancia empaises de economia de ba ixa renda ou em desenvolvimenton Nestes, o sistema formal de credito no consegue geralmenter atender à necess i daces do setor agropecurio seja pola falta de recursos, seja pela exessiva burocracia do s isteman como principas problemas, regietramese os altos custos de transacaro e de administrato dos emprestimos, o racionamento de credito e o rigido controle das taxas de j $140 \%$

Fica patente que sem a 1 iberacoro efetiva das taxas de juros do ceredito formal, de modo a refletir o custo de oportunidade dos recursos, o risco operacional es os custos de transaca dos empréstimosy será dificil adcangar um sistema formal eficiente. Com isso, crescem as vantagens dos mercados financeiros informats

Entretanto, náo se deve desprezar ofato de que nos mercados informas de credito sa cobradas altas taxas de jurosn beradmente, essas taxas incluem o custo de 
oportunidade dos recursos o o risco de inadimplenciar dentre outros componentes"

lisses tipo de comparacio tem levado, mutas veses a sugestoes de que ligacoses entre os mercados formal e informal de coredito deveriam ser estabelecidasn seria intersesante aproveitar o medhor de caca um e formar, talvezy um sistema misto ou intermediarior sem prejudicar

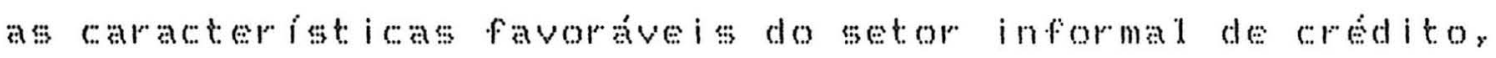
qua is sejama flexibilidade, rapidezy transparencia nos procedimentosy redacionamento pessond e batios custos de trangan

0 methor conhecimento dos mercados financeiros informats pode fornecer subsidios aos responsiveis pela

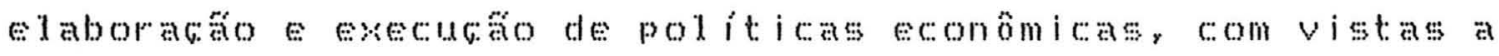
anmentar a eficiencia do proprio sistema formaln

Entre os diversos tipos de intermediactio informal, os ma is populares e difundidos parecem ser os empréstimos

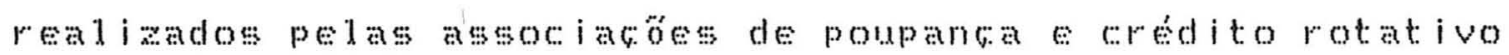
-.. ROSCAS E a compra/venda antecipada de producton

No Brasil, os mercados informase desempenham papel relevante junto aos produtores agricolas s su participaca no financiamento rural tem crescido substancialmente nos 
litrimos anos. Outras alternativas financeiras tem sidoy também, ut i 1 iandas pedos produtoresn A captacto de recursos através de bolsas de fisico ede futurosé uma delasn Porém, dada a sofisticacta dos mecanismos operacionais, o adcance dessa modal idade fica restrito a um tipo especifico de produtor, geralmente de ma i or porte e mais capitaliacan contudo, a importancia desses instrumentos năo deve ser

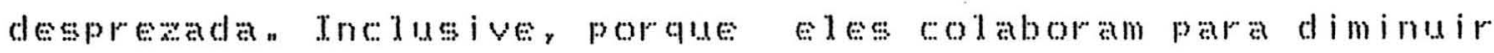
a pressaro sobre o sistema formal de crediton

Criado em 1965, o sistema Nacional de Crédito Rural w. SNCR, transformou o crédito rurat em mecaniamo de planejamento do setor agricola brasileiro, ao inves de mantề co como instrumento de apoio financeiro a produtor A exesesiva intervenca ga governamentad no sistema tornouno frafl. A instabilidace económica que atingiu o pás após os anos 80 desgastowo quase por completon a aceleracádo do ritmo inflacionario abalou as principais fontes de recursos do SNCR: depósitos à vieta e recursos governamentas

Frente à exastao das fontes tradicionais de recursos para o coredito rurad, o governo coriou a caderneta de poupanca rural, cujos recursos captados junto ao publico ser iam apl icados, principalmente, no setor rural " Desdeseu surgimento, a poupana rural desempenhou paped significativo como suporte ao credito rural, alcangando 
$43,2 \%$ do total de coreditos concedidos em 1993. Contudo, nâ foi ela guficientepara compensar a forte diminuica ocorrida nas demats fontes a partir de 1979.

outro ponto, nato menos importante, tem sido o tradicional atraso nas liberacoses do wedito oficialy prejudicando, muitas veres, o desenvolvimento normal das atividades agricolasn o ciclo produtivor depois de initeido, dificilmente pode ser interrompido sem altose proibitivos costos

romados em seu conjunto, esses aspectos contribuiram para a precariedade atual dos mecanismos formas de financiamento da agractura brasileiran E, consequentementer colocaram aos produtores a necessidade de otimiar o uso dos proprios recursos e de buscar novas fontes elou formas de financiamento disponiveis nos mercactos financeiros n

Neste contexto, esta pesquisa buscou evidencias de uso dos mercados informats por ezg produtores rurais mutuar ios

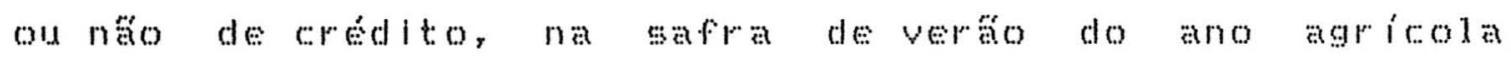
$1.989 / 90$.

As evidencias permitem concluir que a maioria dos

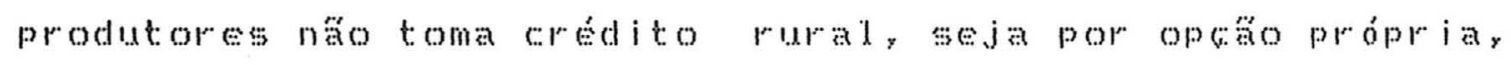


seja por naro ter aceseso aos mercados de crediton tseso é observado particularmente em relacaco aos produtores de pequeno porte e baina rendan

o racionamento no corécito formal e o risco operacional nos mercados informas refletemse em alto custo do dinheiro, pesada exigencia de garantias reaise necessidade de reciprocidades pessonis esoufinanceiras toso restringe o alcance das fontes financeiras formats es informas,

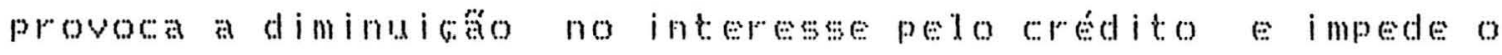
acesso de mator numero de produtores

Outra constatacaso é que os produtores que praticam agrloultura comercial em larga escala buscam intensamente (erécito rurad, independentemente da or igem dos recursos. Tsso é, provavelmente, reflexo da necessidade de recursos financeiros exigidos para a execugo de suas atividades, diante da magnitude da escala de produca e do invest imento para a exploracáo de novas áreas os produtores dessegrupo sáo encontrados em regióes de fronteira agricola do centrom Oeste brasi i 1 eiron

As evidencias permitem concluir também que os produtores comercia is que ut i l izam coap ital intensivamente têm malor capacidade de autowinanciamenton os pequenos produtores, provavelmente por ut il izarem basicamente mán 
dewobra familiar, tem custos reduaidos por hectaren os agricultores em larga escala enfrentam sérios problemas de l iquidezer por isso, tem ma i or propenso ao endividamenton

Como reflexo da liberdace financeira nos mercados informa is e da administracko das taxas de juros no mercado formal, o juro real nos empresetimos informats tem maior ampl itude de variacaro que nos formaisn n Em termos medios, a taka real de juros nos emprestimos informas equivale a 3 vezes a praticada nas operacose formisn No so deve esquecer, porém, que ao coredito formal está as aco iado um a to custo de transaca para o tomador, o que faz aumentar ocusto financeiro efetivo da operation

Em termos de importancing observase que o financiamento informal da atividade agricolar objeto central desta pesquisar representa res\% dos códitos recebidos pelos produtores da amostran

No que respeita a valor prazo das operatoses as transacoses informa is săo de montante e duracăo inferiores aos das formass porem, em termos de taxa de juros a situacto é inversan os agentes informats tem maior liberdade na cobrana de juros ro rabaliando em bases pessonis, algumas veass no ablicam juros sobre o capital emprestadon Em outras, considerando o alto risco 
operacional e aproveitando ofato dos juros nă estarem expl icitos, cobram do tomador taxas extremamente el evadas n

0 modelo econometrico desenvolvido nesta pesquisar visual ieando a amostra em seu todo apesar das 1 imitacoses no ajustamento, mostrou que a rex explorada e as despesas operaciona is tipicas da producto sago importantes variveis explicativas da demanda por $\quad$ iquidez nos mercados informass Alem de mostraremsen estatisticamente significativos, os resultados obtidos indicam que o valor dos empresstimos informas diminui à medida em que a area explorada coresce e vicewersan Em contrapartar observanse

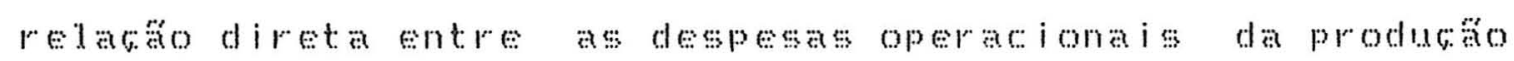
agricola e o valor principal emprestado em fontes informa destediton

Quanto aos grupos des produtoress o modelo dos agricultores de back renda revela que o preac dos recursos \& a categoria do produtor sago variveis importantes na

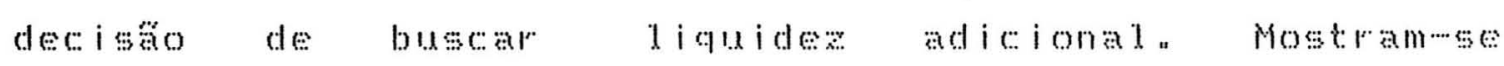
significativos a taka real de juros cobrada no crécito informal, o custo financeiro do corotito formal e a area explorada pelo produtor "Como sugerido em outras pescuisas há um possivel efeitomsubtituicaro do credito formal pelo informaln 
Para os agricultores comerciais os resultados naso saro conclusivos, dado o baxonivel de significancia de todos os coeficientes das variveis naso se descarta, porem, que a maror capacidade de autowinanciamento deseses agricultores tenha influenciado as est imativas econometricis a

0 modedo dos agricultores em larga escada evidencia que a tama real de juros do credito informal, a area explorada pelo produtor e as despesas operaciona

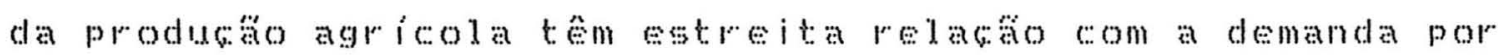
l iquidez nos mercados informasen os resultados indicam, anda, que ovalor dos emprestimos informas varia em sentido contrario aro preso dos recursos financeiros a a tamanho da exploracto: variacoses de mesmo sentido ocorrem entre as despesas operaciona is e a d qu idezedemandada nos MFRTS

As evidencias empiricas desta pescus a indicam a necessidade de mudangas no sistema formal de finaneiamento a agricultura brasileira, principalmente quando se considera uma perspectiva de estabilidade economican Ademais, é importante que os formulares de políticas publicas considerem outras formas existentes cou potenciais) para financiar os agricultoresn Mercados finane iros informa is e comercial izacto atraves das bolsas 
por exemplo, näo podem ser ignorados

No mercado formal de creditoy e importante que ass medidas sejam direcionadas para amentar a eficiencia do sistema bancario, visando à diminuicaro dos custos de transaga para financindores to tomadores.

A politica de credito rural deve ter comoprincipal objetivo o produtormutuario eno a cultura ou atividade a ser desenvolvidan A utilizanto do coredito rural como mecanismo de planejamento do setor, privilegiando

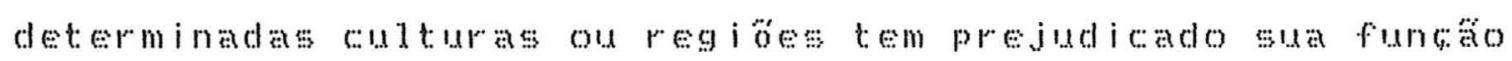
basalca como fonte de 1 iquidez adicional para o agricultor lesta postura tem obrigato os agentes financeiros a controlar de perto a apl icacio dos recursos emprestados o que consome tempo es dinheiron

Diante da restricaro de recursos governamentais para financiar a agricultura e necessario ampliar o uso de fontes financeiras náowinflacionarias Dentre as medidas

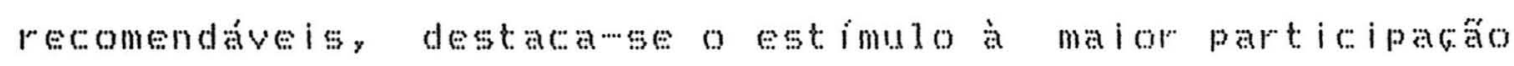
dos bancos privados nos mercados financeiros rurais . Nesta fase inicial de estabilizacanoconomicar os bancos deverăo ampl iar suas at ividades em direcaro a algumas áreas a Porem, no caso da agricultura, eles continuara reticentes enquanto as taxas de juros forem excessivamente 
administradas e náo puderem refletir os custos de captacto e de administracto dos recursos, bem como os riscos operaciona is envolvidosn

A mai dor l iberactén das taxas de juros do credito rural

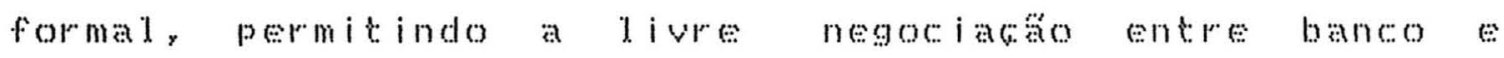
agricultor, pelo menos em nivel de medio e grande produtor, est Imudaria a concorpencia por emprest imos rurais entre os bancosn Tseo poderia beneficiar os produtores tanto pelo ma ior volume de recursos à sua disposican, como por um custo financeiro efetivo mas baxo nos emprestimosn possivel que o SNCR seja tamberm beneficiado com aumento da eficácia do coredito, uma vez que o produtor tomará emprestimo apenas quando o retorno do seu projeto for mar or que o custo financeiro do emprestimon Certamente, isso terá efeito inibidor sobre eventuais desvios de recursos parat outros fins.

Devido à rigidez no mereado formal de ceredito, os produtores tem incorrio em custos de transacto muto elevados na obtencia dos emprestimos n Neste aspector os

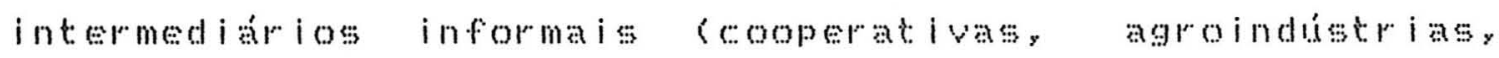
comerciantes de insumos/produtos, dentre outross tem levado vantagem sobre o sistema bancarion by portanto, recomendáved que os procedimentos no mercado formal sejam simplificados no sentido de diminuir a burocracia e 


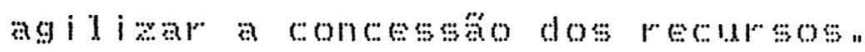

\begin{abstract}
Fespecial atencáo deve ser dacta também a comercializacto da productoro atraves de estímulos aos produt orese agentes privados para gue utilizem bolsas de

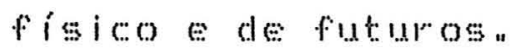

Quanto aos mercados informats, e relevante que novas

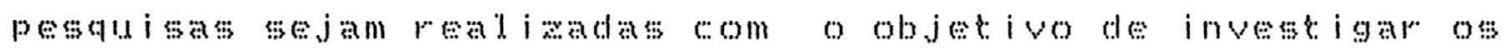
principais fatores associados a demanda e a oferta de recursos financeiros nesses mercados do dado da demanda é necessario acompanhar e analisar, ao longo do tempo, eventua is munam nos fatores que condicionam a procura por liquidez nos MFRIs Do lato da oferta é preciso conhecer agentes e mecanismos operacionats, bem como avaliar sua capacidade potencial de financiamenton As informacoses resultantes desses estudos poder bo ser biteisy inclusive, para aumentar a eficiencia do própro mercaco formal de coredito. 


\section{REFERENNCIAS BIBLIDGRAFICAS}

ADAMs, D.W. Tmpato de las finanas en el desarollo

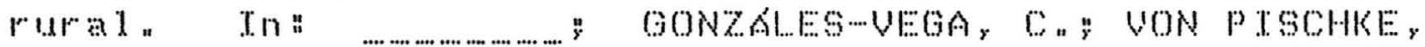
J.D. Crédito agrícola y desarrollo rural a la meva vision. Columbus, The ohio state University, 1987 "P. 1. 1...2.

raking a fresh look at informal finance n Jn" GEMTNARTO SOBRE PROBLEMAS FE PERSPECTTUAS DA AGRTCULTURA, 5. Piracicabar 1989" Anais. Piracicabar,

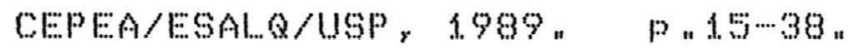

k CANAUEST, M.l... Rotating savings credit associations in Bolivian Columbus, The ohio state University, 1.988. 18p. (Economices and Sociology Oct:asional paper, 1.417)

ARAúJO, $P$ "F̈. agricultura brasileira. piracicaba, 1980. 2espn (L... ivre- docencia, ESALA (USP)

An economic study of factors affecting the demand for agricultural credit at the farm

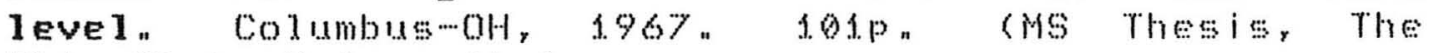
Ohio state University)

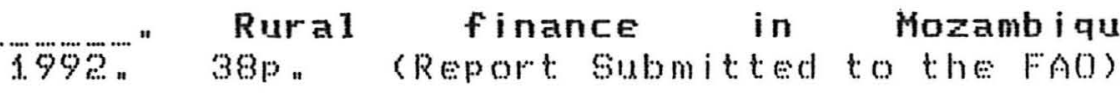

\& ALMETDA, An Finane i amento rural nos mercados

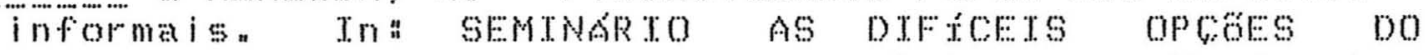
FTNANCTAMENTO RURAL... Belo HOr izonte, 1.992. Anais" Be10 Hor izonte. FAEMOCNA, 199?" 


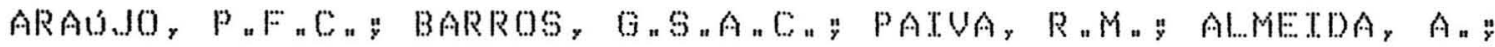
PTRES PERES, A "R " Característica da agricultura das regióes estudadas" primeiros resultados de campon Piracicabar 1990an 60p n (Relatorio de Resultados, f)

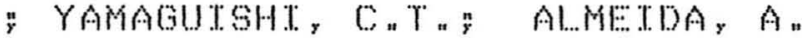
Brazilian agricultural finance" impressions ftom the

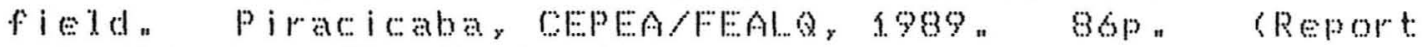
submitted to The World Bank)

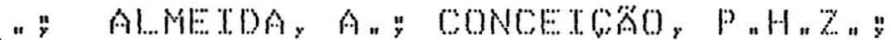
CONCETC\%, J " dos mercados financeiros formais $E$ informais na agricultura brasileiran Piracicaba, CEPlEA / FEALQ, 1991. 36p" (Relatorio de Resultados, 8)

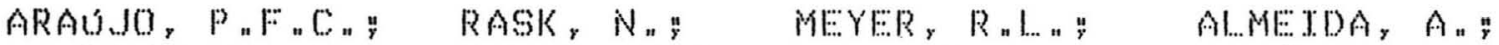
SHTROTA, Rn: PATUA, Rn "M Aspectos metodológicos E literatura sobre mobilizacão de poupanca, formacão de capital E mercados financeiros rurais" Piracic: aba,

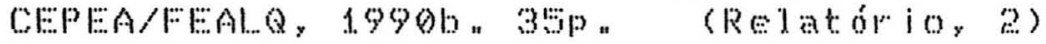

BANCO CENTRAL... DO BRASTI... M Manua 1 de crédito rural" Brasilia, BACEN, 1.994,

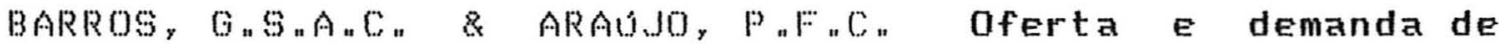
crédito rural no Brasil: algumas evidências empíricas sobre seus determinantes. Pir acican, CEPEA/FEAL $Q$,

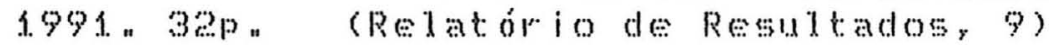

BESSER, HD, Rural credit markets in the Northeast of Brazil. Massachusets. 1979. (PhD rhesis, Massachusets Tnst itute of rechnology)

BISERRA, InV, Utilizacto do crédito rural pelos agricutrores de batin renda no sertato central do Cearán Revista de Economia Rura1, Brasilia, 16(1) ngi.... 69, jan $\cdots$ mar. 1978 .

BOUMAN, F.J AA Thformal savings and credit arrangement: in developing countries a observations from sri Lanka. Tn" COLLQQUIUM ON RURAL FINANCE, Washington D. "C, , 1981. Washington D "C, "The World Bank/USATD/OSU, 1.981. 288p. (Discussion paper, A)

"Sma11, short and unsecured informal rural finance in Indian Delhi, Oxford University Press, 1.989 " $1.45 \mathrm{p}$ 
BOUMAN, F"JAAn \& BASTTAANSEN, R " Pawnbroking as an attrate ive alternat ive to cheap credit. cases from tonda and $5 r$ i Lankan Tn" SEMTNAR ON TNFORMAL FTNANCIAL... MARKETS TN DEUELOPMENT, Wahington D.C., 1.989. Washington Do. OSU/USATD/The Worda Bank, $1.989 . \quad 17 \%, \quad(P a p e r, 23)$

2 HourmaNy R. Pawnbroking as an instrument of rural banking in the third world" Economic Development and Cultural Change, Chicago, 37(1) a $69-69$, 00 t. " 1988 ,

CARUALIHO, M.A. Capacidade de autofinanciamento da agricultura paulista. Sĭo Palo. TA,

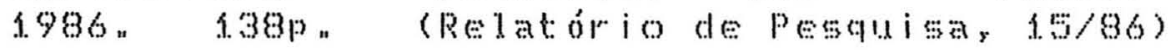

BTLUA, CR equivalência em produto como fonte de financiamento

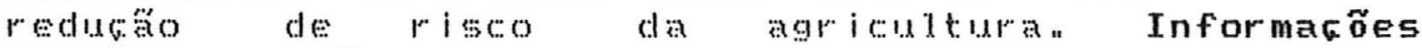

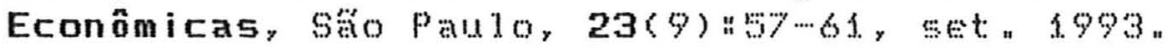

CAsTRo, JKnL" Legislagấ de crédito ruraln Rio de

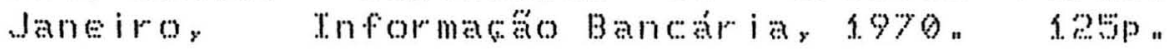

CHRTSTEN, R" " Formal ceredit for informal borrowers: 1 essons from informal Ienders " Tn "SEMTNAR ON TMFORMAL. FINANCTAL MARKETS TN DEUEIOPMENT, Washington D,

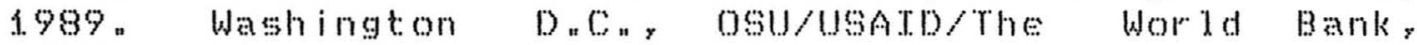
1.989" 1.1. " (paper, 14)

CUEVAS, C.E " Informal financial markets in African main issues and select cose studies. Tn" THE ROLE OF TNFORMAL TNSTTRUTONS AND COOPERATTVES IN RURAL... FTNANCTAL MARKETS, Coté d"TVOFE, 1989, Columbus, The ohio state Universituy 1989" $13 \%$ " (Exonomics and Sociological occasional paper, 1.638)

DELANCY, $V$, Rural credit in an islamic african countrya

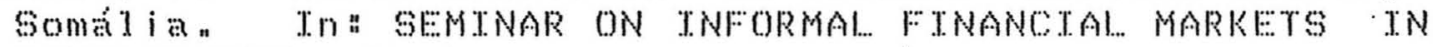

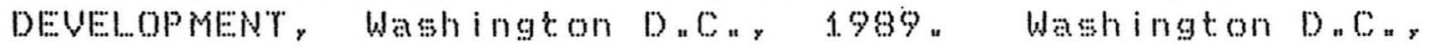
osu/USATD/The Worla Bank, 1989" 17p " (Paper, 1.5 )

E:I. MEDANI, ${ }^{\prime}$ Interest rates in the informal credit markets of underdeveloped rural areas" the case of the "shail" credit in the sudan bezira schemen sudfo, Univereity of Khartoum, 1983. (Department of Rural Economic:s - Research Bulletin, 32) 


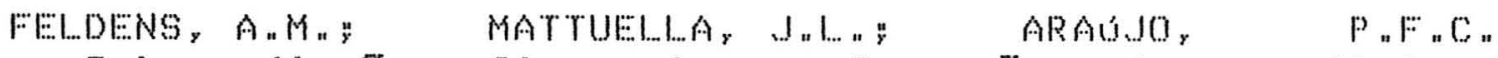
Intermediacão financeira, formaçáa de capital inovacóes tecnológicas em duas regióes agricolas do Rio Grande do Sul " Carazinho e lajeadon Piracicabay CEPEA/FEALQ, $1990,74 P . \quad$ (RElatório de Resultados, 3 )

FERNANDO, N.An Tnformal finance in papua New Guinean an OVEYVIEW. TO" SEMTNAR ON TNFORMAL..F FNANCTAL.. MARKETS IN DEVEl..OPMENT, Washington Doc, 1989 " Washington D.C.

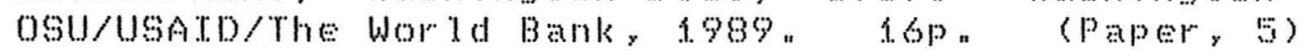

FLAMANG, RAAn Tnformal financial markets in senegat and

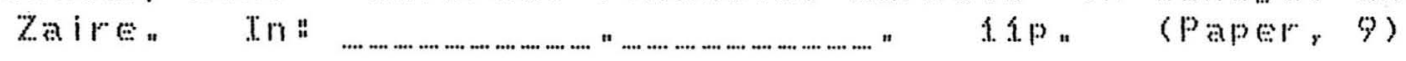

GERMTDS, D.; KESSIER, D,; MEOHTR, R " Financial systems and development: what role for the formal and informal financial sectors?" Paris, OECD Development Centrey 1.991.

GERON, M.P.s. Philippine informal rural coredit markets " efficiency and equity issues sournal of Agricultural Economics and Development, Quexón, 20(1) " $95-1.38$, JanJul " $1990 \%$

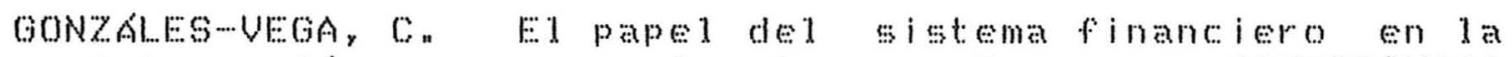
integración rural wurbana " Tn " CONFERENCTA

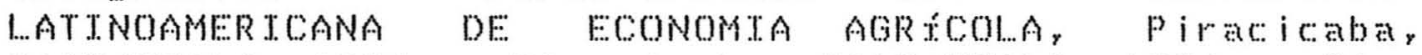

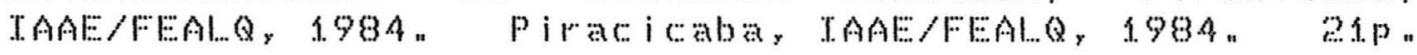

GRAHAM, D n. Tnformal rural finance in Niger" 1 essons for building more efficient and sustainable formal institutions" Tn: SEPTNAR ON TNFORMAL.. FINANCTAL.. MARKETS TN DEUELOPMENT, Washington D.C. 1.989" Washington D.C", OSU/USATD/The World Bank, 1989. 19p" (Paper, 4)

GREENE, WH" LIMDEP UsEr's manual and reference guide version 6.0. Bellport...NY, Econometicic software. 1.901. $894 \%$

TZUMTDA, Kn The Kou in Japana a precursor of modern Financ: " TU" SEMTNAR ON TNFORMAL. FINANCTAL... MARKETS IN DEUELOPMENT, Washington D.C. 1989 "Washington D. 0SU/USATD/The World Bank, 1989" 23p" (Paper, 3)

KEUANE, $M_{n}$ Ts the sheil a shill?Thformal coredit in Rural Sudan. The Journal of Developing Areas, Tllinoisy

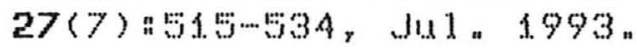

KMENTA, J Elementos de Econometrian Sä Palo, At las, 1.978" 685\%" 
LADMAN, J "R, Loan-wransact i on costs, credit rat ioning and marketing structure: the cosse of Bolivian Th" ADAPs, D.W"; GRAHAM, D.H": UON PTSCHKE, J D. Undermining rural development with cheap credit. Boulder, Westiview

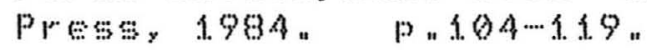

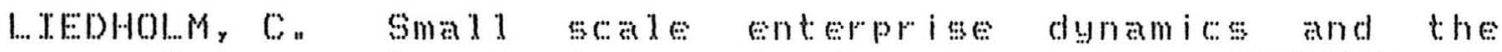
evolving role of informal finance " In: SivTNAR ON TNFORMAL.. FTNANCTAL... MARKETS TN DEVELOPPENT, Washington

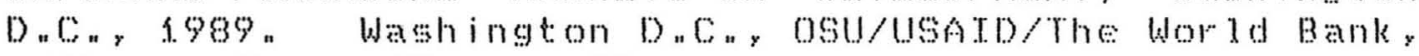
1.989" 17 . $^{\circ}$ " (Paper, 8 )

LOPES, MaRn O poder das conlisoes politicas de grupos de interesse de bloquear o desenvolvimento agricolan th" TE:TXETRA, E.: De Desenvolvimento agrícola na década de 90

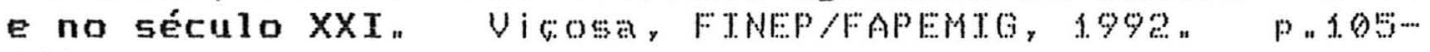
1. 30.

MADDALA, G.S" Introduct ion to econometrics" NEW York, Macmillan, 1988 " $972 p$ "

MEYER, R,L. \& CUEUAS, CNE " Reducing the transaction costs of financial intermediation" theory and innovations. Columbus. The ohio state University. $1990,47 \% n$ (Draft)

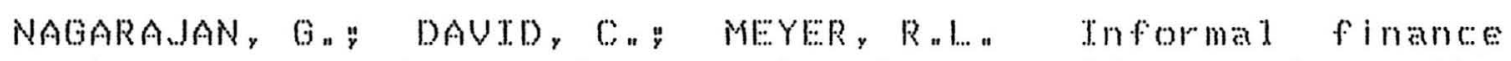
through land pawning contracts: evidenes from the Philippines " Tn" TNTERNATTONAL.. CONFERENCE: OF

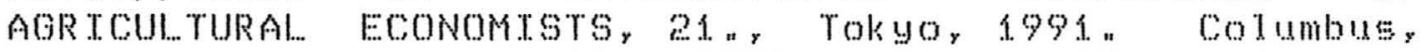
The ohio state University y 1991" Pfp " CEonomics and sociological occasional paper, 1. 775 )

NAKANO, $Y_{n}$ o ciredito rural mum contexto de modernizace da economia brasileiran In" SEMTNART AS DTFUCES OPCEES DO FTNANCTAMENTO RURAL, , " y BE10 HOF izont:, 1.992" Anais" Be10 Hor i

NAYAR, C.P. "S. The inherent strength os informal financial institutions " In " SEMTNAR ON TNFORMAL. FTNANCTAL. MARKETS TN DEUELOPMENT, Washington, D.C. 1.989" Washington, D.C. $1989.40 \%$ " (paper, 7 )

NEGR NETO, An Analise grafica e taxa de crescimenton Informaçóes Econômicas, Să paulo, 23(10) "99-1.08, out: "1993"

NEHMANN, O.T. Small farmer credit use in a depressed comunity of Såo Paulo, Brazil " Columbus... OH, 1.973. (PhD Thesis The onio state Universitu). 
NóBREGA, M. A necessidade da criaca de fontes nấ inflacionarias, permanentes e definitivas para financiar a agricultura brasileiran In: SEMTARTO AS DTF́tCETS OPCBES DO FTANCTAMENTO RURAL, A., BEIO HOF 1.992. Anais. BE10 HOF i monte, CNA/FAEYG, 1992.

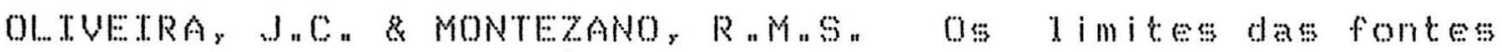
de financiamento à agricultura no Brasil" Estudos Econômicos, Säo Paulo, 12(0) a 139-159, agon/nov " 198?"

ONCHAM, $r$, Tnformal rural finance in That and an

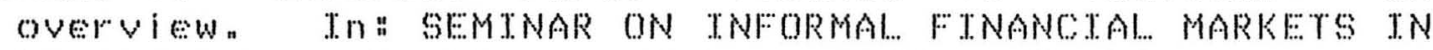
DEVELLPMENT, Washington D "C, 1989" Washington D.C. OSU/USATD/The World Bank, 1989.490, (Paper, 2.1.)

OTERO, M. Meeting women ${ }^{*}$ s financial needs lessons for informal financial institutions" thn"

$1.70 .(p a p e r, 1.2)$

PATUA, R "Mn " SCHATTAN, S " FREITAS, C.F" T, SEtor agrícola do Brasil - comportamento econômico, problemas E possibilidades. "Sá Paulo, Secretaria de Agricultura, $1.973 .456 \mathrm{p}$.

POMAREDA, C. \& CEBREROS, A. MECanismos financeiros para la modernización de la agricultura" Comércio Exterior, México, 43(4) " 328-336, abr " 1993 ,

PRABOWO, D. The role of informal financial intermediation in the mobiliation of household savings and allocations in TndOnESia Tn: SEMTNAR ON TNFORMAL.. FTANCTAL... MARKETS TN DEVELOPMENT, Washington D.C., 1989" Washington D.C." osu/usato/The World Bank, 1.989" 21. " (Paper, 1.6)

REI..ATORTO SOBRE O DESENUOLUTMENTO MUNDTAL... RIO dE Janeiro, FOO, 1.989,

REZENDE, O, C. Politica económica a aricultura ra década dE 8O. Tn: CONGRESSO BRASTLETRO DE ECONOMTA EE SOCTOLOOTA RURAL... 27, Piracicaba, 1989" Anais" Brasília, SOBER, 1989" V"? P.284-309"

SANDERATNE, $N_{n}$ Informal $l$ enders in Sr $i$ l.ankan 1 inking formal and informal markets. Tn" SEMTNAR ON INFORMAL... FTNANCTAL MARKETS TN DEVELOPMENT, WaShington D,C., f.989" Washington D.C. osu/usard/The World Bank, $1.989 .15 p$ " (Paper, 10) 


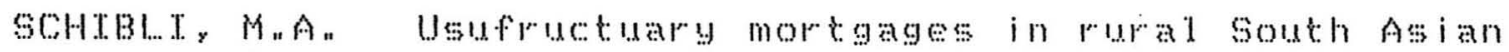
economies" collateral valuation and internal rat:s. American Journal of Economics and Sociology. $52(2)$ " $167-1.81$, Apr * 1993 "

SCHRTEDER, G \& CUEVAS, C nE The structure and importance of informal financial grours in Cameroon " Tn" SFMTNAR ON TNFORMAL.. FTNANCTAL MARKETS TN DEVELOPMENT, Wash Ington D. " 1989" Washington D.C. , 05U/USATD/The World Bank, 1.989. 15p" (Paper,

SETBEI.., H.D. Upgrading informal financial institutionsa NGOs and self whelp groups establish their own banks in Tndones i a Tn" SEMTNAR ON TNFORMAL. FTMANCTAL MARKETS IN DEVELOPMENT, Washington DC, A989 "Washington

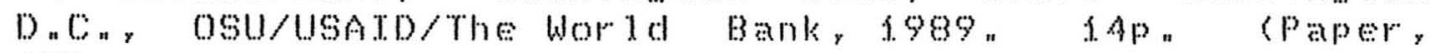
(.7)

\& MARX, Mr Tn Dual financial markets in Africa case studies of linkages between informal and formal financial institutions" American Journal of

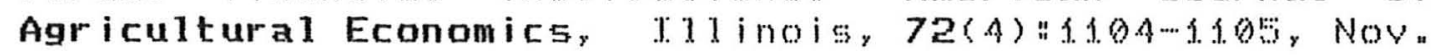
1990.

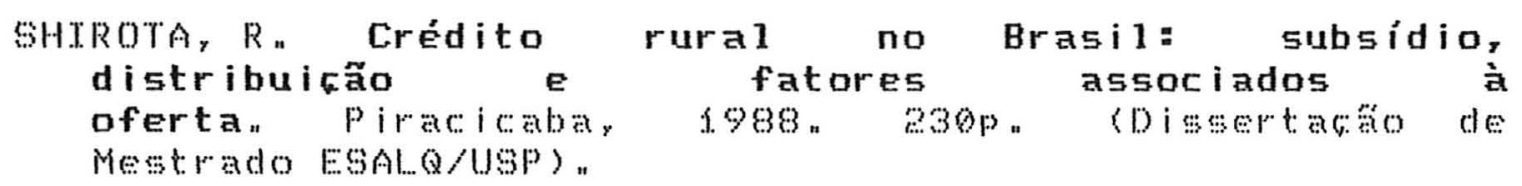

roBte, In Estimation of relationships for limited dependent variables " Econométrica, New Haven, $26(1)=24-36$, J

USATD -- UNTED STATE AGENCY FOR TNTERNATTONAL DEVELOPMENT. Mobilizing savings and rural finance - The AID experience. USATD, 1991. 1.00\%"

VON PISCHKE, J.D. \& ADAMS, D.W. Fungibility and the design and evaluation of agricultural corectit projects. American Journal of Agricultural Economics,

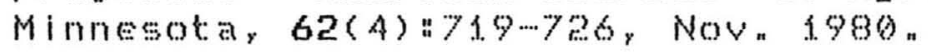

"GRAHAN, D. Rural financial markets in deve11 oping countries. Baltimore, The John Hopkins University press, $1983 . \quad 4410 "$ 


\section{A P E N D I C E}

MODELOS DE REGRESS\%O ESTTMADOS NA PESQUTSA 


\section{Legenda das Var iáveis Ut i 1 izadas.}

a ) L.T TNF :-: Valor tota 1 dos emprest imos tomados em fontes informa is de coreditoy

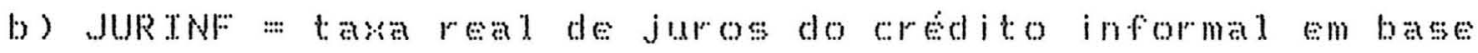
mensad (JURTNFM) OU andul (JURTNFA):

(i.) VALFFR =:- valor total dos emprestimos formats tomados pelo produtor:

d) Corfor a: custo finance iro da operacio formal de: emprestimo, considerando a a casa reat de juros e o custo de transaga para o tomador, em base meneal (CSTFORM) OU anual (CSTFORA):

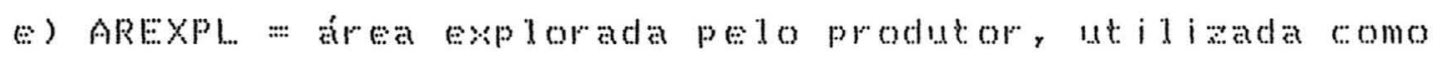
representante da categor ia do produtor"

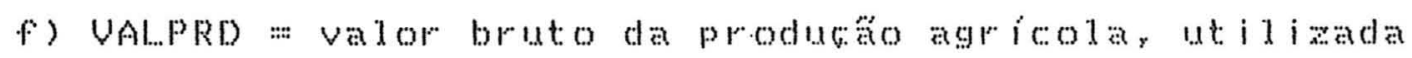
como representante da categoria do produt ory

9) DESOPE: valor total das despesas operacionais tipicas da productóno agrolay

h) EDUFOR =: numero de anos de educago formal do produtor 


\section{Modelos de Regressão Estimados na Pesquisa}

\subsection{Amostra Total}

(TOBAM3.0UT)

MODEL COMMAND:

DSTAT; RHS=JUR INFM, VALFOR, CSTFORH, AREXPL, DESOPE, EDUFOR ; OUTPUT $=39$

Descriptive Statistics

$\begin{array}{lccrcllr}\text { Variable } & \text { Mean } & \text { Std. Dev. } & \text { SkEw. } & \text { Kurt. } & \text { Minimum } & \text { Maximum } & \text { Cases } \\ \text { JURINFM } & 2.7065 & 1.6595 & -0.145 & 2.515 & 0.0000 & 7.200 & 279 \\ \text { UALFOR } & 14891 . & 35119 . & 2.695 & 9.618 & 0.0000 & 0.1800 \mathrm{E}+06 & 279 \\ \text { CSTFORM } & 0.86555 & 0.42678 & 3.306 & 19.418 & 0.1761 E-01 & 3.946 & 279 \\ \text { AREXPL } & 173.64 & 274.96 & 2.868 & 13.919 & 0.6000 & 2000 . & 279 \\ \text { DESOPE } & 36254 . & 59168 . & 2.310 & 8.298 & 0.0000 & 0.3077 E+06 & 279 \\ \text { EDUFOR } & 5.5842 & 4.1655 & 0.750 & 2.632 & 0.0000 & 15.00 & 279\end{array}$

TOBIT;LHS=LIQINF ; RHS=ONE, JUR INFH, VALFOR , CSTFORM, AREXPL, DESOPE, EDUFOR\$

Limited Dependent Variable Model - CENSORED regression Maximum Likelihood Estimates Log-Likelihood.............. -703.5360

Threshold values for the model: Lower $=0.0000 \quad$ Upper $=+$ Infinity $N[\theta, 1]$ used for significance levels.

Variable Coefficient Std. Error t-ratio Probiti=x Mean of $X$ Std.Dev. of $X$

$\begin{array}{lccrccc}\text { Constant } & -32255 . & 7700 . & -4.189 & 0.00003 & & \\ \text { JURINFM } & -535.99 & 1396 . & -0.384 & 0.70093 & 2.7065 & 1.6595 \\ \text { UALFOR } & -0.47087 E-02 & 0.7891 E-01 & -0.060 & 0.95242 & 14891 . & 35119 . \\ \text { CSTFORM } & 1821.5 & 5944 . & 0.306 & 0.75926 & 0.86555 & 0.42678 \\ \text { AREXPL } & -31.193 & 18.52 & -1.684 & 0.09220 & 173.64 & 274.96 \\ \text { DESOPE } & 0.22507 & 0.7764 E-01 & 2.899 & 0.00374 & 36254 . & 59168 . \\ \text { EDUFOR } & 584.29 & 595.1 & 0.982 & 0.32621 & 5.5842 & 4.1655 \\ 0 & 27708 . & 3008 . & 9.213 & 0.00000 & & \end{array}$




\begin{tabular}{|c|c|c|c|c|c|c|c|}
\hline \multicolumn{8}{|c|}{ MODEL COMMAND: } \\
\hline \multicolumn{8}{|c|}{ DSTAT; RHS=JUR INFM, VALFOR, CSTFORM, VALPRD, DESOPE, EDUFOR; OUTPUT $=39$} \\
\hline \multicolumn{8}{|c|}{ Descriptive Statistics } \\
\hline Variable & Mean & Std. Dev. & SkEW. & Kurt. & Minimum & Maximum & Cases \\
\hline JUR INFH & 2.7065 & 1.6595 & -0.145 & 2.515 & 0.0000 & 7.200 & 279 \\
\hline VALFOR & 14891. & 35119. & 2.695 & 9.618 & 0.0000 & $0.1800 E+06$ & 279 \\
\hline CSTFORM & 0.86555 & 0.42678 & 3.306 & 19.418 & $0.1761 E-01$ & 3.946 & 279 \\
\hline UALPRD & 43950. & 84674. & 4.086 & 24.782 & 150.3 & $0.6838 E+06$ & 279 \\
\hline DESOPE & 36254 . & 59168. & 2.310 & 8.298 & 0.0000 & $0.3077 E+06$ & 279 \\
\hline EDUFOR & 5.5842 & 4.1655 & 0.750 & 2.632 & 0.0000 & 15.00 & 279 \\
\hline
\end{tabular}

TOBIT; LHS =LIQINF; RHS=ONE, JURINFM, VALFOR , CSTFORM, VALPRD, DESOPE, EDUFOR

Limited Dependent Variable Model - CENSORED regression Maximum Likel ihood Est imates Log-Likelihood. ............... -703.4114

Threshold values for the model: Lower $=0.0000$ Upper $=+$ Infinity $N[0,1]$ used for significance levels. Variable Coefficient Std. Error t-ratio Probiti=x Mean of $X$ Std.Deviof $X$

$\begin{array}{lccrccc}\text { Constant } & -33289 . & 7632 . & -4.362 & 0.00001 & & \\ \text { JURINFM } & -42.423 & 1382 . & -0.031 & 0.97551 & 2.7065 & 1.6595 \\ \text { VALFOR } & -0.78292 \mathrm{E}-02 & 0.7779 \mathrm{E}-01 & -0.101 & 0.91983 & 14891 . & 35119 . \\ \text { CSTFORM } & 754.22 & 6028 . & 0.125 & 0.90043 & 0.86555 & 0.42678 \\ \text { VALPRD } & -0.93453 \mathrm{E}-01 & 0.5304 \mathrm{E}-01 & -1.762 & 0.07810 & 43950 . & 84674 . \\ \text { DESOPE } & 0.21544 & 0.7028 \mathrm{E}-01 & 3.065 & 0.00217 & 36254 . & 59168 . \\ \text { EDUFOR } & 582.40 & 586.3 & 0.993 & 0.32057 & 5.5842 & 4.1655 \\ 0 & 27578 . & 2993 . & 9.215 & 0.00000 & & \end{array}$


(TOBAMi. OUT)

MODEL COMMAND:

DSTAT; RHS=JUR INFA, VALFOR , CSTFORA, AREXPL, DESOPE, EDUFOR ; DUTPUT $=3 \$$

Descriptive Statistics

$\begin{array}{lccccccr}\text { Variable } & \text { Mean } & \text { Std. DEV. } & \text { SkEw. } & \text { Kurt. } & \text { Minimum } & \text { Maximum } & \text { Cases } \\ \text { JURINFA } & 36.218 & 23.690 & 0.130 & 2.556 & 0.0000 & 96.00 & 279 \\ \text { UALFOR } & 14891 . & 35119 . & 2.695 & 9.618 & 0.0000 & 0.1800 E+06 & 279 \\ \text { CSTFORA } & 11.033 & 6.1147 & 3.861 & 24.750 & 0.2116 & 59.10 & 279 \\ \text { AREXPL } & 173.64 & 274.96 & 2.868 & 13.919 & 0.6000 & 2000 . & 279 \\ \text { DESOPE } & 36254 . & 59168 . & 2.310 & 8.298 & 0.0000 & 0.3077 E+06 & 279 \\ \text { EDUFOR } & 5.5842 & 4.1655 & 0.750 & 2.632 & 0.0000 & 15.00 & 279\end{array}$

TOBIT: LHS=LIQINF ; RHS=ONE, JUR INFA, VALFOR, CSTFORA, AREXPL, DESOPE, EDUFOR

Limited Dependent Variable Model - CENSORED regression

Maximum Likelihood Estimates

Log-Likelihood............... $\quad-703.6243$

Threshold values for the model: Lower $=0.0000$ Upper $=+$ Infinity

$N[0,1]$ used for significance levels.

Variable Coefficient Std. Error t-ratio Probiti=x Mean of $X$ Std.Deva of $X$

\begin{tabular}{|c|c|c|c|c|c|c|}
\hline Constant & -32594. & 7404. & -4.402 & 0.00001 & & \\
\hline JURINFA & -8.7685 & 94.82 & -0.092 & 0.92632 & 36.218 & 23.690 \\
\hline VALFOR & $-0.38822 E-02$ & $0.7900 E-01$ & -0.049 & 0.96080 & 14891. & 35119. \\
\hline CSTFORA & 68.507 & 418.2 & 0.164 & 0.86989 & 11.033 & 6.1147 \\
\hline AREXPL & -30.735 & 18.45 & -1.666 & 0.09569 & 173.64 & 274.96 \\
\hline DESOPE & 0.22340 & $0.7740 E-01$ & 2.886 & 0.00390 & 36254 & 59168. \\
\hline EDUFOR & 592.90 & 594.5 & 0.997 & 0.31860 & 5.5842 & 4.1655 \\
\hline ó & 27684. & 3005. & 9.214 & 0.00000 & & \\
\hline
\end{tabular}


(TOBAK2.OUT)

MODEL COMMAND:

DSTAT ; RHS=JUR INFA, VALFOR , CSTFORA, VALPRD, DESOPE, EDUFOR ; OUTPUT $=3 \$$

Descriptive Statistics

$\begin{array}{lccccccr}\text { Variable } & \text { Mean } & \text { Std. Dev. } & \text { Skew. } & \text { Kurt. } & \text { Mininum } & \text { Maximum } & \text { Cases } \\ \text { JURINFA } & 36.218 & 23.690 & 0.130 & 2.556 & 0.0000 & 96.00 & 279 \\ \text { UALFOR } & 14891 . & 35119 . & 2.695 & 9.618 & 0.0000 & 0.1800 \mathrm{E}+06 & 279 \\ \text { CSTFORA } & 11.033 & 6.1147 & 3.861 & 24.750 & 0.2116 & 59.10 & 279 \\ \text { UALPRD } & 43950 . & 84674 . & 4.086 & 24.782 & 150.3 & 0.6838 E+06 & 279 \\ \text { DESOPE } & 36254 . & 59168 . & 2.310 & 8.298 & 0.0000 & 0.3077 E+06 & 279 \\ \text { EDUFOR } & 5.5842 & 4.1655 & 0.750 & 2.632 & 0.0000 & 15.00 & 279\end{array}$

TOB IT ; LHS=LIQINF; RHS=ONE, JUR INFA, VALFOR , CSTFORA, VALPRD, DESOPE, EDUFOR

Limited Dependent Variable Model - CENSORED regression Maximum Likel ihood Estimates Log-Likelihood.............. -703.3929

Threshold values for the model: Lower $=0.0000$ Upper $=+$ Infinity $N[\theta, 1]$ used for significance levels. Variable Coefficient Std. Error t-ratio Probiti=x Mean of $X$ Std.Dev. of $X$

\begin{tabular}{lccrlll}
\hline Constant & -33532. & 7349. & -4.563 & 0.00001 & & \\
JURINFA & 21.393 & 94.24 & 0.227 & 0.82042 & 36.218 & 23.690 \\
VALFOR & $-0.60722 E-02$ & $0.7786 \mathrm{E}-01$ & -0.078 & 0.93784 & 14891. & 35119. \\
CSTFORA & -0.41772 & 425.2 & -0.001 & 0.99922 & 11.033 & 6.1147 \\
VALPRD & $-0.95447 E-01$ & $0.5332 E-01$ & -1.790 & 0.07345 & 43950. & 84674. \\
DESOPE & 0.21710 & $0.7029 E-01$ & 3.089 & 0.00201 & 36254. & 59168. \\
EDUFOR & 591.60 & 585.6 & 1.010 & 0.31239 & 5.5842 & 4.1655 \\
0 & 27544. & 2988. & 9.217 & 0.00000 & & \\
\hline
\end{tabular}


2.2. Grupo 1

(TOBGR13.0UT)

MODEL COMMAND:

DSTAT; RHS =JUR INFM, UALFOR , CSTFORM, AREXPL , DESOPE, EDUFOR ; OUTPUT $=39$

Descriptive Statistics

Variable Mean Std. Dev. Skew. Kurt. Minimum Maximum Cases

$\begin{array}{llllllll}\text { JURINFH } & 3.0209 & 1.8356 & -0.333 & 2.064 & 0.0000 & 5.700 & 111\end{array}$

$\begin{array}{llllllll}\text { VALFOR } & 106.18 & 632.17 & 6.615 & 48.181 & 0.0000 & 5225 . & 111\end{array}$

$\begin{array}{llllllll}\text { CSTFORM } & 0.78079 & 0.13735 & 0.099 & 1.278 & 0.5882 & 1.066 & 111\end{array}$

$\begin{array}{llllllll}\text { AREXPL } & 56.023 & 134.18 & 4.380 & 25.956 & 0.6000 & 1000 . & 111\end{array}$

DESOPE $\quad 2 \% 1.0 \quad 4691.9 \quad 4.178 \quad 21.973 \quad 0.0000 \quad 0.3136 \mathrm{E}+05 \quad 111$

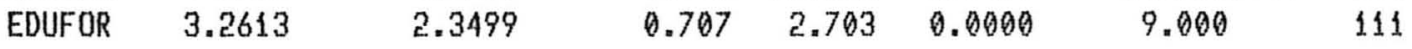

TOB IT; LHS=LIQINF ;RHS=ONE, JUR INFM, VALFOR , CSTFORH, AREXPL, DESOPE, EDUFORT

Limited Dependent Variable Model - CENSORED regression

Maximum Likelihood Est imates

Log-Likelihood............. -149.1934

Threshold values for the model: Lower $=0.0000$ Upper $=+$ Infinity

$N[0,1]$ used for significance levels.

Variable Coefficient Std. Error t-ratio Probiti=x Mean of $X$ Std.Dev. of $X$

\begin{tabular}{llcrrrr}
\hline Constant & -2274.1 & 1285. & -1.770 & 0.07666 & & \\
JURINFM & -199.65 & 124.9 & -1.598 & 0.10996 & 3.0209 & 1.8356 \\
VALFOR & $0.89776 E-01$ & 0.2346 & 0.378 & 0.70510 & 106.19 & 632.17 \\
CSTFORM & 2765.4 & 1398. & 1.978 & 0.04790 & 0.78079 & 0.13735 \\
AREXPL & -26.043 & 18.48 & -1.409 & 0.15880 & 56.023 & 134.18 \\
DESOPE & $0.10589 E-01$ & $0.6240 E-01$ & 0.170 & 0.86525 & 2261.0 & 4691.9 \\
EDUFOR & -10.410 & 71.65 & -0.145 & 0.88449 & 3.2613 & 2.3499 \\
0 & 1070.1 & 232.2 & 4.609 & 0.00000 & &
\end{tabular}




\begin{tabular}{|c|c|c|c|c|c|c|c|}
\hline \multicolumn{8}{|c|}{ MODEL COMMAND: } \\
\hline \multicolumn{8}{|c|}{ DSTAT; RHS =JUR INFA, VALFOR, CSTFORA, AREXPL, DESOPE, EDUFOR ; OUTPUT $=3{ }^{\circ}$} \\
\hline \multicolumn{8}{|c|}{ Descriptive Statistics } \\
\hline Variable & Mean & Sto. Dev. & SkEW . & kurt. & Minimum & Maximum & Cases \\
\hline JURINFA & 40.383 & 26.780 & -0.001 & 1.886 & 0.0000 & 82.79 & 111 \\
\hline UALFOR & 106.18 & 632.17 & 6.615 & 48.181 & 0.0000 & 52.25 & 111 \\
\hline CSTFORA & 9.8106 & 1.7980 & 0.097 & 1.280 & 7.292 & 13.57 & 111 \\
\hline AREXPL & 56.023 & 134.18 & 4.380 & 25.956 & 0.6000 & 1000. & 111 \\
\hline DESOPE & 2261.0 & 4691.9 & 4.178 & 21.973 & 0.0000 & $0.3136 \mathrm{E}+05$ & 111 \\
\hline EDUFOR & 3.2613 & 2.3499 & 0.707 & 2.703 & 0.0000 & 9.000 & 111 \\
\hline
\end{tabular}

TOBIT; LHS=LIQINF;RHS=ONE, JURINFA, VALFOR , CSTFORA, AREXPL, DESOPE, EDUFOR\$

Limited Dependent Variable Model - CENSORED regression

Maximum Likel ihood Estimates

Log-Likel ihood.............. -149.9866

Threshold values for the model: Lower $=0.0000 \quad$ Upper $=+$ Infinity

$N[\theta, 1]$ used for significance levels.

Variable Coefficient Std. Error t-ratio Probit $i=x$ Hean of $X$ Std.Dev. of $X$

$\begin{array}{llcrlll}\text { Constant } & -2637.6 & 1317 . & -2.003 & 0.04520 & & \\ \text { JURINFA } & -7.0420 & 8.203 & -0.858 & 0.39063 & 40.383 & 26.780 \\ \text { UALFOR } & 0.45555 E-01 & 0.2460 & 0.185 & 0.85310 & 106.18 & 632.17 \\ \text { CSTFORA } & 211.19 & 112.9 & 1.871 & 0.06140 & 9.8106 & 1.7980 \\ \text { AREXPL } & -20.171 & 16.89 & -1.194 & 0.23232 & 56.023 & 134.18 \\ \text { DESOPE } & 0.35531 E-02 & 0.6429 E-01 & 0.055 & 0.95592 & 2261.0 & 4691.9 \\ \text { EDUFOR } & -18.977 & 74.60 & -0.254 & 0.79919 & 3.2613 & 2.3499 \\ \text { ǵ } & 1112.0 & 241.8 & 4.598 & 0.00000 & & \end{array}$


(TOBGR14.OUT)

MODEL COMMAND:

DSTAT ; RHS =JURINFM, VALFOR, CSTFORH, VALPRD, DESOPE, EDUFOR ; OUTPUT $=39$

Descriptive Statistics

$\begin{array}{lccrrrrr}\text { Variable } & \text { Mean } & \text { Std. Dev. } & \text { SkEw. } & \text { Kurt. } & \text { Minimum } & \text { Maximum } & \text { Cases } \\ \text { JURINFM } & 3.0209 & 1.8356 & -0.333 & 2.064 & 0.0000 & 5.700 & 111 \\ \text { UALFOR } & 106.18 & 632.17 & 6.615 & 48.181 & 0.0000 & 5225 . & 111 \\ \text { CSTFORM } & 0.78079 & 0.13735 & 0.099 & 1.279 & 0.5882 & 1.066 & 111 \\ \text { UAL.PRD } & 3641.1 & 6071.8 & 3.687 & 17.474 & 150.3 & 0.3843 E+05 & 111 \\ \text { DESOPE } & 2261.0 & 4691.9 & 4.178 & 21.973 & 0.0000 & 0.3136 E+05 & 111 \\ \text { EDUFOR } & 3.2613 & 2.3499 & 0.707 & 2.703 & 0.0000 & 9.000 & 111\end{array}$

TOB IT ; LHS=LIOINF ;RHS=ONE, JUR INFH, VALFOR , CSTFORH, VALPRD, DESOPE, EDUFOR\$

Limited Dependent Variable Model - CENSORED regression

Maximum Likelihood Est imates

Log-Likelihood.............. -151.9110

Threshold values for the model: Lower $=0.0000$ Upper $=+$ Infinity

$N[0,1]$ used for significance levels.

Variable Coefficient Std. Error t-ratio Probiti=x Mean of $X$ Std.Dev.of $X$

\begin{tabular}{llcrrrr}
\hline Constant & -3516.5 & 1315. & -2.673 & 0.00751 & & \\
JURINFM & -54.331 & 105.4 & -0.515 & 0.60621 & 3.0209 & 1.8356 \\
UALFOR & $0.76057 E-01$ & 0.2534 & 0.300 & 0.76406 & 106.18 & 632.17 \\
CSTFORM & 3246.9 & 1492. & 2.177 & 0.02950 & 0.78079 & 0.13735 \\
UALPRD & $-0.87760 \mathrm{E}-02$ & $0.5456 \mathrm{E}-01$ & -0.161 & 0.87220 & 3641.1 & 6071.8 \\
DESOPE & $-0.48375 \mathrm{E}-01$ & $0.8756 \mathrm{E}-01$ & -0.552 & 0.58061 & 2.61 .0 & 4691.9 \\
EDUFOR & -25.772 & 75.03 & -0.343 & 0.73124 & 3.2613 & 2.3499 \\
$0 \sigma$ & 1138.7 & 249.6 & 4.561 & 0.00001 & &
\end{tabular}

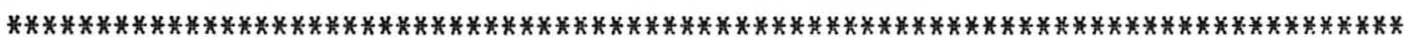


(TOBGR12.OUT)

HODEL COMMAND:

DSTAT;RHS=JUR INFA, UALFOR , CSTFORA, VALPRD, DESOPE, EDUFOR;OUTPUT $=39$

Descriptive Statistics

$\begin{array}{lccrrrrr}\text { Variable } & \text { Mean } & \text { Std. DeV. } & \text { SkEw. } & \text { Kurt. } & \text { Minimum } & \text { Maximum } & \text { Cases } \\ \text { JURINFA } & 40.383 & 26.780 & -0.001 & 1.886 & 0.0000 & 82.79 & 111 \\ \text { VALFOR } & 106.18 & 632.17 & 6.615 & 48.181 & 0.0000 & 5225 . & 111 \\ \text { CSTFORA } & 9.8106 & 1.7980 & 0.097 & 1.280 & 7.292 & 13.57 & 111 \\ \text { UALPRD } & 3641.1 & 6071.8 & 3.687 & 17.474 & 150.3 & 0.3843 E+05 & 111 \\ \text { DESOPE } & 2261.0 & 4691.9 & 4.178 & 21.973 & 0.0000 & 0.3136 E+05 & 111 \\ \text { EDUFOR } & 3.2613 & 2.3499 & 0.707 & 2.703 & 0.0000 & 9.000 & 111\end{array}$

TOBIT ;LHS=LIQINF ;RHS=ONE, JUR INFA, VALFOR , CSTFORA, UALPRD, DESOPE, EDUFOR

Limited Dependent Variable Model - CENSORED regression

Maximum Likelihood Est imates

Log-Likelihood.............. -151.8430

Threshold values for the model: Lower $=0.0000$ Upper $=+$ Infinity

$N[\theta, 1]$ used for significance levels.

Variable Coefficient Std. Error t-ratio Probit $1=x$ Mean of $X$ std.Dev. of $X$

$\begin{array}{llcrlll}\text { Constant } & -3534.9 & 1333 . & -2.653 & 0.00799 & & \\ \text { JURINFA } & 0.43802 & 7.215 & 0.061 & 0.95159 & 40.383 & 26.780 \\ \text { VALFOR } & 0.35383 \mathrm{E}-01 & 0.2596 & 0.136 & 0.89156 & 106.18 & 632.17 \\ \text { CSTFORA } & 238.38 & 116.8 & 2.040 & 0.04132 & 9.8106 & 1.7980 \\ \text { VALPRD } & -0.43738 \mathrm{E}-02 & 0.5607 \mathrm{E}-01 & -0.078 & 0.93782 & 3641.1 & 6071.8 \\ \text { DESOPE } & -0.46840 \mathrm{E}-01 & 0.8882 \mathrm{E}-01 & -0.527 & 0.59795 & 2261.0 & 4691.9 \\ \text { EDUFOR } & -30.786 & 76.49 & -0.402 & 0.68733 & 3.2613 & 2.3499 \\ \text { of } & 1154.3 & 252.8 & 4.566 & 0.00000 & & \end{array}$

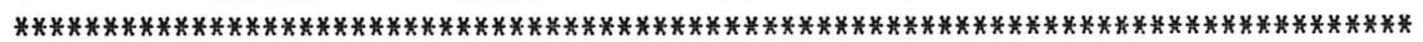


2.3. Grupo 2

(TOBGR24.0UT)

MODEL COMMAND:

DSTAT ; RHS =JUR INFM, VALFOR, CSTFORM, VALPRD, DESOPE, EDUFOR ; OUTPUT $=3 \pi$

Descriptive Statistics

$\begin{array}{lccrcccr}\text { Variable } & \text { Mean } & \text { Std. DEv. } & \text { SkEw. } & \text { Kurt. } & \text { Minimum } & \text { Maximum } & \text { Cases } \\ \text { JURINFM } & 2.1209 & 1.5676 & -0.300 & 1.433 & 0.0000 & 5.400 & 86 \\ \text { VALFOR } & 15948 . & 40818 . & 2.776 & 9.500 & 0.0000 & 0.1800 \mathrm{E}+06 & 86 \\ \text { CSTFORM } & 0.98710 & 0.43246 & 2.830 & 16.146 & 0.4868 & 3.519 & 86 \\ \text { UALPRD } & 60247 . & 0.10310 \mathrm{E}+06 & 3.760 & 20.240 & 467.7 & 0.6838 E+06 & 86 \\ \text { DESOPE } & 42266 . & 60372 . & 2.188 & 7.809 & 243.9 & 0.3077 \mathrm{E}+06 & 86 \\ \text { EDUFOR } & 6.9419 & 4.7486 & 0.348 & 1.944 & 0.0000 & 15.00 & 86\end{array}$

TOBIT; LHS=LIQINF; RHS=ONE, JUR INFM, VALFOR, CSTFORM, UALPRD, DESOPE, EDUFOR\$

Limited Dependent Variable Model - CENSORED regression Maximum Likelihood Est imates

Log-Likelihood.............. -137.8423

Threshold values for the model: Lower $=0.0000$ Upper $=+$ Infinity $N[\theta, 1]$ used for significance levels.

Variable Coefficient Std. Error $t-r a t i o$ Probit $i=x$ Mean of $X$ 5td.Dev. of $X$

$\begin{array}{lccrccc}\text { Constant } & -13720 . & 8113 . & -1.691 & 0.09080 & & \\ \text { JURINFM } & 967.29 & 1596 . & 0.606 & 0.54452 & 2.1209 & 1.5676 \\ \text { UALFOR } & -0.11800 \mathrm{E}-01 & 0.6180 \mathrm{E}-01 & -0.191 & 0.84858 & 15948 . & 40818 . \\ \text { CSTFORM } & -5031.4 & 8602 . & -0.585 & 0.55863 & 0.98710 & 0.43246 \\ \text { UALPRD } & -0.23334 E-01 & 0.3995 \mathrm{E}-01 & -0.584 & 0.55914 & 60247 . & 0.10310 \mathrm{E}+06 \\ \text { DESOPE } & 0.28579 \mathrm{E}-01 & 0.5601 \mathrm{E}-01 & 0.510 & 0.60991 & 42266 . & 60372 . \\ \text { EDUFOR } & 469.55 & 445.9 & 1.053 & 0.29234 & 6.9419 & 4.7486 \\ 0 & 11540 . & 2935 . & 3.932 & 0.00008 & & \end{array}$

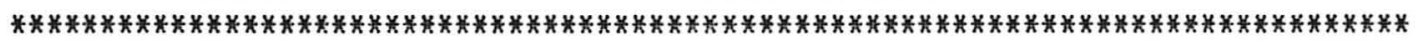


(TOBGR22.0UT)

MODEL COMMAND:

DSTAT ; RHS=JUR INFA, VALFOR , CSTFORA, VALPRD, DESOPE, EDUFOR ; OUTPUT $=39$

Descriptive Statistics

$\begin{array}{lccrcccr}\text { Variable } & \text { Mean } & \text { St.d. DeV. } & \text { SkEW. } & \text { Kurt. } & \text { Mininum } & \text { Maximum } & \text { Case5 } \\ \text { JURINFA } & 27.538 & 20.622 & -0.085 & 1.945 & 0.0000 & 87.70 & 86 \\ \text { UALFOR } & 15948 . & 40818 . & 2.776 & 9.500 & 0.0000 & 0.1800 E+06 & 86 \\ \text { CSTFORA } & 12.650 & 6.2126 & 3.355 & 20.199 & 6.001 & 51.44 & 86 \\ \text { UALPRD } & 60247 . & 0.10310 \mathrm{E}+06 & 3.760 & 20.240 & 467.7 & 0.6838 \mathrm{E}+06 & 86 \\ \text { DESOPE } & 42266 . & 60372 . & 2.188 & 7.809 & 243.9 & 0.3077 \mathrm{E}+06 & 86 \\ \text { EDUFOR } & 6.9419 & 4.7486 & 0.348 & 1.944 & 0.0000 & 15.00 & 86\end{array}$

TOBIT; LHS=LIQINF ; RHS=ONE, JUR INFA, VALFOR, CSTFORA, VALPRD, DESOPE, EDUFOR \$

Limited Dependent Variable Mode1 - CENSORED regression Maximum Likelihood Estimates Log-Likelihood............. -137.7550

Threshold values for the model: Lower $=0.0000$ Upper $=+$ Infinity $N[\theta, 1]$ used for significance levels. Variable Coefficient Std. Error t-ratio Probiti=x Mean of $X$ Std.Dev. of $X$

$\begin{array}{lccrlll}\text { Constant } & -1.4099 . & 7821 . & -1.803 & 0.07144 & & \\ \text { JURINFA } & 78.788 & 110.4 & 0.713 & 0.47556 & 27.538 & 20.622 \\ \text { VALFOR } & -0.11012 \mathrm{E}-01 & 0.6141 \mathrm{E}-01 & -0.179 & 0.85770 & 15948 . & 40818 . \\ \text { CSTFORA } & -377.56 & 622.0 & -0.607 & 0.54387 & 12.650 & 6.2126 \\ \text { VALPRD } & -0.23595 \mathrm{E}-01 & 0.4018 \mathrm{E}-01 & -0.587 & 0.55710 & 60247 . & 0.10310 \mathrm{E}+06 \\ \text { DESOPE } & 0.29128 \mathrm{E}-01 & 0.5607 \mathrm{E}-01 & 0.519 & 0.60343 & 42266 . & 60372 . \\ \text { EDUFOR } & 471.80 & 444.3 & 1.062 & 0.28827 & 6.9419 & 4.7486 \\ 0 & 11529 . & 2932 . & 3.933 & 0.00008 & & \end{array}$


(TOBGR21_OUT)

MODEL COMMAND:

DSTAT ; RHS=JUR INFA, VALFOR , CSTFORA, AREXPL, DESOPE, EDUFOR ; QUTPUT =3\$

Descriptive Statistics

$\begin{array}{lccrcccr}\text { Variable } & \text { Mean } & \text { Std. Dev. } & \text { SkEw. } & \text { Kurt. } & \text { Mininum } & \text { Maximum } & \text { Cases } \\ \text { JURINFA } & 27.538 & 20.622 & -0.085 & 1.945 & 0.0000 & 87.70 & 86 \\ \text { UALFOR } & 15948 . & 40818 . & 2.776 & 9.500 & 0.0000 & 0.1800 E+06 & 86 \\ \text { CSTFORA } & 12.650 & 6.2126 & 3.355 & 20.199 & 6.001 & 51.44 & 86 \\ \text { AREXPL } & 148.69 & 219.26 & 2.289 & 7.843 & 5.220 & 999.0 & 86 \\ \text { DESOPE } & 42266 . & 60372 . & 2.188 & 7.809 & 243.9 & 0.3077 E+06 & 86 \\ \text { EDUFOR } & 6.9419 & 4.7486 & 0.348 & 1.944 & 0.0000 & 15.00 & 86\end{array}$

TOBIT; LHS=LIQINF ; RHS=ONE, JUR INFA, VALFOR , CSTFORA, AREXPL, DESOPE, EDUFOR

Limited Dependent Variable Model - CENSORED regression

Maximum Likelihood Est imates

Log-Likelihood. ............ -137.9121

Threshold values for the model: Lower $=0.0000$ Upper $=+$ Infinity

$N[0,1]$ used for significance levels.

Variable Coefficient Std. Error t-ratio Probiti=x Mean of $X$ Std.Dev. of $X$

$\begin{array}{lccrccc}\text { Constant } & -13827 . & 7769 . & -1.780 & 0.07512 & & \\ \text { JURINFA } & 69.905 & 111.1 & 0.629 & 0.52905 & 27.538 & 20.622 \\ \text { UALFOR } & -0.12872 E-01 & 0.6118 E-01 & -0.210 & 0.83336 & 15948 . & 40818 . \\ \text { CSTFORA } & -423.46 & 616.1 & -0.687 & 0.49189 & 12.650 & 6.2126 \\ \text { AREXPL } & 5.3322 & 18.06 & 0.295 & 0.76776 & 148.69 & 219.26 \\ \text { DESOPE } & -0.12399 E-01 & 0.7270 E-01 & -0.171 & 0.86458 & 42266 . & 60372 . \\ \text { EDUFOR } & 465.07 & 450.7 & 1.032 & 0.30215 & 6.9419 & 4.7486 \\ 0 & 11674 . & 2968 . & 3.933 & 0.00008 & & \end{array}$


(TOBGR23.0UT)

MODEL COMMAND:

DSTAT; RHS =JUR INFH, VALFOR , CSTFORM, AREXPL, DESOPE, EDUFOR ; OUTPUT =3\$

Descriptive Statistics

$\begin{array}{lccrrrrr}\text { Variable } & \text { Mean } & \text { Std. Dev. } & \text { SkEw. } & \text { Kurt. } & \text { Minimun } & \text { Marimum } & \text { Cases } \\ \text { JURINFM } & 2.1209 & 1.5676 & -0.300 & 1.433 & 0.0000 & 5.400 & 86 \\ \text { UALFOR } & 15948 . & 40818 . & 2.776 & 9.500 & 0.0000 & 0.1800 E+06 & 86 \\ \text { CSTFORM } & 0.98710 & 0.43246 & 2.830 & 16.146 & 0.4868 & 3.519 & 86 \\ \text { AREXPL } & 148.69 & 219.26 & 2.289 & 7.843 & 5.220 & 999.0 & 86 \\ \text { DESOPE } & 42266 . & 60372 . & 2.188 & 7.809 & 243.9 & 0.3077 E+06 & 86 \\ \text { EDUFOR } & 6.9419 & 4.7486 & 0.348 & 1.944 & 0.0000 & 15.00 & 86\end{array}$

TOBIT;LHS=LIQINF; RHS=ONE, JUR INFM, VALFOR , CSTFORH , AREXPL, DESOPE, EDUFOR \$

Limited Dependent Variable Model - CENSORED regression

Maximum Likel ihood Est imates

Log-Likelihood.............. $\quad-137.9940$

Threshold values for the model: Lower $=0.0000$ Upper $=+$ Infinity

$N[0,1]$ used for significance levels.

Variable Coefficient Std. Error t-ratio Probit $:=x$ Mean of $X$ Std.Dev. of $X$

\begin{tabular}{lccrccc}
\hline Constant & -13483. & 8054. & -1.674 & 0.09409 & & \\
JURINFM & 827.97 & 1605. & 0.516 & 0.60597 & 2.1209 & 1.5676 \\
VALFOR & $-0.13363 E-01$ & $0.6152 E-01$ & -0.217 & 0.82805 & 15948. & 40818. \\
CSTFORM & -5534.8 & 8507. & -0.651 & 0.51529 & 0.98710 & 0.43246 \\
AREXPL & 5.5507 & 18.16 & 0.306 & 0.75987 & 148.69 & 219.26 \\
DESOPE & $-0.13555 E-01$ & $0.7273 \mathrm{E}-01$ & -0.186 & 0.85215 & 42266. & 60372. \\
EDUFOR & 464.37 & 452.3 & 1.027 & 0.30461 & 6.9419 & 4.7486 \\
$\sigma$ & 11684. & 2971. & 3.932 & 0.00008 & &
\end{tabular}


2.4. Grupo 3.

(TOBGR33.0UT)

MODEL COMMAND:

DSTAT; RHS=JUR INFH, VALFOR, CSTFORM, AREXPL , DESOPE, EDUFOR ; OUTPUT =3\$

Descriptive Statistics

$\begin{array}{lccccccr}\text { Variable } & \text { MEan } & \text { Std. Dev. } & \text { SkEw. } & \text { Kurt. } & \text { Minimun } & \text { Maximum } & \text { Cases } \\ \text { JURINFH } & 2.8951 & 1.3274 & 0.477 & 5.106 & 0.0000 & 7.200 & 82 \\ \text { VALFOR } & 33797 . & 42677 . & 1.174 & 3.221 & 0.0000 & 0.1574 E+06 & 82 \\ \text { CSTFORM } & 1.1866 & 0.59657 & 1.700 & 7.082 & 0.6440 & 3.946 & 82 \\ \text { AREXPL } & 359.01 & 360.79 & 2.144 & 8.658 & 10.00 & 2000 . & 82 \\ \text { DESOPE } & 75964 . & 70302 . & 1.358 & 4.134 & 1634 . & 0.3016 E+06 & 82 \\ \text { EDUFOR } & 7.3049 & 4.0052 & 0.264 & 2.003 & 0.0000 & 15.00 & 82\end{array}$

TOBIT; LHS=LIQINF; RHS=ONE, JUR INFM, VALFOR , CSTFORM, AREXPL, DESOPE, EDUFOR

Limited Dependent Variable Model - CENSORED regression

Maximum Likel ihood Est imates

Log-Likelihood. . . . . . . ....... -356.5987

Threshold values for the model: Lower $=0.0000 \quad$ Upper $=+$ Infinity

$N[0,1]$ used for significance levels.

Variable Coefficient Std. Error t-ratio Probit $1=x$ Mean of $X$ Std.Dev. of $X$

$\begin{array}{lcccccc}\text { Constant } & -13933 . & 0.1546 \mathrm{E}+05 & -0.901 & 0.36750 & & \\ \text { JURINFM } & -4975.7 & 3334 . & -1.493 & 0.13555 & 2.8951 & 1.3274 \\ \text { UALFOR } & -0.42940 \mathrm{E}-01 & 0.1341 & -0.320 & 0.74878 & 33797 . & 42677 . \\ \text { CSTFORM } & -3336.3 & 9037 . & -0.369 & 0.71199 & 1.1866 & 0.59657 \\ \text { AREXPL } & -90.155 & 40.86 & -2.206 & 0.02737 & 359.01 & 360.79 \\ \text { DESOPE } & 0.46151 & 0.1648 & 2.800 & 0.00511 & 75964 . & 70302 . \\ \text { EDUFOR } & 1669.3 & 1365 . & 1.223 & 0.22126 & 7.3049 & 4.0052 \\ \text { O. } & 34994 . & 5273 . & 6.637 & 0.00000 & & \\ \end{array}$




\begin{tabular}{|c|c|c|c|c|c|c|c|}
\hline \multicolumn{8}{|c|}{ MODEL COMMAND: } \\
\hline \multicolumn{8}{|c|}{ DSTAT; RHS =JURINFA, VALFOR , CSTFORA, AREXPL , DESOPE, EDUFOR; OUTPUT $=3 \$$} \\
\hline \multicolumn{8}{|c|}{ Descriptive Statistics } \\
\hline Variable & Mean & Std. Dev. & SkEW. & kurt. & Minimum & Maximun & Cases \\
\hline JUR INFA & 39.683 & 19.750 & 0.349 & 4.440 & 0.0000 & 96.00 & 82 \\
\hline VALFOR & 33797 & 42677. & 1.174 & 3.221 & 0.0000 & $0.1574 E+06$ & 82 \\
\hline CSTFORA & 15.477 & 8.6545 & 2.044 & 9.316 & 8.007 & 59.10 & 82 \\
\hline AREXPL & 359.01 & 360.79 & 2.144 & 8.658 & 10.00 & 2000. & 82 \\
\hline DESOPE & 75964. & 70302. & 1.358 & 4.134 & $1634=$ & $0.3016 E+06$ & 82 \\
\hline EDUFOR & 7.3049 & 4.0052 & 0.264 & 2.003 & 0.0000 & 15.00 & 82 \\
\hline
\end{tabular}

TOBIT:LHS=LIQINF; RHS=ONE, JURINFA, VALFOR , CSTFORA, AREXPL, DESOPE, EDUFOR \$

Limited Dependent Variable Model - CENSORED regression

Maximum Likel ihood Est imates

Log-Likelihood.............. -356.3469

Threshold values for the model: Lower $=0.0000$ Upper $=+$ Infinity

$N[0,1]$ used for significance levels.

Variable Coefficient Std. Error t-ratio Probiti=x Mean of $X$ Std.Dev.of $X$

$\begin{array}{lcccccc}\text { Constant } & -14201 . & 0.1494 E+05 & -0.951 & 0.34176 & & \\ \text { JURINFA } & -363.27 & 223.9 & -1.623 & 0.10464 & 39.683 & 19.750 \\ \text { VALFOR } & -0.53052 E-01 & 0.1339 & -0.396 & 0.69199 & 33797 . & 42677 . \\ \text { CSTFORA } & -334.36 & 641.0 & -0.522 & 0.60195 & 15.477 & 8.6545 \\ \text { AREXPL } & -88.110 & 40.61 & -2.170 & 0.03004 & 359.01 & 360.79 \\ \text { DESOPE } & 0.46066 & 0.1643 & 2.804 & 0.00504 & 75964 . & 70302 . \\ \text { EDUFOR } & 1797.7 & 1383 . & 1.300 & 0.19362 & 7.3049 & 4.0052 \\ \text { a } & 35047 . & 5286 . & 6.630 & 0.00000 & & \end{array}$

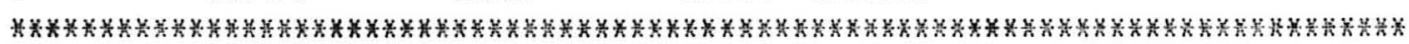




\begin{tabular}{|c|c|c|c|c|c|c|c|}
\hline \multicolumn{8}{|c|}{ (TOBGR32.0UT) } \\
\hline \multicolumn{8}{|c|}{ MODEL COMMAND: } \\
\hline \multicolumn{8}{|c|}{ DSTAT;RHS = JURINFA, UALFOR , CSTFORA, VALPRD, DESOPE, EDUFOR ; OUTPUT $=3 \$$} \\
\hline \multicolumn{8}{|c|}{ Descriptive Statistics } \\
\hline Variable & Mean & Std. Dev. & SkEW. & Kurt. & Minimum & Maximum & Cases \\
\hline RINFA & 39.683 & 19.750 & 0.349 & 4.440 & 0.0000 & 96.00 & \\
\hline LFOR & 33797. & 42677. & 1.174 & 3.221 & 0.0000 & $0.1574 E+06$ & 82 \\
\hline TFORA & 15.477 & 8.6545 & 2.044 & 9.316 & 8.007 & 59.10 & 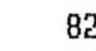 \\
\hline PRD & 81422. & 97321. & 2.837 & 13.315 & 3541. & $0.6097 E+06$ & \\
\hline SOPE & 75964. & 70302. & 1.358 & 4.134 & 1634. & $0.3016 E+06$ & \\
\hline & 7.3049 & 4.0052 & 0.264 & 2.003 & 0.0000 & 15.00 & \\
\hline
\end{tabular}

TOBIT; LHS=LIQINF; RHS=ONE, JURINFA, VALFOR ${ }_{r}$ CSTFORA, VALPRD, DESOPE, EDUFORI

Limited Dependent Variable Model - CENSORED regression Maximum Likelihood Estimates Log-Likelihood............. -359.0415

Threshold values for the model: Lower $=0.0000 \quad$ Upper $=+$ Infinity $N[\theta, 1]$ used for significance levels.

Variable Coefficient Std. Error t-ratio Probiti=x Mean of $X$ Std.Dev.of $X$

\begin{tabular}{lcccccc}
\hline Constant & -10924. & $0.1536 \mathrm{E}+05$ & -0.711 & 0.47693 & & \\
JURINFA & -288.91 & 227.4 & -1.270 & 0.20400 & 39.683 & 19.750 \\
UALFOR & -0.13203 & 0.1366 & -0.966 & 0.33383 & 33797. & 42677. \\
CSTFORA & -746.43 & 783.0 & -0.953 & 0.34043 & 15.477 & 8.6545 \\
UALPRD & -0.12496 & 0.1050 & -1.190 & 0.23405 & 81422. & 97321. \\
DESOPE & 0.27138 & 0.1330 & 2.041 & 0.04124 & 75964. & 70302. \\
EDUFOR & 1402.2 & 1372. & 1.022 & 0.30664 & 7.3049 & 4.0052 \\
0 & 36217. & 5498. & 6.588 & 0.00000 & &
\end{tabular}


(TOBGR34.OUT)

MODEL. COMMAND:

DSTAT;RHS=JUR INFM, VALFOR, CSTFORM, VALPRD, DESOPE, EDUFOR; OUTPUT $=3 \$$

Descriptive Statistics

$\begin{array}{lccccccr}\text { Variable } & \text { Mean } & \text { Std. DeV. } & \text { SkEW. } & \text { Kurt. } & \text { Minimum } & \text { Manimum } & \text { Case5 } \\ \text { JURINFM } & 2.8951 & 1.3274 & 0.477 & 5.106 & 0.0000 & 7.200 & 82 \\ \text { UALFOR } & 33797 . & 42677 . & 1.174 & 3.221 & 0.0000 & 0.1574 E+06 & 82 \\ \text { CSTFORM } & 1.1866 & 0.59657 & 1.700 & 7.082 & 0.6440 & 3.946 & 82 \\ \text { UALPRD } & 81422 . & 97321 . & 2.837 & 13.315 & 3541 . & 0.6097 E+06 & 82 \\ \text { DESOPE } & 75964 . & 70302 . & 1.358 & 4.134 & 1634 . & 0.3016 E+06 & 82 \\ \text { EDUFOR } & 7.3049 & 4.0052 & 0.264 & 2.003 & 0.0000 & 15.00 & 82\end{array}$

TOBIT; LHS=LIQINF; RHS=ONE, JURINFM, VALFOR , CSTFORH, VALPRD, DESOPE, EDUFOR\$

Limited Dependent Variable Model - CENSORED regression

Maximum Likelihood Estimates

Log-Likelihood.............. -359.3881

Threshold values for the model: Lower $=0.0000$ Upper $=+$ Infinity

$N[0,1]$ used for significance levels.

Variable Coefficient Std. Error t-ratio Probiti=x Mean of $X$ Std.Dev.of $X$

\begin{tabular}{lrlrlll}
\hline Constant & -11106. & $0.1593 E+05$ & -0.697 & 0.48566 & & \\
JURINFM & -3392.1 & 3345. & -1.014 & 0.31058 & 2.8951 & 1.3274 \\
UALFOR & -0.12724 & 0.1362 & -0.934 & 0.35006 & 33797. & 42677. \\
CSTFORM & -9565.2 & $0.1093 E+05$ & -0.875 & 0.38162 & 1.1866 & 0.59657 \\
UALPRD & -0.12953 & 0.1051 & -1.233 & 0.21759 & 81422. & 97321. \\
DESOPE & 0.26811 & 0.1324 & 2.025 & 0.04286 & 75964. & 70302. \\
EDUFOR & 1282.7 & 1355. & 0.947 & 0.34389 & 7.3049 & 4.0052 \\
0 & 36153. & 5484. & 6.592 & 0.00000 & &
\end{tabular}

